\title{
VALUE CO-CREATION IN MULTI-ACTOR ECOSYSTEMS
}

Patrick Weretecki 


\section{VALUE CO-CREATION \\ IN MULTI-ACTOR ECOSYSTEMS}

Patrick Weretecki 



\title{
VALUE CO-CREATION IN MULTI-ACTOR ECOSYSTEMS
}

\section{DISSERTATION}

\author{
to obtain \\ the degree of doctor at the University of Twente, \\ on the authority of the rector magnificus, \\ prof.dr.ir. A. Veldkamp, \\ on account of the decision of the Doctorate Board, \\ to be publicly defended \\ on Friday the $17^{\text {th }}$ of December 2021 at 10:45 hours
}

by

\section{Patrick Weretecki}

born on the $29^{\text {th }}$ of July 1986

in Hagen, Germany 


\section{THIS DISSERTATION HAS BEEN APPROVED BY:}

Supervisor: $\quad$ Prof. Dr. Ir. J. Henseler

Co-supervisor: Prof. Dr. G. Greve

Cover design: Stefanie van den Herik | HerikMedia | www.herikmedia.nl

Lay-out: $\quad$ Stefanie van den Herik | HerikMedia | www.herikmedia.nl

Printed by: $\quad$ ProefschriftMaken | www.proefschriftmaken.nl

ISBN:

978-90-365-5246-2

DOI:

(C) 2021 Patrick Weretecki, The Netherlands. All rights reserved. No parts of this thesis may be reproduced, stored in a retrieval system or transmitted in any form or by any means without permission of the author. Alle rechten voorbehouden. Niets uit deze uitgave mag worden vermenigvuldigd, in enige vorm of op enige wijze, zonder voorafgaande schriftelijke toestemming van de auteur. 


\title{
GRADUATION COMMITTEE
}

\author{
Chairman/secretary Prof. Dr. Ir. H. F. J. M. Koopman \\ University of Twente \\ Supervisor(s) \\ Prof. Dr. Ir. J. Henseler \\ University of Twente \\ Co-supervisor(s) Prof. Dr. G. Greve \\ Hamburg School of Business Administration \\ Committee Members: Prof. Dr. habil. H. Schiele \\ University of Twente \\ Prof. Dr.-Ing. S. Thiede \\ University of Twente \\ Dr. V. Blazevic \\ Radboud University \\ RWTH Aachen University \\ Prof. Dr. J. Sánchez García \\ University Jaume I \\ Prof. Dr. habil. O. Schnittka \\ University of Southern Denmark
}





\section{SUMMARY}

The common denominator among all companies ever created is their striving for value creation. What sets (most of) them apart from marketing research on value creation is their interpretation of what value is and where, when, how, and by whom, it is created. While most companies and their managers still tend to focus on value-in-exchange-that is, the amount of money or the price received in exchange for products and services - to assess the value they have created (Vargo et al., 2017), marketing (research) has evolved (Eggert et al., 2018) and is increasingly focusing on the value-in-use perspective, specifically, considering the (individual) value customers derive from using the products/services in their contexts (Holmqvist, Visconti, et al., 2020; Macdonald et al., 2016; Medberg \& Grönroos, 2020; Sandström et al., 2008; Yu \& Sangiorgi, 2018).

While the concept of value has been discussed since Aristotle (Vargo et al., 2008), the more recent evolution from a goods-dominant logic, which is based on the idea that companies (on their own) can create and embed value into products/services before they are transferred to customers, towards the service-dominant logic, which considers value creation to be a co-creative process of joint resource integration, as the dominant logic for marketing, only represents one important milestone in a discussion that, by all accounts, is far from over. Most recently, research has started to acknowledge the increasing relevance of taking different actors, their behavior, and their interactions with each other, in the respective service ecosystems, into account (Rapp et al., 2020). This is where this thesis joins the discussion. By means of four stand-alone research papers-Chapters 2 to 5 in this dissertation, respectively-this work addresses two important questions:

$\mathrm{RQ}_{1}$ : What characterizes selling actors and their behavior in multi-actor ecosystems?

$\mathrm{RQ}_{2}$ : How can these actors and their behavior be influenced?

By means of a variety of different qualitative and quantitative methods, this thesis goes beyond a theoretical discussion on selling actors identities and their behavior in multi-actor ecosystems to deduce actionable insights from theory and practice and provides researchers and managers with tools-such as the first salesperson-selling actor relationship/behavior typology or a holistic experiential value measurement scale for multi-actor ecosystems - to actually "walk the talk" and encourage customer participation and citizenship behavior, and in consequence value co-creation in multi-actor ecosystems. 


\section{ACKNOWLEDGMENTS}

"Little of consequence is ever accomplished alone.

High achievement is nearly always a joint effort."

\section{- David McCullough -}

This PhD project would not have been possible without the continuous support of the incredible people I have in my life. Words cannot express my gratitude to all of you!

First, it needs to be said that none of this would have been possible without my supervisor, Jörg, and co-supervisor, Goetz. I am incredibly thankful to both of you for taking me under your wings. At the beginning of the project, I neither knew what kind of professional and/or personal support I might need, nor whether you could provide it to me if needed. Now, almost five years later, I know that I could not have had a better team by my side. Jörg, I am still impressed by your methodological competencies and your unparalleled abilities to analyze data through a statistical lens. It is thanks to you and your high standards that I did not become a research method one-trick-pony. Goetz, a side-by-side comparison, of the exposé I wrote some five years ago and this thesis, makes abundantly clear how much I have learned from you about the art of academic writing. I specifically admire your ability to deduce practical applications from research findings. Over the years, you both have invested a considerable amount of your time in my dream, replied to my emails, answered my questions, joined me at conferences, and read and commented on my work. Thank you for this dedication!

I would also like to thank all the members of my graduation committee, Prof. Dr. habil. H. Schiele, Prof. Dr. habil. O. Schnittka, Prof. Dr.-Ing. S. Thiede, Prof. Dr. J. S. García and Prof. Dr. V. Blazevic, for the time and effort you have invested. It is much appreciated!

Furthermore, I would like to thank the members of the Department of Design, Production and Management at the University of Twente and my fellow PhD students whose feedback was especially helpful at the beginning of this journey. Samuel, I am very grateful to you for becoming a friend and for sharing your experiences and expertise with me. Thank you for leading the way!

I am acutely aware that I only was able to pursue this $\mathrm{PhD}$ project because of the support I have received from the company I work for, specifically from my (former) supervisors and friends, Sven and Sabine. Sven, when I came to you asking for a new job that is combinable with my dream of pursuing a PhD, you made it happen. Over the years you have promoted and sponsored me several times, but the most important thing was that I always knew that I had someone in my corner I could count on, no matter what. Sabine, we have fought many battles together over the years, and there is a good reason why they call us "the dream team." You have been there for me since the beginning of this project and not only took 
interest but also even took part in my research. Above all, you never got tired of encouraging me to keep on going. Thank you very much!

Last but not least, I must thank my family. It is thanks to you, mom and dad, that I had the self-confidence to start this journey. I am so grateful to you that you have raised me with the mindset that there is no limit to what I can achieve as long as I am willing to work tirelessly. I also consider myself blessed to have such an amazing and supportive sister and brother. I probably do not say it often enough, but it is one of the best things in the world to know that I could call you anytime and ask anything of you and that you would move heaven and earth for me. Thank you for that, I will always try my best to do the same for you!

Finally, it is no secret that behind every great man there is a great woman. While I do not consider myself a great man, I certainly have the greatest woman behind me. Without the love and support of my wife Adrienne, this PhD project would not have happened. You are the source of my strength, and everything I have achieved over the last years, this PhD included, is thanks to you. I love you very much! 


\section{CONTENTS}

1 RESEARCH BACKGROUND AND STRUCTURE OF THIS THESIS

1.1 INTRODUCTION 2

1.2 RESEARCH QUESTIONS, DESIGN AND OBJECTIVES 4

1.3 THESIS OUTLINE

1.4 GUIDE TO THE READER 8

2 SELLING ACTORS IN MULTI-ACTOR SALES ECOSYSTEMS

2.1 INTRODUCTION 13

2.2 THEORETICAL BACKGROUND 16

$\begin{array}{lll}2.3 & \text { METHODOLOGY AND SAMPLE } & 18\end{array}$

$\begin{array}{lll}2.4 & \text { FINDINGS } & 23\end{array}$

$\begin{array}{lll}2.5 & \text { DISCUSSION } & 30\end{array}$

2.6 IMPLICATIONS 32

2.7 LIMITATIONS AND FUTURE RESEARCH 33

3 EXPERIENTIAL VALUE IN MULTI-ACTOR SERVICE ECOSYSTEMS 37

3.1 INTRODUCTION 39

3.2 THEORETICAL BACKGROUND AND HYPOTHESES DEVELOPMENT 41

3.3 METHODOLOGY AND SAMPLE 44

3.4 DATA ANALYSIS 46

$\begin{array}{lll}3.5 & \text { FINDINGS } & 47\end{array}$

3.6 DISCUSSION

3.7 LIMITATIONS AND FUTURE RESEARCH 58

4 INFORMATION MANAGEMENT CAN'T BE ALL FUN AND GAMES, CAN IT? HOW GAMIFIED EXPERIENCES FOSTER INFORMATION EXCHANGE IN MULTI-ACTOR SERVICE ECOSYSTEMS

4.1 INTRODUCTION 63

4.2 THEORETICAL BACKGROUND AND HYPOTHESES DEVELOPMENT 65

4.3 METHODOLOGY AND SAMPLE $\quad 70$

$\begin{array}{lll}4.4 & \text { RESULTS } & 73\end{array}$

$\begin{array}{lll}4.5 & \text { DISCUSSION } & 75\end{array}$

4.6 CONTRIBUTIONS AND IMPLICATIONS

4.7 LIMITATIONS AND FUTURE RESEARCH

4.8 CONCLUSION 
5 PUTTING THE RETAIL APOCALYPSE OUT OF BUSINESS 8

5.1 INTRODUCTION 83

5.2 THEORETICAL BACKGROUND

$\begin{array}{lll}5.3 & \text { METHODOLGY AND SAMPLE } & 85\end{array}$

5.4 RESULTS

5.5 DISCUSSION AND IMPLICATIONS

$\begin{array}{lll}5.6 & \text { CONCLUSION } & 100\end{array}$

5.7 LIMITATIONS AND FUTURE RESEARCH OPPORTUNITIES 101

6 SYNOPSIS 103

$\begin{array}{lll}6.1 & \text { INTRODUCTION } & 104\end{array}$

$\begin{array}{ll}6.2 \text { DISCUSSION } & 104\end{array}$

$\begin{array}{lll}6.3 & \text { IMPLICATIONS } & 107\end{array}$

6.4 LIMITATIONS AND FUTURE RESEARCH OPPORTUNITIES 110

6.5 FINAL THOUGHTS 111

$\begin{array}{ll}\text { A APPENDIX } & \mathbf{1 1 3}\end{array}$

$\begin{array}{ll}\text { A.1 APPENDIX CHAPTER 2 } & 114\end{array}$

A.2 APPENDIX CHAPTER $3 \quad 116$

$\begin{array}{lll}\text { A.3 APPENDIX CHAPTER } 4 & 118\end{array}$

$\begin{array}{ll}\text { BIBLIOGRAPHY } & 121\end{array}$ 


\section{FIGURES}

Figure 1.1: Thesis Outline 5

Figure 2.1: QR code for accessing images of the multi-actor sales ecosystem $\quad 15$

Figure 2.2: Schematic overview of the World Café session 21

Figure 2.3: Salesperson-selling actor relationship/behavior typology 24

Figure 3.1: Conceptual model $\quad 44$

Figure 3.2: Results of the structural equation model 54

Figure 4.1: Conceptual Model $\quad 70$

$\begin{array}{ll}\text { Figure 4.2: Results of the structural equation model } & 73\end{array}$

Figure 5.1: Sales Ecosystem Practices and Potential Measures 86 


\section{TABLES}

Table 3.1: Demographic profile of the sample $\quad 46$

Table 3.2: Results of principal axis factoring 48

Table 3.3: Test of composite reliability, convergent and discriminant validity 51

Table 3.4: Confirmatory factor analysis for experiential value in multi-actor service ecosystems $\quad 52$

Table 3.5: Validity matrix (complete model) 54

Table 3.6: Hypothesis testing results 55

Table 3.7: Mediation effects (Bootstrapping Results) 55

Table 4.1: Demographic profile of the sample $\quad 72$

Table 4.2: Convergent and Discriminant Validity 74

Table 4.3: Hypothesis testing results $\quad 74$

Table 4.4: Mediation effects (Bootstrapping Results) 75 
Chapter 1

RESEARCH BACKGROUND

AND STRUCTURE OF THIS THESIS 


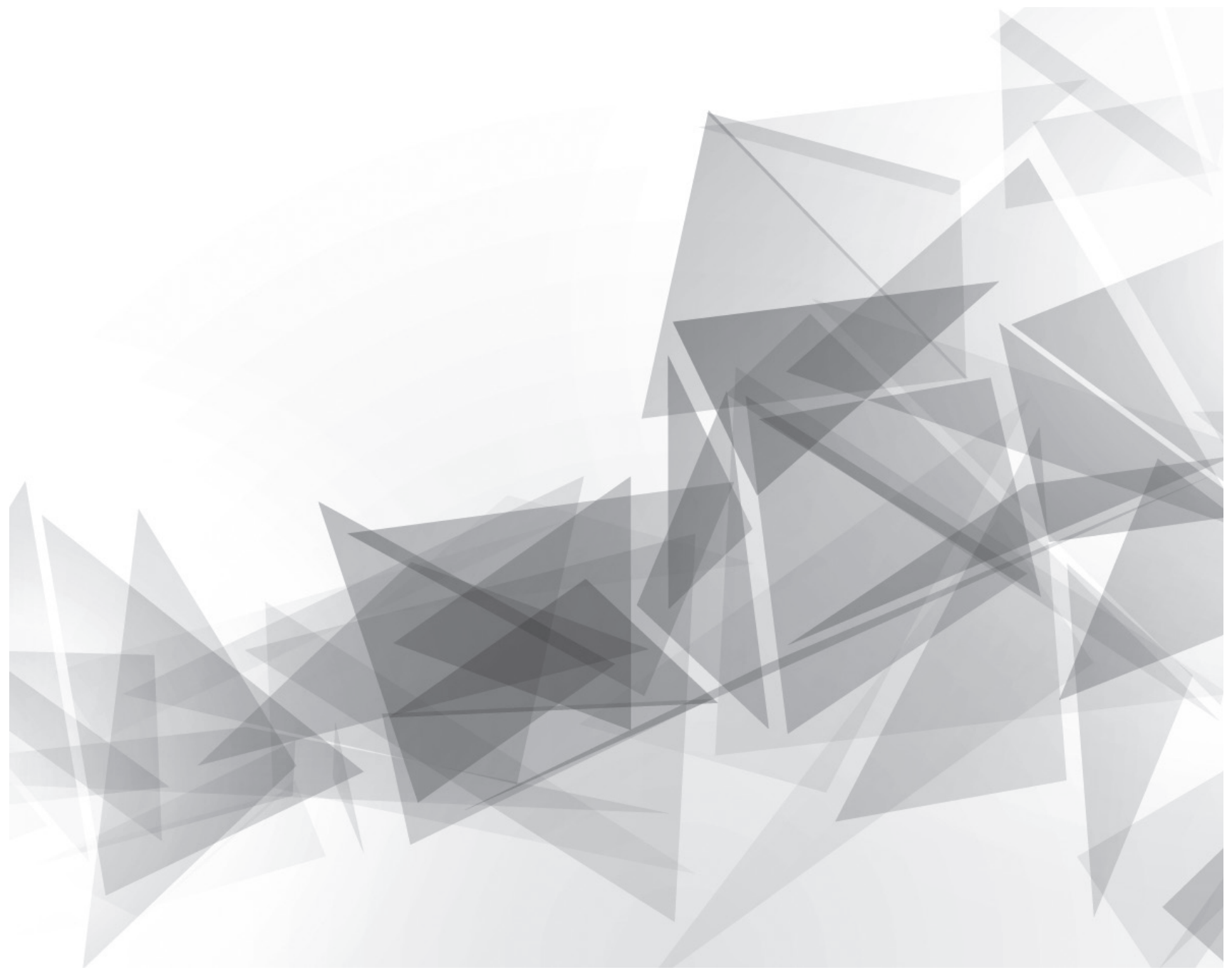




\section{$1.1 \quad$ INTRODUCTION}

According to one of the most successful businessmen of our time, Jeff Bezos, the founder and former chief executive officer (CEO) of Amazon, the success of a business is inextricably linked to its ability to create value: "Any business that doesn't create value for those it touches, even if it appears successful on the surface, isn't long for this world" (Bezos, 2021). Bezos is not alone in this opinion. As of February 2021, the Business Roundtable lists more than 230 CEOs of leading companies (including those of companies such as Walmart, Apple, and Pfizer) that signed the 2019 statement on the purpose of a corporation and thereby committed to focusing on the creation of "long-term value" (Business Roundtable, 2021) in the interest of all their stakeholders.

While most companies and their managers still tend to focus on value-in-exchangethat is, the amount of money or the price received in exchange for products and servicesto assess the value they have created (Vargo et al., 2017), marketing (research) has evolved (Eggert et al., 2018) and is increasingly focusing on the value-in-use perspective-that is, considering the (individual) value customers derive from using the products/services in their contexts (e.g., Holmqvist, Visconti, et al., 2020; Macdonald et al., 2016; Medberg \& Grönroos, 2020; Sandström et al., 2008; Yu \& Sangiorgi, 2018). To illustrate, the value of a laptop can be determined from its nominal market price (value-in-exchange perspective) or from the value-in-use perspective by considering a customer's use of the laptop (e.g., mobile work, video conferencing, and media consumption) and the values associated with it (e.g., freedom to work from anywhere in the world, stay in touch with family and friends, and as a source of entertainment).

However, value-in-exchange and value-in-use are more like two sides of the same (value) coin than absolute truths (Eggert et al., 2018), and merely changing the perspective on value creation from one side to the other will still result in a one-sided view on how, by whom, and where value is created.

This speaks directly to the importance of the evolution from a goods-dominant (G-D) logic-which is based on the idea that companies (on their own) can create and embed value into products and services before they are transferred to customers-toward the service-dominant (S-D) logic-which considers value creation to be a co-creative process of joint resource integration, as the dominant logic for marketing. This paradigmatic shift has its roots in the seminal work of Vargo and Lusch (2004). Despite several additions and modifications to their eleven "foundational premises" (e.g., Vargo \& Lusch, 2008, 2016), the core ideas behind S-D logic-that service, "the application of one's resources for the benefit of another actor - is the basis of exchange; and [...] value is always co-created" (Vargo et al., 2017, pp. 118-119)-essentially remained the same.

In particular, the recognition of actors external to the organization (e.g., customers) as (co-) creators of value and the notion that companies are unable to "create and/or deliver value to customers independently" (Vargo \& Lusch, 2008, p. 7), fueled the interest of 
researchers and practitioners in customers' behavior -in particular, their value co-creation behavior-and how it can be measured and influenced.

$\mathrm{Yi}$ and Gong (2013) provided a tool to capture this behavior: a customer value co-creation behavior (CVCCB) scale comprising customer participation behavior (i.e., information seeking, information sharing, responsible behavior, and personal interaction) and customer citizenship behavior (i.e., feedback, advocacy, helping, and tolerance). The authors' paper has been one of the 20 most cited marketing articles in a four-year moving window (Shugan, 2017) and successfully stimulated research on value co-creation behavior in dyadic interactions (e.g., between customer and frontline employee) in various contexts and industries (e.g., Delpechitre et al., 2018; Gong et al., 2016; Kim \& Byon, 2018; Tuan, 2017).

However, research is increasingly recognizing that interactions between actors-for example, co-creation of value-rarely happens in isolation, but rather in service ecosystems consisting of multiple resource integrating actors (Hartmann et al., 2021). A service ecosystem is a "relatively self-contained, self-adjusting system of resource-integrating actors connected by shared institutional arrangements and mutual value creation through service exchange" (Vargo \& Lusch, 2016, pp. 10-11). In line with the definition of Davis et al. (2021), service ecosystems and sales ecosystems are considered in this thesis to be essentially identical.

Against the described background, Hartmann et al. (2018) argued that the (traditional) dyadic conception of selling is insufficient and that it is therefore necessary to (re)develop a conceptual basis that offers a more comprehensive explanation "for the processes and the roles involved [in] selling" interactions in multi-actor ecosystems (p.1). Consequently, the authors redefined selling as "the interaction between actors aimed at creating and maintaining thin crossing points" (Hartmann et al., 2018, p. 2) and concluded that all actors, whether they are internal (e.g., frontline employees) or external (e.g., customers) to the organization, are "selling actors" (Hartmann et al., 2018, p. 11).

As evidenced by the growing amount of research both independent from (e.g., Delpechitre et al., 2020; Ho et al., 2020; McColl-Kennedy et al., 2020; Mustak \& Plé, 2020) and connected to the recent special issues of prestigious sales journals such as the Journal of Personal Selling and Sales Management (e.g., Paesbrugghe et al., 2020; Ranjan \& Friend, 2020; Wang et al., 2020) and the Journal of Business and Industrial Marketing (e.g., Conde et al., 2020; Rusthollkarhu et al., 2020), research already has started to acknowledge the importance of shifting the focus towards interactions in service/sales ecosystems. The described broadening of scope points towards the increasing relevance of taking different actors, their behavior, and their interactions with each other in the respective service ecosystems into account (Rapp et al., 2020). However, thus far, research has not addressed this knowledge gap, and selling actors and their behavior in multi-actor ecosystems remain largely unexplored. Consequently, this dissertation addresses this important subject and investigates how value is co-created in multi-actor ecosystems. 


\subsection{RESEARCH QUESTIONS, DESIGN, AND OBJECTIVES}

Based on the described developments - that is, the formation of the service ecosystem perspective that "increases the range of activities and the number of actors considered to be involved in selling [and at the same time] expands the view from dyadic exchange to broader value creation practices influenced by institutional arrangements and institutionalization processes" (Hartmann et al., 2018, p. 2) - the purpose of this work is to answer two primary research questions:

$\mathrm{RQ}_{1}$ : What characterizes selling actors and their behavior in multi-actor ecosystems?

$\mathrm{RQ}_{2}: \quad$ How can these actors and their behavior be influenced?

The multidimensional nature of these questions calls for further narrowing; that is, breaking down the central research questions into clearly delineated sub-questions. Within the context of this work, four sub-questions are used:

(1): $\quad$ Who are salespeople's ecosystem partners exactly, what characterizes them, what do they expect, what tasks do they perform, and how do they do perform them?

(2): $\quad$ Which elements of the multi-actor service ecosystems contribute to a customer's experiential value, and can they be used to encourage customers' citizenship behavior?

(3): Can gamified experiences be used to encourage customers' participation behavior in multi-actor service ecosystems?

(4): How exactly are companies achieving ecosystem well-being, and can it be transferred to other businesses?

\subsection{THESIS OUTLINE}

This thesis comprises a total of six chapters that are structured as follows. Following the general introduction to the research topic and research questions in this chapter, Chapters 2 to 5 each address one of the four sub-questions by the means of separate research papers. The papers in Chapters 2 and 3 have been presented at prestigious international marketing conferences and have been published in peer-reviewed journals. The paper presented in Chapter 4 has also been accepted for publication by a peer-reviewed and esteemed journal. A shortened version of Chapter 5 is currently finalized and will soon be submitted to a practitioner's journal, most likely the MIT Sloan Management Review.

The last chapter of the dissertation, Chapter 6, synthesizes the findings of the research papers against the background of the two primary research questions. The following figure illustrates how the individual chapters contribute to answering the main research questions and the four sub-questions. 


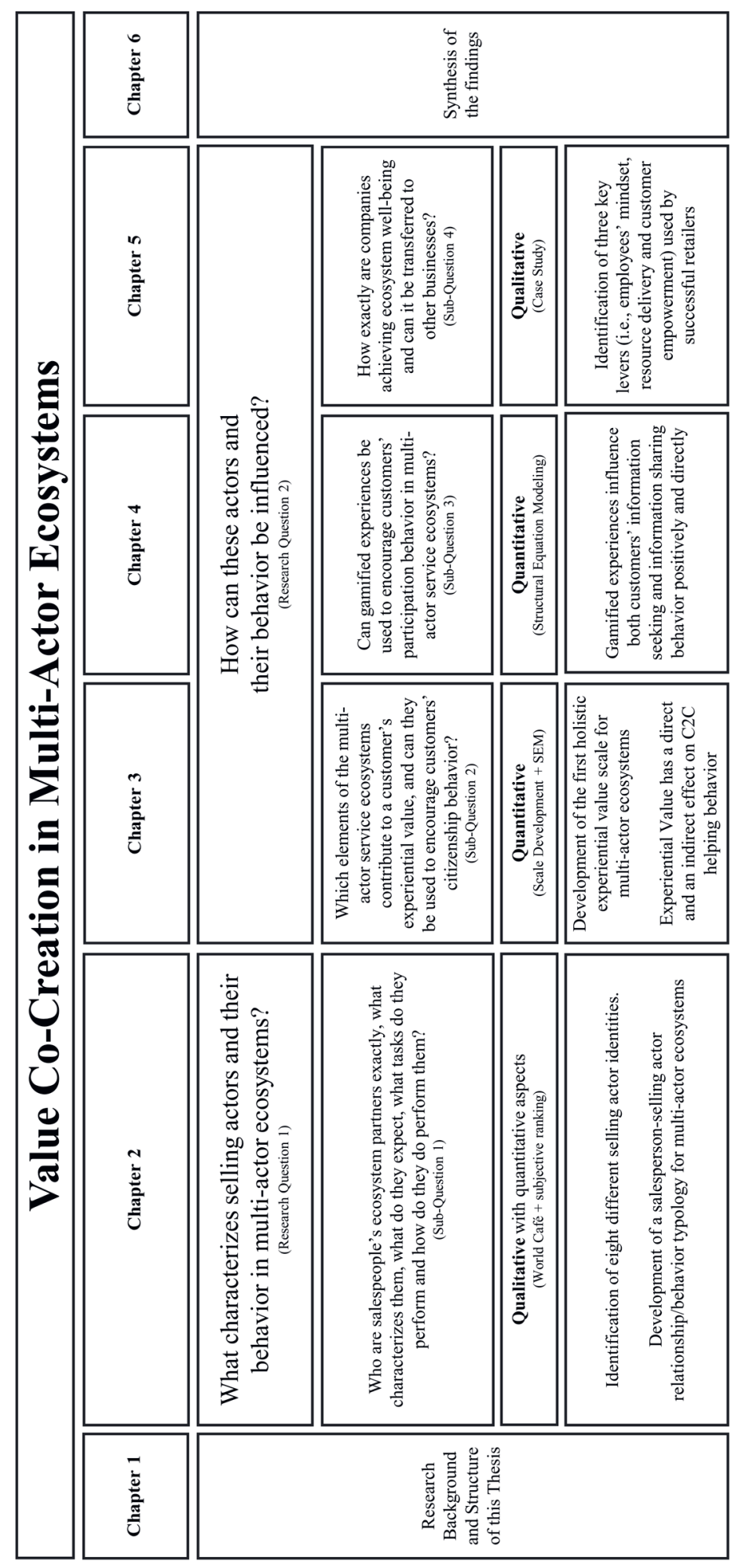

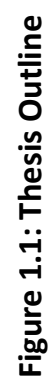




\subsubsection{CHAPTER 2: SELLING ACTORS IN MULTI-ACTOR SALES ECOSYSTEMS}

Sales research, increasingly frequently, acknowledges that customers' contributions to and active participation in (e.g., taking over tasks formerly performed by salespeople) the value co-creation process changes the dynamics between value co-creating partners in multiactor ecosystems and in consequence the role and responsibilities of salespeople (Hartmann et al., 2020). Logically, the investigation of salespeople's ecosystem collaboration partnersthat is, their behavior in multi-actor ecosystems-had to precede any investigation into how that behavior can be influenced, as it represents the foundation for further analysis. Accordingly, the main goal of Chapter 2 was to investigate selling actors' identities and their participation behavior in multi-actor sales ecosystems.

The research approach was specifically designed to overcome two of the most common shortcomings of prior research on that topic. First, the analysis focused on salespersons' perceptions of selling actors' identities and participation behavior instead of surveying the perspective of customers' self-assessment, as done by the majority of other studies (e.g., Revilla-Camacho et al., 2015; Shamim et al., 2017; Yi \& Gong, 2013). Second, a World Caféa qualitative method (Schulze-Horn et al., 2020) rather new to the field of sales researchwas applied in order to counter the effect of a one-sided focus on interviews as the method of choice for qualitative sales research (Johnson, 2015). In order to additionally strengthen the results, the method has been enhanced with quantitative research components. The main contribution of Chapter 2 is the identification of eight different selling actor identities and the development of a salesperson-selling actor relationship/behavior typology for multi-actor ecosystems.

\subsubsection{CHAPTER 3: EXPERIENTIAL VALUE IN MULTI-ACTOR SERVICE ECOSYSTEMS}

Within multi-actor ecosystems, multiple company-internal (e.g., frontline employees or other employees) and company-external (e.g., current, former, or perspective customers) selling actors share the same physical environment and thereby contribute to a "socially interactive experience" (Howard \& Gengler, 2001, p. 189). Values derived from experiences via "interactions involving either the direct usage or [indirect observation] of goods and services" (Mathwick et al., 2001, p. 41), can be captured through experiential value. Unfortunately, none of the existing experiential value scales is sufficiently suitable on its own for the application to multi-actor ecosystems, as no scale simultaneously accounts for customer's interactions with the multisensory physical environment, personal interactions with employees, and interactions between customers. Therefore, Chapter 3 presents the first holistic approach toward the measurement of experiential value in multi-actor ecosystems by synthesizing insights from existing research on experiential value-from various fieldsin one scale. The main goal of Chapter 3 was to identify which elements of the multi-actor service ecosystem contribute to a customer's experiential value and to investigate its relation to a customer's citizenship behavior, specifically, inter-customer helping behavior. To this end, a quantitative study was conducted and scale development (i.e., exploratory, 
and confirmatory factor analysis) was followed by structural equation modeling. The main contribution of Chapter 3 is the development of the first holistic experiential value scale for multi-actor ecosystems. Furthermore, Chapter 3 shows how experiential value can be used to encourage certain customer behavior (e.g., inter-customer helping behavior) directly and indirectly (i.e., through changing customers' attitudes first).

\subsubsection{CHAPTER 4: INFORMATION MANAGEMENT CAN'T BE ALL FUN AND GAMES, CAN IT?}

Customer participation behavior is considered necessary for the value co-creation process (e.g., Groth, 2005; Yi \& Gong, 2013). Information exchange behavior, that is, information-seeking and information-sharing behavior-or rather, the targeted search for information, and the voluntary provision of information to others-is a vital part of customer participation behavior (Yi \& Gong, 2013). This explains researchers' and practitioners' growing interest in how such behaviors can be encouraged.

Gamification, the intentional infusion of gameful affordances in a typically non-game context, to deliver experiences like those created through games (Deterding et al., 2011; Huotari \& Hamari, 2017; Warmelink et al., 2020), has drawn increasing attention from researchers and managers alike as a promising way to influence behavior (Leclercq et al., 2020). However, it is neither clear whether gamified experiences can influence customer participation behavior, more specifically, information exchange behavior, nor if such an influence also extends to multi-actor ecosystems (Koivisto \& Hamari, 2019).

Therefore, the main goal of Chapter 4 was to investigate if and how gamified experiences in a multi-actor service ecosystem can be used to encourage customers' information exchange behavior. To this end, a quantitative research approach (structural equation modeling) was used. The main contribution of Chapter 4 is the finding that gamified experiences influence both customers' information-seeking and information-sharing behavior positively and directly. Furthermore, Chapter 4 provides clear evidence that this also applies to multi-actor ecosystems.

\subsubsection{CHAPTER 5: PUTTING THE RETAIL APOCALYPSE OUT OF BUSINESS}

In line with most marketing research, the research presented in the Chapters 2, 3, and 4 follows the paradigm of empirical realism, in "trying to understand the current world and seeking the validity of its concepts" (Henseler \& Guerreiro, 2020, p. 5). In contrast, Chapter 5 leans toward the intersection of design and marketing and acknowledges that it is certainly possible that practitioners have (pragmatically) designed functional approaches-helping them to achieve ecosystem well-being - that can be transferred to other businesses. Indeed, there needs to be an explanation why (under comparable circumstances) some companies thrive and others fail. Inspired by the famous proverb "necessity is the mother of invention," the paper presented in Chapter 5 took a closer look at how companies from different industries, deal with the threat of the ongoing retail apocalypse. The main goal of Chapter 
5 was to identify the best practices, applied by three different companies, to achieve sales ecosystem well-being. To this end, qualitative research (case study research) was conducted. The main contribution of Chapter 5 is the identification of three key levers (i.e., employees' mindset, resource delivery, and customer empowerment) used by successful retailers. The chapter provides inspiring examples of company-designed functional approaches toward ecosystem well-being.

\subsubsection{CHAPTER 6: SYNOPSIS}

The ultimate goal of this dissertation is to answer two primary research questions: "What characterizes selling actors and their behavior in multi-actor ecosystems?" and "How can these actors and their behavior be influenced?." Each of the Chapters 2 to 5, like pieces of a puzzle, contribute partial answers to these research questions and answer the subquestions. In the last chapter of this dissertation, Chapter 6 , these pieces are put together. First, the chapter summarizes the findings of the previous chapters and places them in the context of the primary research questions. Second, the questions are answered and theoretical as well as managerial implications are deduced. The dissertation concludes, after a presentation of general limitations, with a suggestion of future research opportunities.

\subsection{GUIDE TO THE READER}

"The real purpose of books is to trap the mind into doing its own thinking."

- Christopher Morley -

In a similar vein, this dissertation seeks to inspire academics and practitioners alike to interpret, transfer, and make use of the presented findings, in their individual contexts. In order to evoke discussion about the topic, parts of this dissertation already were presented at scientific conferences in the UK, Germany and the United States of America; included in peer-reviewed conference proceedings; and published in peer-reviewed academic journals over the course of the last four years. Furthermore, the feedback received from practitioners, experienced scholars, and thoughtful reviewers, showed how well the topic already resonates with the target audience but also how to further refine it. Against the described aspiration of this dissertation, Chapters 2 to 5 were designed as stand-alone research papers. However, due to the fact that they are all pieces of the same "value cocreation in multi-actor ecosystem" puzzle, a certain degree of overlap and repetition, especially in their respective theoretical background and discussion sections, is inevitable. Before you continue reading this dissertation, I would like to thank you for your interest in my work and the time you have chosen to designate to it. No matter if you read the entire book or just selected chapters, as long as the work succeeds in stimulating your mind into doing its own thinking, it was worth my effort. 


\section{Chapter 2 SELLING ACTORS IN MULTI-ACTOR SALES ECOSYSTEMS}


This chapter investigates who salespeople's ecosystem partners are, what their characteristics and expectations are, and what tasks they perform and how they perform them. Based on a mixed-method research approach-a World Café with 32 participants in combination with subsequent quantitative evaluation by the participants-selling actors' identities and participation behavior in a multi-actor sales ecosystem were investigated from the salesperson perspective.

\section{Publication history:}

A short version of the paper, written together with Prof. Dr. Goetz Greve and Prof. Dr. Jörg Henseler, was submitted to and presented at the $47^{\text {th }}$ European Marketing Academy Annual Conference:

Weretecki, Patrick, Greve, Goetz and Jörg Henseler. 2018. "Salespersons' missing perspective on Customer participation behavior in value co-creation: an exploratory study." Proceedings of the 47th European Marketing Academy Conference, Glasgow, 29 May - 01 June 2018.

A revised and more comprehensive version of that paper was submitted to and accepted for publication in the Journal of Business and Industrial Marketing (JBIM).

Weretecki, Patrick; Greve, Goetz; Henseler, Jörg (2021). Selling actors in multiactor sales ecosystems: Who they are, what they do, and why it matters. Journal of Business and Industrial Marketing, Vol. 36 No. 4, pp. 641-653, doi:10.1108/JBIM03-2020-0145.

The following chapter is largely based on the paper published in the JBIM. 


\section{ABSTRACT}

The purpose of this chapter is to investigate selling actors in multi-actor sales ecosystems. When selling actors start taking over tasks that were formerly performed by salespeople, the distribution of tasks, allocation of responsibilities, and finally the role of the salespeople changes. However, little is known about salespeople's perceptions of selling actors' identities and participation behavior in multi-actor sales ecosystems. The authors conducted a World Café, a new qualitative method to the field of sales research, in combination with subsequent quantitative evaluation by the participants to obtain first data on selling actor identities in multi-actor sales ecosystems. Salespeople, who had the chance to observe and interact with more than 98,000 selling actors, disclosed their perceptions of selling actors' participation behavior in a multi-actor sales ecosystem. Four different data sources were analyzed to develop a comprehensive understanding of the topic and to test validity through the convergence of information from different sources. Using identity theory, a salesperson-selling actor relationship/behavior typology for multi-actor sales ecosystems was developed. Eight different selling actor identities were identified: avoider, observer, receptive actor, prepper, expecter, savvy actor, challenger, and coworker.

The typology provides researchers and managers with a tool to better understand and evaluate multi-actor ecosystems. This knowledge can be used as a starting point for the reassessment of the knowledge, skills, and abilities necessary for salespeople in multi-actor sales ecosystems and to improve their training and coaching. The firsthand experiences reported by the participants of the World Café will enable salespeople to identify different selling actors faster and prepare fitting approaches for all selling actor identities.

Keywords: Sales ecosystem, Multi-actor, Selling actor, Identities, Participation behavior, Cocreation 


\section{$2.1 \quad$ INTRODUCTION}

Traditionally, selling refers to a dyadic interaction in which a salesperson tries to convince a customer to agree to a transaction, which represents the value creation (Hartmann et al., 2018). In recent years, this point of view has changed, mainly because of rising interest in service-for-service exchange, in combination with the wide availability of useful information to customers (Kaski et al., 2017). Due to the fact that (nowadays) information is easily and instantly available to customers via a variety of different sources (e.g., Godes \& Mayzlin, 2009; Prahalad \& Ramaswamy, 2004; Verhoef et al., 2015), customers are becoming "increasingly knowledgeable and empowered" (Bagheri et al., 2019, p. 198), thereby fundamentally changing the "traditional" sales process of rapport building, needs discovery, solution presentation, closing the sale, and following up.

The way value is co-created and extracted on both the company's and the customer's side has evolved. The sales literature has acknowledged the necessity of looking beyond the traditional and transactional salesperson-customer dyad, calling for a new definition of selling (Dixon \& Tanner, 2012). The perception of the value creation process started to change with the introduction of the service-dominant (S-D) logic (Vargo \& Lusch, 2004). S-D logic is based on the foundational premises that "value is [always] co-created by multiple actors" (Vargo et al., 2017, p. 120) and that it is "never created through isolated efforts of one individual actor" (Vargo et al., 2017, p. 121). This led to the development of the ecosystem perspective of S-D logic, which "increases the range of activities and the number of actors considered to be involved in selling" (Hartmann et al., 2018, p. 2). Ultimately, the perspective redefines "selling in terms of the interaction between actors aimed at creating and maintaining [...] locations at which service can be efficiently exchanged for servicethrough the ongoing alignment of institutional arrangements and the optimization of relationships" (Hartmann et al., 2018, p. 2). This implies that all actors actively participating in exchange within the sales ecosystem (e.g., customers and employees) engage in selling and therefore are considered to be "selling actors" (Hartmann et al., 2018, p. 11).

However, when selling actors start performing tasks formerly performed by salespeople, the distribution of tasks, allocation of responsibilities, and finally the role of the salespeople changes. Singh et al. (2019) conclude that future "selling processes are likely to be collaborative endeavors wherein [salespeople] are likely to work hand in hand with multiple [participating sales] ecosystem partners to orchestrate complex sales solutions" ( $p$. 11). However, it remains unclear who these partners are exactly, what characterizes them, what they expect, what tasks they perform and how they perform them. This knowledge gap has to be addressed, as the answers to these questions are directly relevant for the work of salespeople because salespeople, who are challenged with new tasks, probably also require a different set of "knowledge, skills and abilities (KSAs)" (Hartmann et al., 2018 , p. 14). Furthermore, an investigation into buyer versus salesperson expectations for initial sales meetings indicates that there is still a mismatch between what buyers seek and what salespeople actually provide, that buyers' expectations are (often) not met, and that 
salespeople's training needs to be improved (Kaski et al., 2017). In order to answer the above-stated questions, two important steps have to be taken.

First, it is imperative to look beyond what the literature traditionally acknowledges as being different types of customers (Parasuraman, 1997) and focus on the different selling actor identities within these types. Therefore, additional examination of selling actors' identities and their participation behavior in multi-actor sales ecosystems is needed to pave the way for a reevaluation of the relative importance of various salesperson knowledge, skills, and abilities. While research has already explored customer identities in dyadic interactions (Swan et al., 2001) and surveyed the perspective of customers' self-assessment with regard to their participation behavior in dyadic interactions (e.g., Revilla-Camacho et al., 2015; Shamim et al., 2017; Yi \& Gong, 2013), little is known about salespersons' perceptions of selling actors' identities and participation behavior in multi-actor sales ecosystems. However, neglecting salespersons' points of view has proven to be problematic. Lassk et al. (2012) suspect that "salespeople are often dissatisfied with the integration of their feedback regarding the training programs may be a reason why sales representatives often doubt that their training is relevant to their day-to-day work" (p. 146).

Addressing the knowledge gap is important because without a clear understanding of the selling actors' behavior in a multi-actor sales ecosystem, identifying the necessary KSAs that salespeople need will not be possible, the salespeople will neither reach their full potential or be satisfied with their training, and investment in training and coaching activities for salespeople will always be inefficient.

Second, it cannot be ruled out that a one-sided focus on interviews as a method of choice for qualitative sales research has limited researchers' ability to get to the bottom of things so far. An examination of the types of data sources for qualitative sales research used in top-quality journals such as Journal of Business \& Industrial Marketing, Journal of Personal Selling \&Sales Management, Journal of Business Research, Industrial Marketing Management reveals that most studies rely primarily on data collected from interviews (Johnson, 2015). Hence, we propose an innovative qualitative method, new to the field of sales research: the World Café. This method is superior to interviews, especially in the exploration of entirely new topics or concepts and when researching groups (Löhr et al., 2020).

Thus, the purpose of this study is to identify selling actors' identities and investigate their participation behavior in a multi-actor sales ecosystem from the salesperson's perspective. Due to the currently limited understanding of the topic and the fact that prior research is scant, a qualitative approach was applicable (Drumwright, 1994). An exploratory research design was used to obtain the first qualitative data from the salesperson's perspective. A group of 32 salespeople-temporarily working as staff at one of the world's largest experiential events-and eight moderators participated in this study. This study considers experiential events to be an ideal example of a "relatively self-contained, self-adjusting system of resource-integrating actors connected by shared institutional arrangements 
and mutual value creation through service exchange" (Vargo \& Lusch, 2016, pp. 10-11). Experiential events (can) provide engaging, extraordinary, memorable, and socially interactive experiences. They bring multiple employees and customers together in the same physical environment at the same time (Harmeling et al., 2017). Two popular examples of successful experiential events are the 2015 Facebook IQ Live experience for business-tobusiness (B2B) customers or the 2020 IKEA-Sleepovers for business-to-customer (B2C) customers. We were granted direct access to the salespeople in this sales ecosystem, who had the chance to observe and/or interact with more than 98,000 selling actors, resulting in a large, exclusive, and unique data set. To enable interested researchers to develop a deeper understanding of this multi-actor sales ecosystem, images of this ecosystem can be accessed through the following quick response code (Figure 2.1).

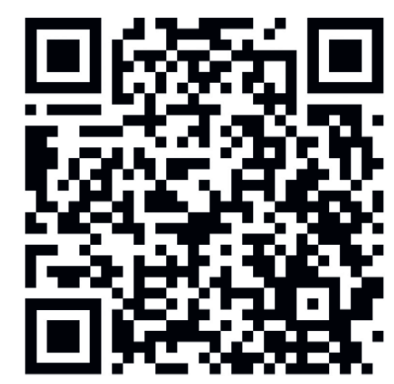

Figure 2.1: Quick response code for accessing images of the multi-actor sales ecosystem

Our research contributes to the existing literature on interactions in multi-actor sales ecosystems in three ways.

First, our study identifies eight different selling actor identities in multi-actor sales ecosystems. Therefore, we provide managers and researchers with a tool to better understand and evaluate sales ecosystems. This knowledge can also be used for the reassessment of salespersons' necessary KSAs and the development of more effective salesperson training. Second, we used the descriptions of the identities and developed a salesperson-selling actor relationship/behavior typology. Similar to Swan et al. (2001) we used an identity theory approach. Therefore, our research on identities and participation behavior in multi-actor sales ecosystems can be directly related and compared to the authors' findings on dyadic interactions. Thus, we not only identify identities in multi-actor sales ecosystems and provide a new typology, but we also contribute by highlighting differences and similarities between actor identities and their behavior in both systems. Third, we introduce a new qualitative method to the field of sales research, thereby enabling researchers to better understand how the sales process changes based on how selling actors co-create and/or extract value. 


\subsection{THEORETICAL BACKGROUND}

\subsubsection{Symbolic interaction and identity}

Sociology research has argued that "the starting point for any social analysis is the meaning that actors give to their situation" (Gonos, 1977, p. 863). Blumer (1969) suggested participant observation in the real world as the preferred method for studying interactions. Symbolic interaction refers "to the peculiar and distinctive character of interaction as it takes place between human beings" (Blumer, 1969, pp. 78-79). Howard (2000) argued that the "basic premise of symbolic interaction is that people attach symbolic meaning to objects, behaviors, themselves, and other people, and they develop and transmit these meanings through interaction" (p. 371). Hence, behavior toward others, is largely depending on the meanings that one actor attributes to another.

In our case, this means that salespeople consciously or unconsciously assign identities to other actors in the sales ecosystem and act according to these assignations. Howard (2000) found that identities are best described as "strategic social constructions created through [the participation in reciprocal] interaction, with social and material consequences" (p. 371). Therefore, this article uses the concept of selling actor identity; that is, the meaning and characteristics a salesperson assigns to a (company-external) selling actor based on the perceived participation behavior of that actor.

\subsubsection{Differences between types and identities}

The modern sales literature still distinguishes between four different types of customers, primarily based on relationship duration (e.g., Nguyen et al., 2018). New customers are those in the "exploration phase" (Dwyer et al., 1987, p. 16), and it is generally assumed that they have not yet had a relationship to the company (e.g., Nguyen et al., 2018). Short-term customers are considered to have had first (positive) experiences with the company and salespeople performed above expectations, likely resulting in further development (Nguyen et al., 2018). Long-term customers have a longstanding relationship with the company and are in a position to bargain (Wieseke et al., 2014). Finally, lost customers have had a prior relationship with the company but switched to competition. While this framework primarily focuses on dyadic interactions between customers and salespeople, it is largely based on an actor's relationship with the company and can therefore also be applied to selling actors in multi-actor sales ecosystems. Hence, there are also four types of selling actors (companyinternal personnel excluded).

In an effort to better understand the dyadic relationships between salespersons and their customers, Swan et al. (2001) looked beyond the mere relationship duration and focused more on the behaviors displayed by the customers. The authors interviewed salespeople and identified three categories of customer identities; namely, commercial friends, customer coworkers, and business acquaintances. These customer identities can be distinguished based on the customers' participation behavior. According to the authors' research, "[c]ommercial friends customers have interactions with salespeople that 
salespeople experience as close to personal friendships and incorporate intimacy, sharing casual conversation and joint leisure" (Swan et al., 2001, p. 32). In comparison, interactions with customer coworkers were described "as more similar to the intimacy found between people at work than the near personal friendships of commercial friends" (Swan et al., 2001, p. 33). The companionship between salespersons and customer coworkers blends together personal and business aspects but is limited in terms of intimacy (Swan et al., 2001). Since then, research has investigated the idea of friendship in the context of service provider relationships and personal selling on numerous occasions (e.g., Heide \& Wathne, 2006; Rosenbaum, 2009; Rosenbaum et al., 2015). In contrast to commercial friends and customer coworkers, salespeople described relationships with business acquaintances as "enduring relationships [characterized by] particularly commitment and reliance on each other for economic gain" (Swan et al., 2001, p. 34) and with little or no interaction outside the context of the service exchange that would constitute a friendship. Confusingly, the authors also referred to the identified customer identities as customer types. However, this study assumes that it is more accurate to characterize customer identities as subcategories of customer types. Based on the authors' descriptions, as well as their classification schemata, both commercial friends and customer coworkers, were considered identities of long-term customers, whereas being a business acquaintance was considered an identity of a short-term customer. The identities of customers with no prior relationship with the company and the identities of customers who discontinued the business relationship have remained unexplored. However, an increasing number of studies have started to recognize the considerable influence of other actors on the value co-creation process and the necessity to look beyond the dyadic relationship between a salesperson and his or her customer. For instance, research on shopping companions has provided evidence of their influence on other actors in the sales ecosystem in terms of time spent on value co-creation (e.g., Gillison et al., 2015; Hart \& Dale, 2014). In spite of this, researchers do not specify companions in terms of their identity and define co-shopping as the situation where any kind of a person accompanies a shopper (e.g., Hart \& Dale, 2014; Yim et al., 2014). The work of Swan et al. (2001) on actors' identities in dyadic interactions can certainly be used as a starting point for further analysis, as selling actor identities are assumed to be subcategories of selling actor types.

\subsubsection{Participation behavior}

This study considers "selling in terms of the interaction between actors aimed at creating and maintaining [...] locations at which service can be efficiently exchanged for service" (Hartmann et al., 2018, p. 1). According to Hartmann et al. (2018) within ecosystems "[a]ll actors participate in exchange by receiving and applying knowledge and forming mutually beneficial relationships" (Hartmann et al., 2018, p. 12). In contrast to dyadic customer-employee interactions, selling actors' participation behavior in multiactor sales ecosystems has been neglected by research so far. Research considers customer 
participation behavior (i.e., information seeking, information sharing, responsible behavior, and personal interaction) necessary for successful value co-creation in dyadic interactions (e.g., Delpechitre et al., 2018; Revilla-Camacho et al., 2015; Yi \& Gong, 2013). However, this study argues that these four elements for successful value co-creation -that is, service-forservice exchange-are a "minimum requirement" (Randall Brandt, 1988, p. 35) for any value co-creation process and therefore apply not only to dyads but also to triads or complex multiactor ecosystems. To illustrate the above, similar to customers in a dyad, selling actors need information (information-seeking behavior) "about how to perform their tasks as value cocreators as well as information on what they are expected to do and how they are expected to perform" (Yi \& Gong, 2013, p. 1280) during a service-for-service exchange. Furthermore, selling actors need to share information (information-sharing behavior) with other actors in the ecosystem. If a selling actor fails to provide accurate information, the quality of the service exchange will be low. Furthermore, for successful value co-creation between two or more actors, the actors need to be cooperative, follow rules (Bettencourt, 1997), and recognize their responsibilities (responsible behavior) within the value co-creation process. Personal interaction focuses on the "interpersonal relations" (Yi \& Gong, 2013, p. 1280) between value co-creating actors. It has been argued that service for service exchange occurs in a social setting and that the more enjoyable and positive the social environment is, the more likely it is that the actors will engage in value co-creation (Lengnick-Hall et al., 2000). Consequently, personal interaction should be at least as important in multi-actor sales ecosystems as in dyadic interactions. Hence, the necessary elements for successful value co-creation in dyads-that is, participation behavior-also apply to selling actors in multi-actor sales ecosystems. As indicated above, different identities display different participation behavior in interactions with salespeople and can therefore be differentiated based on their information-seeking behavior, information-sharing behavior, and responsible behavior in a personal interaction with the salespeople. In conclusion, the main questions of this exploratory study must be based on these four elements of participation behavior.

\subsection{METHODOLOGY AND SAMPLE}

\subsubsection{World Café method}

In the spirit of looking beyond the dyadic interactions (between customer and salesperson), we applied the World Café methodology, an innovative and creative methodology for hosting "authentic conversation[s]" (Brown \& Isaacs, 2005, p. 16) with multiple salespeople simultaneously. This exploratory research design was used to obtain the first qualitative data from the salesperson's perspective. Multiple small group discussions are used to foster knowledge sharing between a large number of participants and generate insights (Brown \& Isaacs, 2005). Chang \& Chen (2015) argue that " $[\mathrm{t}]$ he style of discussion is appreciative inquiry, which draws on discussing issues more than once, encouraging members to share their personal perspectives, and listening to others to discover the context and deep problem of multiple perspectives" (p. 1284). World Cafés 
are superior to the conventional focus group approach because of the "built-in iterations in which participants discuss and evaluate the outcomes of their peers from the previous discussions" (Pulles et al., 2016, p. 132), leading to increased robustness of the World Cafés outcomes. The method has proven to be extremely successful in handling topics that benefit from different perspectives, multiple sources of knowledge, and debate (Chang \& Chen, 2015). Varying group constellations ensure rich data collection. Typically, the World Café setup and process is as follows: Over the course of several (at least three) rounds of conversation, each lasting between 20 and 30 minutes, the participants in the World Café discuss the topic previously assigned to each individual table before they switch to the next table and topic (Lagrosen, 2019). The number of tables and therefore topics, is equal to the number of rounds of conversation; therefore, every participant discusses every topic. Each table has a moderator, who remains at his or her respective table for the entire time of the discussion rounds, welcomes new groups, and reports findings of prior discussions to them (Lagrosen, 2019). Shortening the discussion rounds in the World Café is common because the groups use the findings formulated by prior groups. Writable tablecloth on each table allows participants to note opinions and ideas and to catch up on and relate to the findings of prior groups. A rotation schedule can be used to ensure the smooth transition of participants and to ensure that every participant discusses each topic. After the discussion rounds, moderators and participants come together in a plenary session for a summary and quantitative evaluation of the findings.

\subsubsection{Sample descriptions}

The study was conducted at the Internationale Funkausstellung, the leading experiential event for consumer electronics and home appliances in Berlin (Germany). The participants of the World Café worked for one of the largest telecommunications companies in the world. The company is the leading provider within Europe, and the number of competitors (or alternatives) in the market is very limited. A group of 32 salespeople-temporarily working as staff at one of the world's largest experiential events-and eight moderators participated in this study. All of the participants were able to communicate fluently in English and German. Based on the results of electronic and manual visitor frequency counting and a network of high-precision 3D sensors mounted on the ceiling, by the time the study was conducted, this experiential event brought together more than 98,000 resources integrating selling actors and salespeople from all over the world and of all ages, who were connected by shared institutional arrangements and engaged in mutual value co-creation through servicefor-service exchange. The main criteria for selecting the participants for the study involved selecting a representative sample from all company exhibits and a balanced mix regarding age, gender, and career level. Furthermore, we ensured the inclusion of salespeople with varying degrees of customer interaction frequency in their daily jobs. This means that, while all participants were salespeople for the six days of the experiential event, their "regular" job might not have been in sales and/or service, which, in our opinion, added unique 
perspectives and enriched the data collection. Sample characteristics are displayed in the Appendix in Table A.2.1.

\subsubsection{Conversation topics and rotation schedule}

Following the research proposition, the main questions for the conversations were based on the four elements of participation behavior. To foster the free flow of ideas and the collaborative conversations between participants, we tried to minimize the external input and influence of the moderators. However, we also considered the possibility that the participants might misunderstand or misinterpret questions. To this end, all moderators were briefed beforehand. A general guideline for all questions was to "help" as much as necessary and as little as possible. Typically, the moderators started the discussions by asking the participants if the question was clear and asked how exactly it was understood. If this initial discussion drifted off course, the moderators carefully adjusted the course by shifting the participants' focus on the abovementioned aspects. Regarding the questions, the moderators were advised to ensure that the participants of the World Café focused on the behaviors of actors; that is, anyone external to the own organization they deemed as relevant for the value co-creation process and who had an observable goal or motive within the sales ecosystem environment. Furthermore, the moderators were required to ensure that the discussions on information-seeking behavior focused on the ways actors searched for, discovered and accessed information (Savolainen, 2019), whereas the discussions on information-sharing behavior had to be about the provision of information to other actors and confirming that the recipient(s) had received and understood that information (Sonnenwald, 2006). Moderators ensured that the discussion on the actors' responsible behavior focused on whether actors recognized their relevance for the value co-creation process and behaved accordingly (Ennew \& Binks, 1999). Moderators were briefed that the discussions about the personal interaction with the actors were to focus on the interpersonal relations between the actors in the multi-actor sales ecosystem, including aspects such as courtesy, friendliness and respect. To ensure the highest quality and quantity of the results, each of the four elements was permanently assigned to two specific rooms and discussed in parallel sessions. Hence, eight different tables were simultaneously used. The participants were asked to answer the following questions:

- Table 1/1b: How would you describe the actor's information-seeking behavior?

- Table 2/2b: How would you describe the actor's information-sharing behavior?

- Table 3/3b: How would you describe the actor's responsible behavior?

- Table 4/4b: How would you describe the personal interaction with the actors?

Over the course of four rounds, participants switched rooms in accordance with a schedule. The numbers in Figure 2.2 illustrate that the participants mixed when rotating between the tables to increase the degree of "knowledge exchange" (Prewitt, 2011, p. 190). 


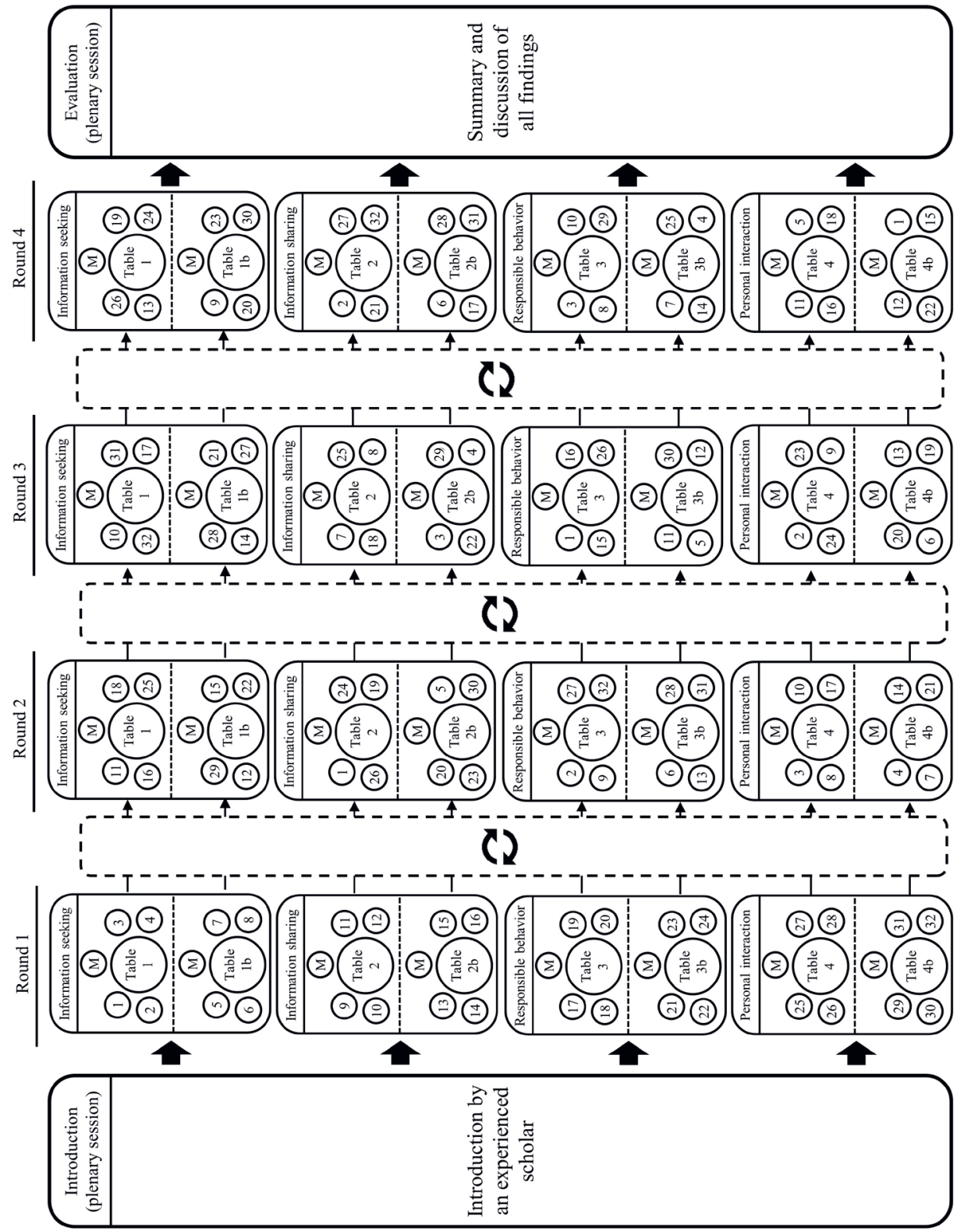

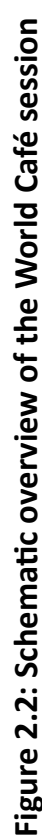


Every participant received a detailed schedule of his or her individual rotation order. The session started with an introduction to the World Café method by one of the moderators. Afterward, the participants and the moderators went to their rooms and the discussions began. While the participants moved after each round, the moderators remained at their tables. At the beginning of each new round, each participant and moderator briefly introduced himself or herself to the discussion group before the moderator summed up the findings of the previous group(s). Varying groups explored the selling actors' participation behavior based on their own observations and interactions with the-by that timeapproximately 98,000 actors that they had encountered. The four rounds lasted 30 minutes, 25 minutes, 20 minutes and 20 minutes.

\subsubsection{Data recording and analysis}

The moderators' notes, writable tablecloths, and audio recordings ensured that all the generated results were captured and available for analysis. After the four discussion rounds, moderators and participants came together in a plenary session for a final discussion and quantitative evaluation of the findings.

In the first step, the audiotaped discussion rounds were transcribed. To ensure the highest quality, two researchers independently transcribed the approximately 760 minutes of discussions. A native speaker was used to ensure the accuracy of translation. The 760 minutes of discussions translated into more than 102,000 words.

Subsequently, the material was analyzed using the method of qualitative content analysis, which is a systematic and rule-bound procedure (Mayring, 2015). We used inductive category formation in order to derive summarizing categories directly from the collected data and not from theoretical considerations (Mayring, 2015). The process of inductive category formation dictates that first, "the level or theme of categories to be developed must be defined" (Mayring, 2015, p. 374). The necessary "criterion for the selection process in category formation [is] established within theoretical considerations about the subject matter and the aims of analysis" (Mayring, 2015, p. 374). Furthermore, the establishment of the abstraction level is imperative for inductive category formation. Based on the aim of our qualitative approach, we included all material covering selling actors' information-seeking, information-sharing, and responsible behavior. In addition, we analyzed descriptions of personal interactions, types, and identities of selling actors within the sales ecosystem. We used qualitative data analysis software (MaxQDA) and handled all interview transcripts carefully. Two coders analyzed the data separately, following the procedures developed for the inductive category formation technique of qualitative content analysis (Mayring, 2015). This included a revision of the emerging categories after approximately $50 \%$ of the content analysis, resulting in only minor changes. Finally, the codings of the researchers were merged based on a thorough discussion. Additionally, the final codings were presented to and approved by the moderators of the World Café. 


\subsubsection{Classification schemata}

One important goal of this research is that the identities and participation behavior in multi-actor sales ecosystems can be directly related and compared to the findings on dyadic interactions. Therefore, using and refining the typology of Swan et al. (2001) - that is, their classification schemata-is not only efficient but also necessary. For instance, we have already pointed out that selling actor identities are assumed to be only subcategories of selling actor types; hence, investigating this additional layer in the framework is necessary. Within the traditional framework of Swan et al. (2001), identities are differentiated based on a set of four behavioral elements: intimacy, sharing casual conservation, engaging in leisure activities, and becoming a spokesperson for the company, and on a second set of behaviors and perceptions: exchange of benefits and business information, time frame, account responsibility, mutual self-disclosure, and tension in the relationship. In the following analysis, we make use of the same two sets.

\subsection{FINDINGS}

\subsubsection{Overview of identities in multi-actor sales ecosystems}

We followed the example of Swan et al. (2001) and engaged in a subjective rating of the behaviors of Set 1 and the behaviors and perceptions of Set 2 to expand upon their classification schemata. The analysis of the intense discussion rounds between the participants revealed eight different selling actor identities, two for each selling actor type. The participants described that Type 1 selling actors, who (in their opinion) had had prior experiences with the company and are currently the customers of a competitor, displayed either the identity of the "avoider" or the "observer." Type 2 selling actors, who (presumably) had no prior experiences with the company but who are currently looking for new representation, displayed either the identity of the "receptive" actor or the "prepper." Furthermore, the participants described that Type 3 selling actors who had first experiences with the company and who are already customers displayed either the identity of the "expecter" or the "savvy" actor. Type 4 selling actors with a longstanding relationship with the company displayed either the identity of the "challenger" or the "coworker." The process of reduction, as suggested by Barton (1955), confirmed our assumption that selling actor identities can in fact be understood as subcategories of selling actor types. Figure 2.3 gives a detailed overview of all selling actor types and identities as well as their characteristics.

\subsubsection{Selling actor: Type 1}

"Avoider"

This actor is part of the multi-actor sales ecosystem but tries to avoid any contact with salespeople. The avoider is not interested in building rapport with the salespeople or company or in disclosing his product and service needs, nor in listening to possible solutions. Value co-creation with this actor is not possible because this selling actor refuses to take part in any part of the sales process. As Monica summarized, 


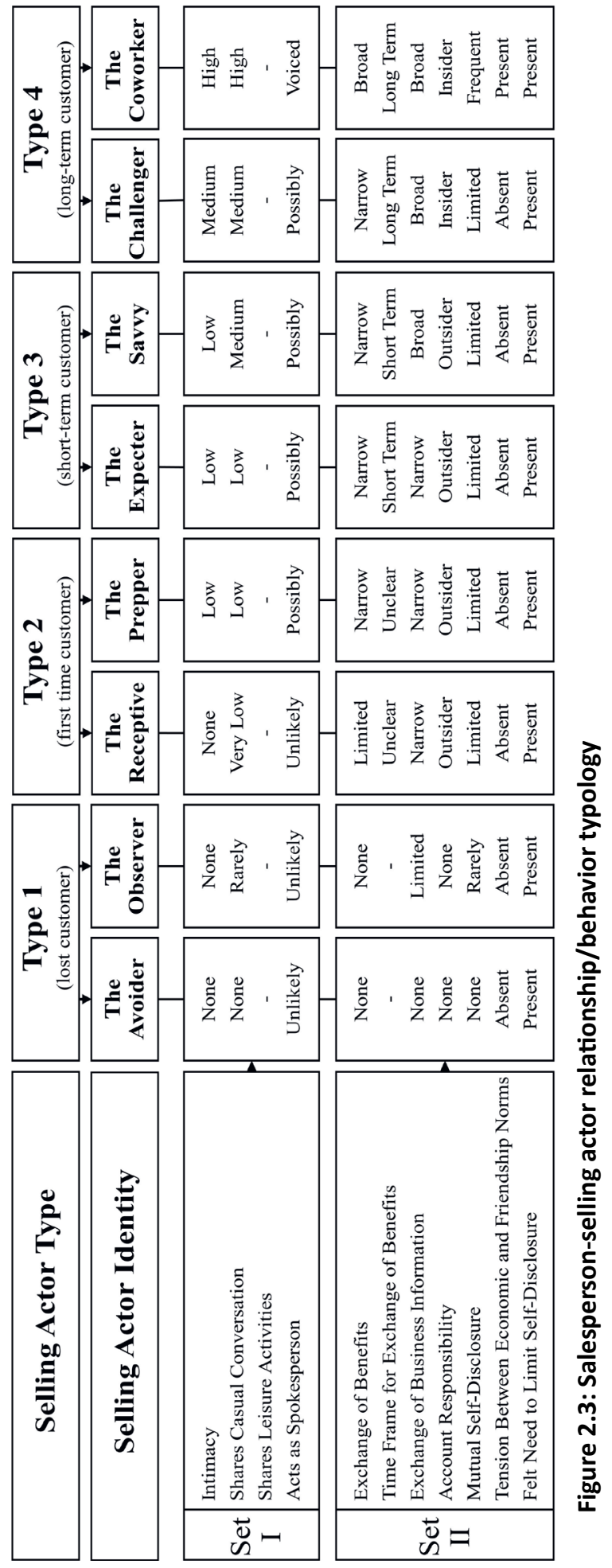


"[...] not everyone with a negative attitude wants to make themselves familiar with [the] topic. Some of them just pass [by], and if you talk to them, they tell you that everything is bad and that you should leave them be and go on."

Because these actors avoided interaction with the salespeople, information on the relations with the company can only be assumed. It was suspected that these selling actors have had prior experience with the company but are currently customers of the competition.

"Observer"

The participants described selling actors with an observer identity as shy and afraid, but also curious. These actors fear personal interaction and that they might be approached by salespeople, which makes rapport building difficult. They do not like to engage in conversion because they do not like to share information or disclose information about their needs. However, these actors are interested in the offerings and display signs of informationseeking behavior. Hence, there is an opportunity for solution presentation. An observer positions himself or herself at a safe distance from salespeople to avoid being talked to. Participants noticed that there is an actual information-seeking behavior in contrast to the avoider. Christopher described,

"[...] while he [the avoider] just goes with the flow and rummages or something like that, he [the observer] stays in the hall and maybe does not enter the experience area."

David added,

"[...] he is trying to conduct his search from the outside. Without entering by himself, so to say, if he can get the information that he is looking for from the outside. It probably costs a lot of willpower, as we have said, to enter, to address someone."

The participants agreed that a selling actor with an observer identity is very difficult to connect with. They must be treated with extreme caution and even then, meaningful exchange of business information, self-disclosure, and responsible behavior is rarely achieved by salespeople. Lisa summarized the only thing that seems to work on this occasion:

"[...] he [the observer] wants to be treated like a child, to be taken by the hand."

Hence, value co-creation with these selling actors, let alone selling something to them, is next to impossible. These selling actors have had a prior relationship with the company in the past but are currently engaged with the competition. This explains their curiosity, as well as their restraint.

\subsubsection{Selling actor: Type 2}

"Receptive" actor

This selling actor approaches salespeople proactively, making it easy for salespeople to build rapport. He or she actively searches for personal interaction and someone who is able to provide information. The receptive selling actor typically has a negative or neutral attitude toward the company; therefore, no intimacy is expected, but this actor is open to 
engaging in casual conversation and even mutual self-disclosure. However, this actor has an open mind and sometimes wants to be convinced by the salespeople. As Lydia explained,

"[...] they approach you with their negative attitude and actually want to be convinced."

The receptive actor often is a (former) customer of a competitor. These selling actors are not satisfied with their (former) representation. However, that is rarely openly admitted by the actor and must be discovered by the salesperson in the "needs-discovery phase" of the process. One participant recollected hearing something resembling the following:

"I am currently [a customer of XY] and now you have to convince me to switch to you."

As Monica explained,

"Competitor customers do not come with, "I know I am with a bad provider, and you are in fact a premium provider.'”

"Competitor customers are always extremely dominant and say, 'I am [a customer of $X Y]$."

The participants in the World Café agreed that the receptive selling actor makes for a good prospective customer. This actor is unsatisfied with his or her current representation and is open to a presentation of solutions-i.e., switching the service provider and even accepting the proposal. Participants also reported examples of successful emotional approaches toward receptive selling actors, indicating that the open-mindedness might go beyond the business context.

"Prepper"

Furthermore, the discussions revealed the identity of a selling actor with unmatched levels of preparation for interaction with salespeople. Building rapport with these actors is easy for salespeople, as these actors approach salespeople directly and proactively. These actors seek information and are aware of the fact that salespeople need information about their needs in a certain quality and quantity to service them appropriately. The prepper trusts salespeople and reveals any information necessary for the value co-creation process. This also includes disclosing more personal or intimate information and engaging in casual conversation. Felix described,

"[...] they are open and give information. Like I said, if I ask, I get an answer."

Other participants added,

"[...] they are more open to sharing because they are focused on a solution" (Tom),

"[...]he [the prepper] comes straight out with the information" (Beatrice) and "[they] approach us very often and tell us which provider they use, how much they pay, and so on, because they actually have an issue and are looking for help. I think that is the reason they are ready to share information. They show us their phones, how much data they have, or how fast the connection is, and they hope to get a solution that way." (Joe) 
Tom concluded,

"[...] with us, they are pretty open with giving information, like the customer number or phone number and name, because it's about something concrete, there's a disturbance, or an issue or they'd like a new product, and then they give this information very readily. Because they know that without this info, I can't offer any help, or with errors, for example."

This actor wants to be offered a possible solution.

The prepper typically has had no personal experience with the company but is currently an unsatisfied (former) customer of the competition. The prepper has learned his or her lesson, so to speak. Based on the negative experience with the former service provider and the good reputation of the new provider, a level of trust and confidence in the new company starts to build. For salespeople, closing a sale on the spot is certainly possible.

\subsubsection{Selling actor: Type 3}

"Expecter"

Salespeople described selling actors with an expecter identity as cautious and even slightly insecure. These actors intentionally choose to position themselves in proximity to a salesperson but still maintain a distance because of a lack of intimacy. The actors expect to be approached proactively by a salesperson, hence the name "expecter." One participant described,

"[...] you have to actively approach the people. I don't know, they are shy." (Lisa)

Christopher added,

"I don't think that they come to us directly and say 'Okay, I want to know this, this and that.' But they idle around a bit, look around a bit, and wait to be addressed. They don't come to you and say 'Oh hi, do you work here, can you tell me something.' But they stand there and wait to be addressed."

Hence, salespeople must engage proactively to build rapport. After the salespeople approach the expecter and engage in dialog, the relationship deepens, and trust builds. Typically, the expecter lowers his or her guard and even engages in casual conversation. Some descriptions of this include the following:

"The customers open up when they have spoken two, three sentences. And it all relaxes a bit. Then they open up and reveal a lot more about themselves as well" (Jonathan) or "I was just about to write that down here, the clients open up after a short while." (Lisa)

Nevertheless, the interaction is certainly more of a business relationship than a friendship. The selling actor wants to be approached to talk about business. He or she is searching for information and wants to be taken care off. He or she is aware of his or her role and responsibilities; voluntarily discloses needs; and shares items such as self-disclosure, information, and benefits but also has high expectations of the salespeople. The participants described, 
"[...] when the [selling actor] connects with an employee, the expectation is that he [the employee] will answer all the questions" (Jonathan) and that

"[...]what happened quite often to me is that the people, once they are in a conversation, would like to resolve everything at once with an employee." (Christopher)

It is likely that the expecter has had first experiences with the company and that the salespersons exceeded his or her expectations, which makes this actor receptive to the presentation of offerings. Jonathan explained as follows,

"The [expecter] will never actively address the employee, so you have to address [this selling actor] and activate them first and then [...], Often then, you end up with the same results as with the actors who come directly to you."

There is a good chance that an interaction between a salesperson and an expecter leads to a successful sale.

The descriptions of the expecter identity in the multi-actor sales ecosystem show similarities to the business acquaintance identity, as described by Swan et al. (2001).

"Savvy" actor

The discussions also revealed the identity of a selling actor with expert-level knowledge. This selling actor has a specific, business-related interest and wants to address the issue directly. Generally, building rapport can be challenging because this actor has low motivation to engage in a casual conversation and develop a personal connection or a level of intimacy with the salespeople. However, when the salespeople are deemed "worthy," in the sense that they are perceived as sufficiently competent, the savvy actor likes to engage in conversation. A savvy actor is well aware of his or her responsibilities in the value cocreation process, and he or she approaches salespeople directly and engages in information exchange to demand very specific information from the salesperson. His or her expert-level knowledge makes him or her a demanding and challenging interlocutor for the salespeople. As the participants summarized,

"[...] they already know everything. They have made themselves familiar with the topic so deeply that they also want to obtain very detailed answers" (Jennifer) and "[...] they mostly come with specific information that they want me to show and explain. That is how I feel it is. This is mostly a pro, who knows what is available and what he is looking for [...] additional information." (Beatrice)

Solution presentation to savvy actors rarely leads to a successful sale.

These selling actors were already short-term customers of the company. However, as these customers are often interested in the latest technology in products and services, they are not the most loyal customers and display highly rational behavior. 


\subsubsection{Selling actor: Type 4}

\section{"Challenger"}

The selling actor with the "challenger" identity was described as highly active and participative in the value co-creation process. The challenger is typically not interested in deepening their relationship with the salespeople. This selling actor has a predetermined goal and engages in personal interaction and casual conversation with salespeople to achieve this goal. While these actors proactively approach salespeople, it is difficult for salespeople to build rapport because these selling actors also tend to set the topic for the conversion. As the participants explained,

"[...] from my point of view, [they] are in the role of the driver of [the]conversation" (Harry) and

"[...] they display an active demanding expectation role, cancelling [their] contract. [The] customer expects a new offer, expects a new solution and is very specific in his requests." (David)

The challengers are fully aware of their position and power in the business relationship. The challenger displays his or her business needs and is willing to pressure salespeople to obtain what he or she wants. The participants gave three examples of what they regularly hear from a selling actor with a challenger identity:

"Hey, I have this and that, but it will be cancelled" (Sarah) or something like

"I will cancel my [...] contract and now I will get a nice, new offer or get an up-todate tariff." (Sarah)

Harry added the example,

\section{"[...]if I cancel, I will get a better offer."}

These selling actors already mostly have a long relationship with the company and understand that they are in a position to bargain. Although these actors do not seem to be interested in ending the business relationship, they threaten to do so to obtain a better deal. The discussions revealed that interaction with these selling actors almost always results in the salespeople making the best possible offer and the selling actors taking them up on that offer. This is a power game rather than a two-way relationship. The challenger will return as soon as he or she feels that he or she could obtain a new (better) offer. Hence, salespeople do not have to worry about following up.

\section{"Coworker"}

Similar to the findings of Swan et al. (2001), salespeople described a type of selling actor identity with whom they shared a certain intimacy and casual conversations and who even acted as an advocate for the company. Building rapport comes almost naturally. As Finn explained,

"[...] they identify themselves with us, I would say. [They feel like] I am a customer, so I will stop by. I get to feel that I have value here. If we have customers who have been with us for a while, then they are proud to highlight this fact and not because they expect something, just because they are proud." 
Furthermore, selling actors with a coworker identity actively participate in the value cocreation process. The actors exchange the necessary information, behave responsibly, and frequently engage in mutual self- disclosure. They are interested in being offered a solution to their specific needs. As Dominik explained,

"[...] they are actually looking for something; they also approach our booth directly when they find it or just say, 'Hey I already have [...]. Who can give me some advice?' They come to us directly and look for the answer to their question. In this case, you can help them. If they have a specific question, they approach you directly and find our model displays; if they do not, they look for help and let themselves be taken to us."

This selling actor is aware of his or her role in successful value co-creation and often already has a longstanding relationship with the company. However, similar to the findings on the coworker identity in dyads, the relationship is constrained in terms of intimacy, as the focus is on the relationship between the selling actor and company rather than on the relationship with the salespeople. Rhonda summarized,

"[...] they have been with us for thirty years and like to form a friendship with us."

\subsection{DISCUSSION}

The aim of this study was to take a closer look at selling actors' identities and participation behavior in a multi-actor sales ecosystem, from the salesperson's perspective. We used an exploratory research design to obtain the first qualitative data from the salesperson's perspective. The participants' descriptions provided more clarity and precision as the World Café progressed, indicating that the participants were able to use the built-in iterations in which the participants discussed and evaluated the outcomes of their peers from the previous discussions to their advantage. Therefore, applying the World Café method was revealed to be an excellent choice. The discussions revealed that the perceived participation behavior in fact differs, depending on the actor's selling type and identity with whom the salespeople interacted. The findings of our study support the following conclusions.

First, the results suggest that selling actor identities exist. The findings show that salespeople assign different meanings and characteristics to eight selling actors' identities based on the perceived participation behavior of these actors. The "avoider" is suspected to be a former customer who is currently lost to the competition and who is neither interested in a relationship with the salespeople/company nor in the offered products and services. The "observer" is also a former customer who has had a prior relationship with the company. While he or she is shy and afraid of being talked to, he or she also is curious and interested in the offerings and displays signs of information-seeking behavior. The "receptive" actor on the other hand, is both unsatisfied with his or her current representation and is open to a new service provider. He or she is actively searching for personal interaction and approaches salespeople proactively. The "prepper" has had no personal experience with the company but is currently an unsatisfied (former) customer of the competition. The prepper engages 
in personal interaction with salespeople proactively, is highly prepared, trusts salespeople, and reveals any information necessary. The "expecter" has had first experiences with the company, and the salespeople exceeded his or her expectations, which makes him or her interested in offerings. He or she is cautious and insecure and expects to be approached proactively by a salesperson. The "savvy" actor is already a short-term customer of the company and has expert-level knowledge and high expectations of salespeople, which makes him or her a demanding and challenging interlocutor. The "challenger" has a longer relationship with the company and understands his or her strong negotiating position. The challenger is willing to pressure salespeople to obtain what he or she wants. The "coworker" is also a long-term customer. However, in contrast to the challenger, he or she shares a certain intimacy and casual conversations with the salespeople and even acts as an advocate for the company.

Second, we related our findings from a multi-actor sales ecosystem to the findings of Swan et al. (2001) regarding dyadic interactions and developed a salesperson-selling actor relationship/behavior typology. While we were able to validate the authors' identification of the coworker and the expecter (also known as "business acquaintance") identities, we were unable to identify the identity referred to as "commercial friends." However, this can be explained by the wholly B2B sample that Swan et al. (2001) used. The salespeople in their study referred to customers as their "accounts," indicating that they were responsible account managers. It seems reasonable to assume that in the context of long-lasting relationships with frequent interactions and exchange of information, where both parties are reliant on each other, friendships are more likely to occur than in infrequent B2C interactions. The fact that we identified six additional identities by also including Type 1 and Type 2 selling actors in the investigation -in contrast to Swan et al. (2001), who limited their investigation to Type 3 and Type 4 selling actors-supports our decision to investigate the identities of actors beyond the traditional customer-salesperson dyad.

Third, the World Café can be a valuable tool for qualitative sales research. Based on the moderator and participant feedback we received immediately after the World Café but also after sorting through the vast amount of data generated, we see several advantages in comparison to interviews. One of the greatest strengths of this method is that directly after the World Café, a first summary of results (which can also be evaluated quantitatively) is available. In our case, each of the moderators was able to present a structured and redundancy-free overview of the results, which had already been validated over several rounds of discussions by all of the 32 participants. Furthermore, in contrast to interviews, there is no interviewer bias in the World Café because the moderators only facilitate the discussions, whereas the participants are responsible for the content of the discussions.

Finally, the variety of data sources (audio recordings, moderators' notes, writable tablecloth, plenary session) enabled researchers to develop a comprehensive understanding of the topic and test validity through the convergence of information from different sources. 


\subsection{IMPLICATIONS}

\subsubsection{Theoretical implications}

At the beginning of this chapter, we claimed that when selling-actors start performing tasks formerly performed by salespeople, the distribution of tasks and allocation of responsibilities change. We assumed that salespeople challenged with new tasks also require a different set of KSAs. Based on the thorough analysis of the World Café discussions, we can support this statement. The participants in our study revealed how they perceive and define the identity of a selling actor and how the identity determines how the participants interact with and adapt to these selling actors. This is highly relevant to the field of sales management for several reasons.

First, it is of utmost importance for sales research on selling actor-salesperson topics (e.g., behavior, performance and/or relationship) to be as precise as possible in the description of the types of selling actors and their identities. When sales literature fails to specify these, then the results and findings of a study are neither verifiable nor comparable. For example, two studies on salesperson performance in an identical scenario can show fundamentally different results if in one case, the salespeople mainly deal with the avoider, observer, or receptive actor identities and, if in the other case, there are primarily prepper, expecter, and/or coworker identities; however, the studies only refers to customers/selling actors.

Second, rather than merely confirming the findings of Swan et al. (2001), we identified six additional identities, and we thereby offer a critical refinement of their classification schemata. This fact highlights the importance of looking beyond the dyad and taking a more holistic perspective.

Third, this is the first time that a World Café approach was used in the context of investigating personal selling and the selling actor-salesperson interaction. In our opinion, the quality and quantity of the findings more than justify the complex and expensive setup. Our hope is that other researchers will follow our lead by applying this method across a variety of other selling and sales-related topics.

\subsubsection{Managerial implications}

The results reveal that the participation behavior displayed by the selling actors varies widely depending on identity. While some selling actors approach salespersons directly and proactively (e.g., the receptive actor, the prepper, the savvy actor, the challenger, the coworker) others tend to wait to be approached (e.g., the observer, the expecter) or even try to avoid any interaction (e.g., the avoider) with a salesperson. Furthermore, some selling actors tend to share information voluntarily (e.g., the expecter, the coworker) and in detail (e.g., the prepper, the savvy actor, the challenger), whereas others are cautious (e.g., the observer) or even reluctant (e.g., the avoider). Some actors expect a rather personal approach (e.g., the coworker), whereas other actors are more concerned with the professional expertise of the salesperson (e.g., the savvy actor). The salesperson-selling 
actor relationship/behavior typology and the firsthand experiences reported by participants of the World Café will be useful to salespeople for two reasons. First, the examples of cues to look for when interacting with selling actors enable salespeople to identify them faster. Second, salespeople can use the knowledge about selling actors' expectations and behaviors regarding the sales process to prepare fitting approaches for all selling actor identities. We follow the reasoning that it can be assumed "that salespeople who misjudge the type of relationship that a [selling actor] desires will experience difficulty in establishing effective" (Swan et al., 2001, p. 36) relationships. Thus, it is important that salespeople possess the necessary skills to identify a selling actor identity correctly, the knowledge on how to best engage with that actor, and the ability to do all of this instantly. Management needs to be aware of these requirements and invest in training and coaching activities. Furthermore, managers need to recognize that there are considerable differences between selling actors and that salesperson performance management must consider this fact. For example, while both the expecter and the savvy actor already have a short-term relationship with the company and an interaction between these selling actors and a salesperson might take the same amount of time, there is a large difference in what could be considered a "successful" outcome. An expecter is likely to intensify the relationship and might even act upon offerings (up/cross-selling) made by the salesperson, whereas the interaction with a savvy selling actor could already be considered a success if that selling actor does not leave the company for another company. However, traditional performance evaluation would suggest that only one of these interactions was a success. Therefore, we see an opportunity for improvement. From an efficiency standpoint, the identified selling actor identities could also be used for a targeted approach. For example, if the primary goal of a certain sales activity were to (quickly) boost revenue, focusing on selling actors with the prepper and/or the expecter identity would probably be more efficient than focusing on interactions with the coworker or the challenger identity. In conclusion, practitioners can greatly benefit from the identified selling actor identities reported in this article.

\subsection{LIMITATIONS AND FUTURE RESEARCH}

This study is the first to make an effort to identify selling actors' identities and investigate their participation behavior in a multi-actor sales ecosystem from the salesperson's perspective. Using identity theory, eight different selling actor identities were identified. While the study succeeds in answering the questions of who the selling actors in multi-actor sales ecosystems are, what characterizes them, what tasks they perform, and how they do these, our study is not without limitations, implicating opportunities for future research.

The company studied is the leading provider within Europe and the number of competitors (or alternatives) in the market is limited. Therefore, the company and its employees, by extension, have considerable bargaining power both in terms of buying and selling of services. It cannot be ruled out that the company's size and/or its position in the industry has an influence both on the selling actor's behavior and on the participants' 
perceptions of that behavior. Hence, one important next step for future research is to validate the identified selling actor identities in other multi-actor sales ecosystems and industries as well as in companies with a different position within the market (e.g., follower or challenger).

Furthermore, we consciously decided against conducting the World Café solely with "professional" salespeople. From our point of view, the advantages of having a diverse group of participants (with different skills, knowledge, professional backgrounds, level of education, etc.) outweighed the disadvantages of not having solely professional salespeople. In addition, we made sure that in each discussion round, at least one participant had a professional/full-time sales background. We believe that through the built-in iterations, in which participants discussed and evaluated the outcomes of their peers from the previous discussions as well as the open discourse between the participants, professional/full-time salespeople would have intervened at some point if the results had not reflected their opinion. Nevertheless, we cannot rule out that a sample solely consisting of professional salespeople might have generated additional and/or different results.

Additionally, we made every effort to deduce as much actionable intelligence for managers as possible. However, temporal and/or budgetary limitations might make it difficult to implement certain suggestions, especially in cases of small and medium-sized firms.

As this study was the first to look beyond the dyad and investigate selling actor identities instead of customer identities, we aimed to directly compare prior findings on the dyad with our findings. To achieve this goal, we based the salesperson-selling actor relationship/ behavior typology on the classification schema of prior researchers; however, as suggested by Swan et al. (2001), it might not be complete. Therefore, we would like for future research to refine the proposed selling actor identities in detail and to expand upon our typology. More detailed information about the selling actors will help salespeople to identify identities even faster and craft their approaches accordingly.

Furthermore, the possibility cannot be excluded that the customer's self-assessment differs from the salesperson's assessment. Hence, future research is invited to confirm whether both assessments match each other. Finally, the classification was developed based on the subjective judgment of the authors. While member checking indicated the high quality of our classification, future research should also aim for a quantitative confirmation. 
Chapter 3

EXPERIENTIAL VALUE IN MULTIACTOR SERVICE ECOSYSTEMS 
This chapter investigates which elements of the multi-actor service ecosystem contribute to a customer's experiential value and its relation to a customer's citizenship behavior, more specifically, inter-customer helping behavior. To this end, a quantitative study was conducted and scale development (i.e., exploratory, and confirmatory factor analysis) was followed by structural equation modeling.

\section{Publication history:}

An early-stage version of the paper, written together with Prof. Dr. Goetz Greve and Prof. Dr. Jörg Henseler, was submitted to and accepted for poster presentation at the $48^{\text {th }}$ European Marketing Academy Annual Conference:

Weretecki, Patrick, Greve, Goetz and Jörg Henseler. 2019. “Conceptualization and development of a multi-item experiential value measurement scale for experiential marketing." Proceedings of the 48th European Marketing Academy Conference, Hamburg, 28 May - 31 May 2019.

An advanced version of that paper was submitted to and accepted for presentation at the 2020 AMA Winter Academic Conference:

Weretecki, Patrick, Greve, Goetz and Jörg Henseler. 2020. "Experiential value of experiential marketing: Multi-item scale development and validation." Proceedings of the AMA Winter Academic Conference, San Diego, 14 February - 16 February 2020.

The final version of that paper was submitted to and accepted for publication by Frontiers in Psychology.

Weretecki, Patrick; Greve, Goetz; Henseler, Jörg. 2021. "Experiential value in multiactor service ecosystems: Scale development and its relation to inter-customer helping behavior." Frontiers in Psychology, 11, 3819, doi:10.1108/JBIM-03-20200145 .

The following chapter is largely based on the paper accepted by Frontiers in Psychology. 


\section{ABSTRACT}

Interactions in service ecosystems, as opposed to the service dyad, have received much attention from research. However, it is still unclear how they influence a customer's experiential value and trigger desired prosocial behavior. The purpose of this study is to identify which elements of the multi-actor service ecosystem contribute to a customer's experiential value and investigate its relation to a customer's interaction attitude and intercustomer helping behavior. The authors adopted a scale-development procedure from the existing literature. Service, brand, retail, and tourism management research as well as expert feedback was used to generate a pool of 33 items. Exploratory and confirmatory factor analyses were conducted. The scale was validated based on more than 468 responses to a Computer-Assisted Self-Interviewing at one of the world's largest trade shows. The scale-development procedure was followed by structural equation modeling. Confirmatory factor analysis supports that experiential value in multi-actor ecosystems comprises five dimensions: The functional value of personnel (professionalism), the perception of other customers' appearance (similarity), the perception of other customers' behavior (suitable behavior), multisensory stimuli (sensory appeal), and a customer's enjoyment (playfulness). Experiential value positively and directly relates to a customer's interaction attitude and inter-customer helping behavior. Furthermore, the effect of experiential value on intercustomer helping behavior is partially mediated by interaction attitude. Managers interested in getting more out of interactions with customers will develop an understanding of the interplay between the physical environment and individuals within a multi-actor ecosystem. Social scientists and managers can use the scale to assess experiential value, encourage a customer's interaction attitude and utilize the customers' influence on their peers. This paper synthesizes insights from existing research on experiential value-from various fields-into one scale. This holistic approach is the first to simultaneously account for a customer's interactions with the multisensory physical environment, personal interactions with employees, and interactions between customers in a multi-actor service ecosystem.

Keywords: Multi-actor ecosystem, Experiential Value, Inter-customer helping behavior, Citizenship behavior, Co-creation 


\subsection{INTRODUCTION}

Prosocial behavior, like inter-customer helping behavior, can be observed in dyadic constellations and multi-actor ecosystems, as well as in other contexts and environments (e.g., business environment). For example, customers are increasingly interacting within service ecosystems, "serving as pseudo-marketers, actively, and voluntarily contributing to marketing functions, such as customer acquisition, expansion and retention; product innovation; and marketing communication" (Harmeling et al., 2018, p. 307), often in more efficient and effective ways than professionals (Harmeling et al., 2018). Managers face the challenge of influencing customers in a way that they both want and such that they can contribute to the firm and engage in value co-creation behavior, as this is critical in facilitating customer engagement (Harmeling et al., 2018). The concept of customer engagement is directly connected to the evolving role of customers and the idea that they can contribute value in more ways than just financially (Harmeling et al., 2017). To date, research on customer engagement has mostly focused on a customer's interactions with "specific focal objects" (Alexander et al., 2018, p. 334) such as the product, the company, or the frontline employees while overlooking the importance of customer-to-customer (C2C) interactions (Alexander et al., 2018). In particular, the growing importance of prosocial behaviors, like inter-customer helping behavior as a form of interaction within a service ecosystem, has become a promising research avenue (e.g., Kim, 2017; Yi \& Kim, 2017). Recent research emphasizes the importance of broadening the scope of engagement research toward a holistic approach toward engagement in multi-actor service ecosystems (e.g., Fehrer et al., 2018; Harmeling et al., 2017; Ho et al., 2020; Li et al., 2017; McColl-Kennedy et al., 2020; Mustak \& Plé, 2020).

Dunfield (2014) finds that research is increasingly acknowledging "that understanding prosocial behavior will require a multidimensional approach that considers the variety of [influences] that may lead to different prosocial responses" (p. 2). One important step toward this goal is to learn more about the experiences in multi-actor service ecosystems and understand what constitutes the experiential value in these systems. Experiential events that bring different actors together in one physical space are an ideal example of a multiactor service ecosystem. Companies have realized that experiential events (can) provide "engaging, pleasurable, memorable and meaningful experiences to customers" (Varshneya et al., 2017, p. 340) and (can) have a positive influence on customer's experiential value. Welldesigned experiential events generate shifts in the customer's value co-creation attitude (McAlexander \& Schouten, 1998), which consequently leads to more customer engagement (Schouten et al., 2007). Experiential events are often "socially interactive experiences" (Howard \& Gengler, 2001, p. 189), meaning that multiple actors (e.g., employees and customers) share the same physical environment at the same time and influence each other. This is particularly important because a customer's reaction to an experience can contribute to the overall experience of other customers (Grove \& Fisk, 1997). Therefore, it is necessary to adopt a broader perspective that goes beyond dyadic interactions, and toward 
interactions among groups of actors in multi-actor service ecosystems (Li et al., 2017; Vargo \& Lusch, 2017). Experiential events must be designed in a way that they motivate customers to engage in interaction with fellow customers, employees, and the physical environment, but they also have to induce prosocial behavior and empower customers to share knowledge and engage in effective and productive dialog (Harmeling et al., 2018). However, thus far, researchers and practitioners do not know which elements of multi-actor service ecosystems (e.g., fellow customers) encourage prosocial behavior such as intercustomer helping behavior. As the voluntary contributions that customers make can have not only value-creating but also value-destroying outcomes (e.g., Echeverri \& Skålén, 2011), it is imperative to close this knowledge gap.

Thus, the purpose of this study is to identify which elements of the multi-actor service ecosystem contribute to a customer's experiential value and to investigate whether and how it relates to inter-customer helping behavior. Furthermore, our research examines the relevance of a customer's interaction attitude to the relationship between experiential value and inter-customer helping behavior. This was achieved through a scale-development procedure followed by structural equation modeling.

Our research contributes to the existing literature on quantitative psychology and measurement - as well as to literature on customer engagement marketing - in three ways. First, our study identifies the underlying experiential value dimensions of multi-actor service ecosystems. Therefore, we provide managers and social scientists with a tool to better understand, design, and evaluate multi-actor service ecosystems. This knowledge can also be used to understand the relationship between customers and utilize customers' influence on their peers. Second, we included existing experiential value scales from adjacent fields into our scale-development procedure. In this way, we are not only simply developing a new scale, but we are also contributing by highlighting how existing scales could be improved. Third, our holistic approach is the first to simultaneously account for a customer's interactions with the multisensory physical environment, their personal interactions with employees, and interactions between customers. This will be useful to managers and social scientists in understanding the interplay between the physical environment and individuals within a multi-actor ecosystem.

The remainder of this chapter is structured as follows: First, the theoretical background is outlined, along with the presentation of relevant constructs (i.e., value, attitude, and behavior) and their relation to one another. Moreover, this second section displays how the research hypotheses are derived from knowledge gaps in the existing literature. The third section is focused on the methods used in this study and elaborates on the measures, sample, and data collection as well as the data analysis method. The fourth section summarizes the results of the data analysis. The section "Discussion" discusses the paper's implications for researchers and practitioners before the section "Limitations and Future Research" summarizes the study's limitations and further research implications. 


\subsection{THEORETICAL BACKGROUND AND HYPOTHESES DEVELOPMENT}

\subsubsection{Relationship among value, attitude, and behavior}

Recent engagement research states that behaviors are generally driven by customer' attitudes toward a company (e.g., Bergel et al., 2019; Petersen et al., 2018). How the constructs of behavior and attitudes are related to the elements of multi-actor service ecosystems remains unclear. One possible approach to understanding the interplay in multiactor service ecosystems is through the value-attitude-behavior (VAB) model. Researchers have reported findings of the mediating role of attitudes between values and behaviors in their work (e.g., Jayawardhena, 2004; Kautish \& Sharma, 2019; Razali et al., 2021; Shamim et al., 2017; Shim \& Eastlick, 1998). According to this framework, values have a direct as well as an indirect influence on behavior (Homer \& Kahle, 1988). However, it has been argued that "the main feature of the model is its emphasis on the mediating role of attitudes [between] values and behaviors" (Milfont et al., 2010, p. 2792).

Homer and Kahle (1988) distinguished between internal, external, and interpersonal values. Internal values are internally validated; hence, the presence and feedback of other actors are not necessary (Kropp et al., 2005). For external values, it is exactly the other way around (Homer \& Kahle, 1988). Interpersonal values, such as fun or enjoyment, involve "an interactive motivation to fulfill [the values] with others" (Gurel-Atay et al., 2010, p. 65). Attitudes are distinct from values and best described as a "predisposition to respond in a consistently favorable or unfavorable manner with respect to a given object" (Fishbein et al., 1975, p. 6, italics in original). Within the VAB model, behaviors represent the outcome of prior influences. Researchers have validated the principles of the VAB model for a variety of different $V A B$ combinations in different industries and contexts. For example, Cai and Shannon (2012) researched the influence of personal values on mall shopping attitudes and behavior; Hansen (2008) investigated the influence of consumers' personal values on their attitude and behavior regarding online grocery shopping; Kang et al. (2015) examined the influence of individual health values on individuals' attitude and behavior regarding purchasing healthy food items; and Shamim et al. (2017) provided initial evidence that the experiential value of the physical environment influences the value co-creation attitude, which subsequently influences value co-creation behavior.

\subsubsection{Value in multi-actor service ecosystems}

Multi-actor service ecosystems are characterized primarily by interactions among groups of actors as opposed to dyadic interactions. Multiple actors (e.g., employees and customers) experience the same physical environment at the same time. Simultaneously, these actors themselves consciously or unconsciously shape and influence the experience of other actors. Values derived from experiences via "interactions involving either the direct usage or [indirect observation] of goods and services" (Mathwick et al., 2001, p. 41) can be captured through experiential value. Therefore, we have focused our attention on the experiential value of multi-actor service ecosystems. Consequently, this value must account 
for both external values (i.e., interaction with employees, other customers, and the physical environment) and interpersonal values (e.g., fun, enjoyment, and entertainment).

The concept of experiential value, as well as the definition provided by Mathwick et al. (2001), is theoretically largely based on the work of Holbrook (1999), who defined value as an "interactive relativistic preference experience" (Holbrook, 1999, p. 5, italics in original), characterizing a subject's experience of interacting with a product or a service. Mathwick et al. (2001) proposed a four-dimensional scale comprising aesthetics, playfulness, service excellence, and customer return on investment, which was tested and validated in a catalog and internet shopping context. However, while this experiential value scale is probably the most widely used, we argue that due to its context-specificity, it is not sufficient to capture experiential value in multi-actor service ecosystems. We propose the following revisions and extensions:

Aesthetics, due to the context of their study, are limited to visual appeal and entertainment-related factors (Mathwick et al., 2001). There is evidence that visual, acoustic, haptic, and olfactory elements are significantly relevant in terms of the overall experience and therefore should be addressed within a marketing concept (Wiedmann et al., 2018). Therefore, we believe that the multisensory environment should be evaluated holistically, especially in multi-actor service ecosystems.

Service excellence currently reflects customers' general assessment of the performance displayed by the service provider (Mathwick et al., 2001). We believe that in multi-actor service ecosystems, the functional value of the contact personnel is highly relevant to the overall experience. Therefore, the professionalism of contact personnel, as proposed by Sánchez et al. (2006), should also be considered.

Playfulness currently reflects entertainment value and escapism. Entertainment value is reflected in the "intrinsic enjoyment" (Mathwick et al., 2001, p. 44) resulting from interacting with(in) the ecosystem, while escapism reflects the extent to which customers can temporarily forget their surroundings (and escape) (Mathwick et al., 2001). We believe that these constructs are also relevant to experiential value in multi-actor service ecosystems.

Due to its context, the scale provided by Mathwick et al. (2001) does not account for the impact of other customers on experiential value. Brocato et al. (2012) found evidence that other customers influence service experience in a retail setting and identified its relevant dimensions. These other customer perception (OCP) dimensions are "similarity" to other customers and the "physical appearance" and "suitable behavior" of other customers. We propose that the OCP dimensions should also be considered in a multi-actor service ecosystem.

\subsubsection{Interaction attitude in multi-actor service ecosystems}

Interaction-more specifically direct interaction-in multi-actor service ecosystems, takes place among multiple actors, including employees and customers, in a shared physical environment (Grönroos, 2011; Vargo \& Lusch, 2016). Dependent on its design, 
a servicescape has the ability to "encourage social interaction among and between [customers] and employees" (Bitner, 1992, p. 61). Interactions with customers help companies learn about customers' preferences (Srinivasan et al., 2002), which can be used to achieve more profitable customer relationships (Ramani \& Kumar, 2008). Based on the definition of Shamim et al. (2017) of interaction attitude in dyadic constellations, we define interaction attitude in multi-actor service ecosystems as the customer's willingness, caused by experiential factors, to respond favorably to interaction opportunities with employees, other customers, and the physical environment.

Research shows that experiential value influences various customer attitudes. Keng and Ting (2009) found that experiential value positively influences a customer's attitude toward engaging in blogs. Maghnati et al. (2012) provided evidence for the positive effect of experiential value on usage attitudes toward mobile apps. Furthermore, Shamim et al. (2017) found a positive direct effect of experiential value on a customer's value co-creation attitude. Drawing on these findings, we hypothesize the following:

$\mathrm{H}_{1}$ : Experiential value in multi-actor service ecosystems positively influences a customer's interaction attitude.

\subsubsection{Inter-customer helping behavior in multi-actor service ecosystems}

Inter-customer helping is a prosocial behavior in the form of $\mathrm{C} 2 \mathrm{C}$ interaction; for example, customers (trying) to assist fellow customers who are displaying a need for help in a service encounter (Yi \& Gong, 2013). The willingness to help fellow customers is a type of customer citizenship behavior (CCB), which is "voluntary and [...] not required for the successful production and/or delivery of the service" (Groth, 2005, p. 11) but adds additional value to the value co-creation process. Companies can benefit from utilizing inter-customer helping behavior in several ways. For example, $\mathrm{C} 2 \mathrm{C}$ helping has been shown to have a positive influence on customers' intention to stay loyal to a company (Gruen et al., 2007). Inter-customer helping behavior entails a cost-saving potential-for example, through successful prevention of service failures-despite reduced employee presence ( $\mathrm{Yi}$ \& Kim, 2017). Evidently, inter-customer helping behavior is favorable, but there is a lack of knowledge in the literature about how companies can encourage this behavior.

There is some evidence that attitude can function as a major predictor of behavior. For example, Shim and Eastlick (1998) found that the attitude toward shopping malls was a direct predictor of mall shopping behavior. Hansen (2008) concluded "that attitude towards online grocery shopping was the most important predictor of actual buying intentions" ( $p$. 135). Furthermore, attitudes formed through direct (firsthand) experiences predict future behavior better than other attitudes (Fazio \& Zanna, 1981). We consider experience in multi-actor service ecosystems to be a suitable example of a direct experience. Therefore, this study hypothesizes the following: 
$\mathrm{H}_{2}$ : Interaction attitude in multi-actor service ecosystems positively influences inter-customer helping behavior.

Furthermore, we suspect that an experience itself influences inter-customer helping behavior. While numerous studies link values to behavior, it has also become apparent that depending on the value, some relate more strongly to behavior than others (Bardi \& Schwartz, 2003). Specifically, the authors' research indicates "that stimulation and tradition values relate strongly to the behaviors that express them; hedonism, power, universalism, and self-direction values relate moderately; and security conformity, achievement, and benevolence values relate only marginally" (Bardi \& Schwartz, 2003, p. 1207). Experiential value and inter-customer helping behavior in multi-actor service ecosystems share properties with hedonism, as they are related to "[p]leasure and sensuous gratification for oneself" (Bardi \& Schwartz, 2003, p. 1208) but also with power and benevolence. With respect to the relationship between experiential value and inter-customer helping behavior, this study hypothesizes the following:

$\mathrm{H}_{3}$ : Experiential value in multi-actor service ecosystems positively influences intercustomer helping behavior.

If all three proposed hypotheses can be validated, we expect that (in line with the VAB model) interaction attitude mediates the relationship between experiential value and intercustomer helping behavior. The three hypotheses are depicted in Figure 3.1.

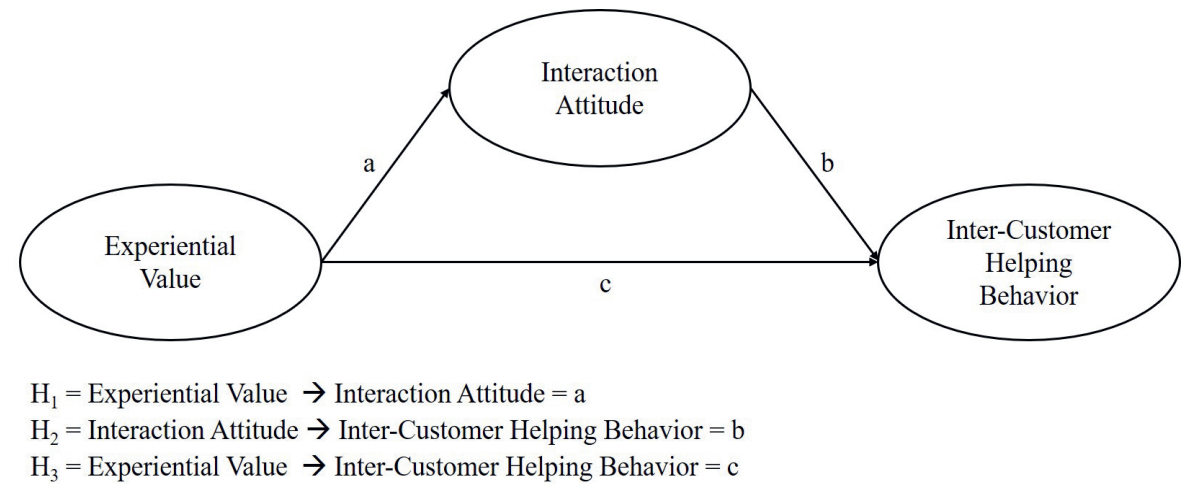

Figure 3.1: Conceptual model

\subsection{METHODOLOGY AND SAMPLE}

\subsubsection{Measures}

Given the described lack of a scale to measure the experiential value in multi-actor service ecosystems, we decided that scale development and investigating the correlation 
must precede testing for causation and running experiments. Experiential value in multiactor service ecosystems can neither be observed directly nor are there existing scales to assess it. Therefore, scale development is appropriate (DeVellis, 2016). We follow Carpenter's (2018) scale-development procedure, a combination of "scale development best practices that yield stronger concepts" (p. 25). Fifty-seven items for measuring experiential value in the multi-actor service environment were gathered from previous studies in the fields of service marketing, brand management, retail, and tourism management (Brocato et al., 2012; Mathwick et al., 2001; Sánchez et al., 2006; Wiedmann et al., 2018). Constructs of experiential value included sensory appeal (visual, acoustic, haptic, and olfactory), playfulness, service excellence, customer return on investment, functional value of personnel, and OCP. Selection and identification of relevant items and dimensions were supported by expert interviews and prior qualitative research. The wording of the items was adapted to fit the context of this research. As recommended by DeVellis (2016), we asked a panel consisting of six experiential event experts (three senior marketing executives and three project managers) of one of the largest German companies (by revenue) and two marketing professors, to evaluate the items regarding their relevance and clarity of wording, resulting in an item pool of 33 items.

We developed measures for interaction attitude toward the physical environment, employees, and other customers from the customer value co-creation attitude scale proposed by Shamim et al. (2017).

Inter-customer helping behavior measurements were extracted from the customer value co-creation behavior scale developed by Yi and Gong (2013). In their study, the authors demonstrated the impact of other customers on customers' behavior in social contexts. Therefore, it is applicable to multi-actor service ecosystems.

We measured the scale with the help of a standardized questionnaire using seven-point Likert scales ( 1 = strongly agree, 7 = strongly disagree). Table A.3.1 in the Appendix provides an overview of the constructs, (sub)dimensions, and measurements of experiential value, interaction attitude, and inter-customer helping behavior in multi-actor service ecosystems.

\subsubsection{Sample and data collection}

The customer survey was conducted at IFA 2018, the world's leading experiential event for consumer electronics and home appliances. Visitors to the experiential event were intercepted and screened for appropriateness after their visit, near the exits of a 5,000 square-meter experience area. The qualifying criteria for the participants required the display of interest in the experiential offerings (exclusion of customers only passing through). Computer-Assisted Self-Interviewing was used, and data were collected from August 31 to September 5, 2018. A total of 468 valid completed questionnaires were obtained from 632 qualified respondents, representing a valid response rate of more than $74 \%$. The decision to discard some of the filled questionnaires was based on obvious outliers and incomplete answers. Among the 468 respondents, most of the respondents were male (66.8\%), in their 
twenties (34.3\%), employed (71.5\%), and had either a high school degree $(41 \%)$ or a degree from a university (41.9\%). Table 3.1 provides a detailed overview of the sample.

Table 3.1: Demographic profile of the sample

\begin{tabular}{llll}
\hline Variable & Characteristics & Cases & \% \\
\hline Age & $16-19$ years & 71 & 15.2 \\
& $20-29$ years & 160 & 34.3 \\
& $30-39$ years & 71 & 15.2 \\
& $40-49$ years & 60 & 12.7 \\
& $50-59$ years & 64 & 13.6 \\
& $60-65$ years & 24 & 5.1 \\
\hline Gender & 66 years and older & 18 & 3.9 \\
\hline Education & Female & 155 & 33.2 \\
& Male & 313 & 66.8 \\
\hline Occupation & High School & 192 & 41.0 \\
& University & 196 & 41.9 \\
\hline Occupation (if unemployed) & Without higher education & 80 & 17.1 \\
\hline & Full time/part time & 335 & 71.5 \\
& Unemployed & 133 & 28.5 \\
\hline & Student & 138 & 29.5 \\
& Pensioner & 162 & 34.5 \\
& Housewife/husband & 121 & 25.9 \\
& Other & 30 & 3.6 \\
& & 6.5 \\
\hline
\end{tabular}

Note: $\mathrm{N}=468$

\subsection{DATA ANALYSIS}

To achieve the purpose of this study and test the hypotheses, SPSS and AMOS statistics package programs were used. Exploratory factor analysis (EFA) using SPSS 25.0 was performed to discover the number of factors of the experiential value scale for experiential events. Using AMOS 25.0, CFA was conducted to examine the validity of the scale, while structural equation modeling was used to test the hypotheses. Convergent validity was assessed based on the average value extracted (AVE), with a recommended cut-off of 0.5 (Hair et al., 2018). Discriminant validity was evaluated by checking whether the AVE of each construct was greater than the inter-construct correlations (Hair et al., 2018). Composite reliability $(C R)$ was used to evaluate internal consistency, with a threshold of 0.7 for the $C R$ values (Hair et al., 2018). The reliability for each construct was assessed based on Cronbach's $\alpha$. 


\subsection{FINDINGS}

\subsubsection{Dimensions of experiential value in multi-actor service ecosystems}

Prior to investigating the relationship between experiential value and a customer's interaction attitude, the dimensions of experiential value in multi-actor service ecosystems (EX-MAS) had to be identified. The sample was checked for adequacy. The results show a value of Kaiser Meyer Olkin $=0.955$, which is considered excellent for factor analysis, and measure of sampling adequacy values for all items above 0.70 , indicating a high degree of inter-correlation among items (Kaiser \& Rice, 1974). Bartlett's test of sphericity indicates a chi-square value of $14,891.187$ with 1,035 degrees of freedom and $p=.000<.05$, confirming that the correlation matrix is not an identity matrix.

To identify the underlying factor structure and reduce the number of items to the optimum, a series of principal axis factoring with oblique rotation (oblimin) was iteratively performed. In an oblique rotation, the supposition is that there is a correlation among at least two of the factors being rotated (Pett et al., 2003). Prior research has provided evidence that the constructs under consideration are in fact correlated (e.g., Brocato et al., 2012; Shamim et al., 2017). We conducted common factor analysis instead of principal component analysis because the results are considered "more generalizable when submitting hypothesized models to a confirmatory factor analysis" (Carpenter, 2018, p. 36).

The optimal number of factors should be identified based on a combination of theory and different tools (Carpenter, 2018). Hence, we used multiple methods and validated them with prior research on similar topics. In our case, the five-factor structure was deemed the best because it explains a considerable amount (60.03\%) of the total variance. The eigenvalue greater than one rule was followed and the scree-test (visual plot of eigenvalues) and prior research clearly supported that structure. The results of the principal axis factoring after the purification process (deletion of five items) are shown in Table 3.2.

An examination of the items comprising each factor led to naming them as follows: professionalism, similarity, suitable behavior, sensory appeal, and playfulness.

Subsequently, CFA was performed on the items identified in the EFA to analyze its model fit, reliability, and validity (Anderson \& Gerbing, 1988). The five-factor structure was confirmed. However, a closer investigation of the model indicated that both sensory appeal and playfulness have underlying sub-constructs and are therefore best designed as second-order constructs (Khadraoui \& Gharbi, 2012). The model fit indices comparative fit index (CFI), Tucker-Lewis index (TLI), normed fit index (NFI), and root mean square error of approximation (RMSEA) represented a good fit with CFI (0.955), TLI (0.949), NFI (0.921), CMIN/DF (2.232), RMSEA (0.052), and PCLOSE (0.275). All items loaded significantly on their respective factors, and the AVE for all five factors was acceptable (>0.50), indicating convergent validity (Hair et al., 2018). The composite reliabilities for all five factors exceeded the recommended level of 0.70 and were therefore acceptable (i.e., professionalism $=0.880$; similarity $=0.871$; playfulness $=0.943$; suitable behavior $=0.894$; sensory appeal $=0.930$ ) . As shown in Table 3.3, the proposed model achieved discriminant validity, as the square 


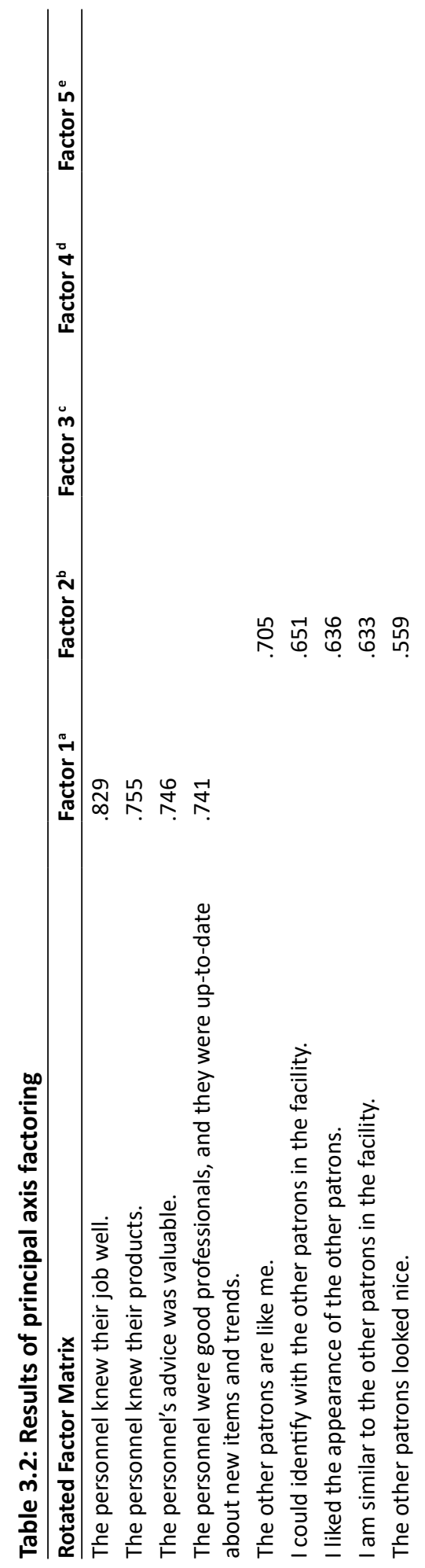

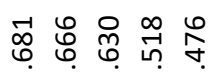

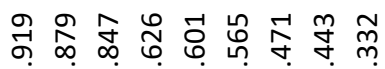
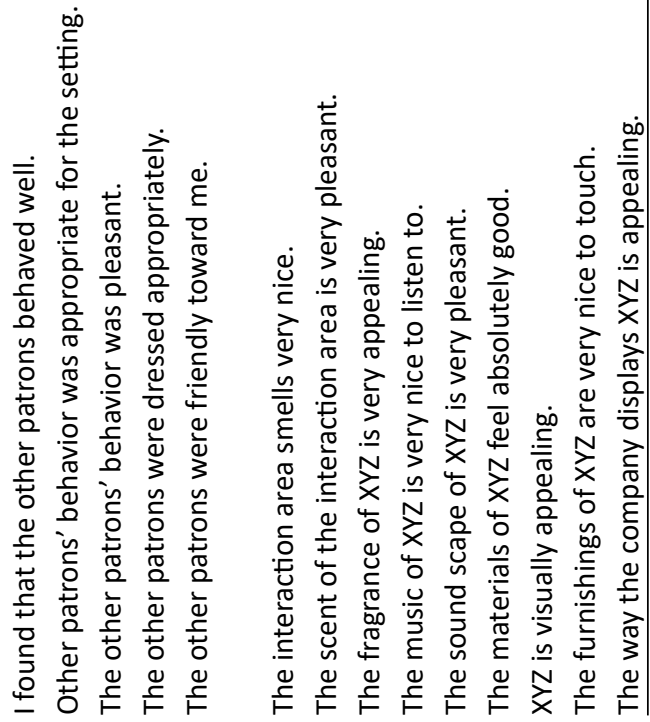


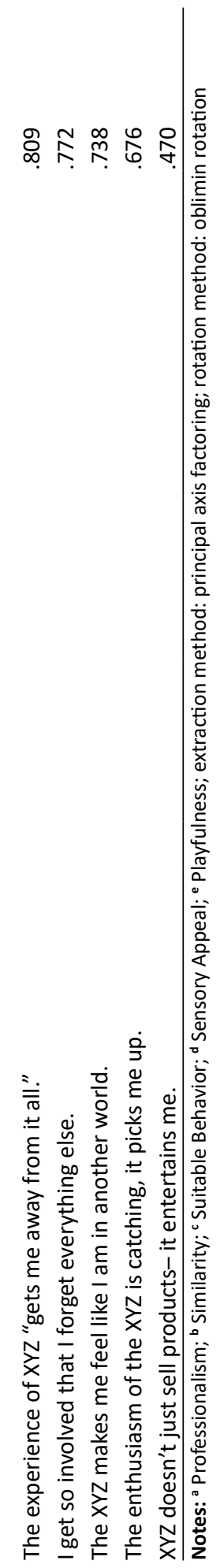


root of the AVE for all three factors-depicted on the diagonal-was greater than the interconstruct correlations (Hair et al., 2018). Thus, the scale was deemed reliable and valid.

The first construct, professionalism, relates to perceived knowledge, valuableness of information and competence of employees within the service ecosystem. The factor loadings of the items ranged from 0.78 to 0.83 , with a Cronbach's $\alpha$ of 0.88 . The second construct, similarity, reflects the degree to which customers feel similar and can relate to other customers in the service ecosystem. The factor loadings of the items ranged from 0.72 to 0.84 , with a Cronbach's $\alpha$ of 0.88 . Construct 3, suitable behavior, may be interpreted as the extent to which a customer considered other customers' behavior to be appropriate, within the context of the multi-actor service ecosystem. The factor loadings of the items ranged from 0.74 to 0.83 , with a Cronbach's $\alpha$ of 0.89 . The fourth construct, sensory appeal, relates to the influence of the multisensory environment on experiential value. Sensory appeal has four sub-constructs (olfactory, acoustic, haptic, and visual). The factor loadings for the sub-constructs ranged from 0.80 to 0.95 , with a Cronbach's $\alpha$ of 0.93 . The last construct, playfulness, represents the influence of experienced entertainment and temporary escape from the daily routine. Factor loadings for the sub-constructs ranged from 0.86 to 1 with a Cronbach's $\alpha$ of 0.88 . A sensitivity analysis was conducted to check for potential threats to the estimates' validity. As suggested by Eggert et al. (2012), we modeled incrementally increasing measurement item error correlations. The analysis revealed that even if the error correlations were one-third of the loadings, our substantial conclusions would remain unaffected. Table 3.4 summarizes the findings of the CFA.

The results indicate that experiential value in multi-actor service ecosystems is in fact highly influenced by other customers and employees. Therefore, their impact cannot be neglected.

\subsubsection{Inter-customer helping attitude}

Additionally, we conducted a CFA of the constructs interaction attitude and intercustomer helping behavior. The latent constructs were correlated, whereas the measurement items and their error items were constrained to be uncorrelated. The CFA achieved good fit (SRMR $=0.076, \mathrm{NFI}=0.96, \mathrm{IFI}=0.97, \mathrm{CFI}=0.97, \mathrm{RMSEA}=0.08, \mathrm{CMIN} / \mathrm{DF}=4.077$ ).

\subsubsection{Structural model}

The structural model was tested. The overall model fit was satisfactory. The model resulted in a chi-square statistic $(X 2=1,448, \mathrm{df}=580)$ and acceptable fit indices as follows: $\mathrm{SRMR}=0.055, \mathrm{NFI}=0.88, \mathrm{IFI}=0.93, \mathrm{CFI}=0.92, \mathrm{RMSEA}=0.05$. The factor loadings of all constructs were significant, with an AVE greater than 0.50 providing evidence for convergent validity. As shown in Table 3.5, the square roots of all three constructs represented in the diagonal are greater than the inter-construct correlations, indicating discriminant validity. 


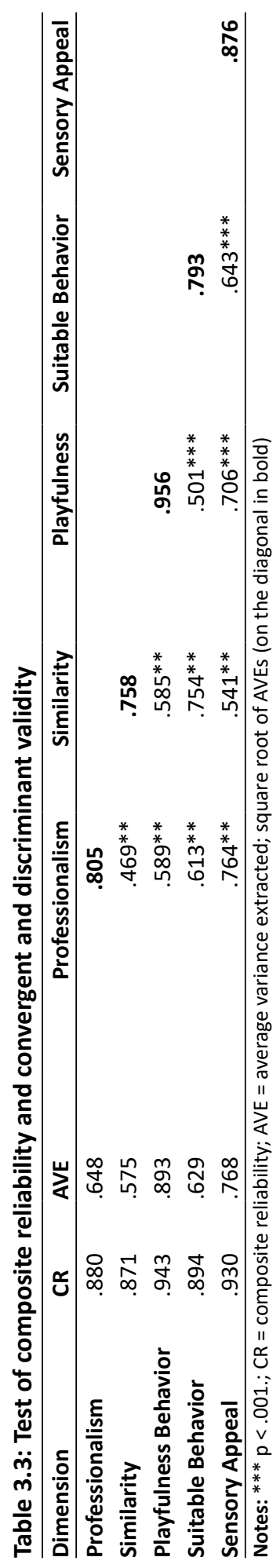




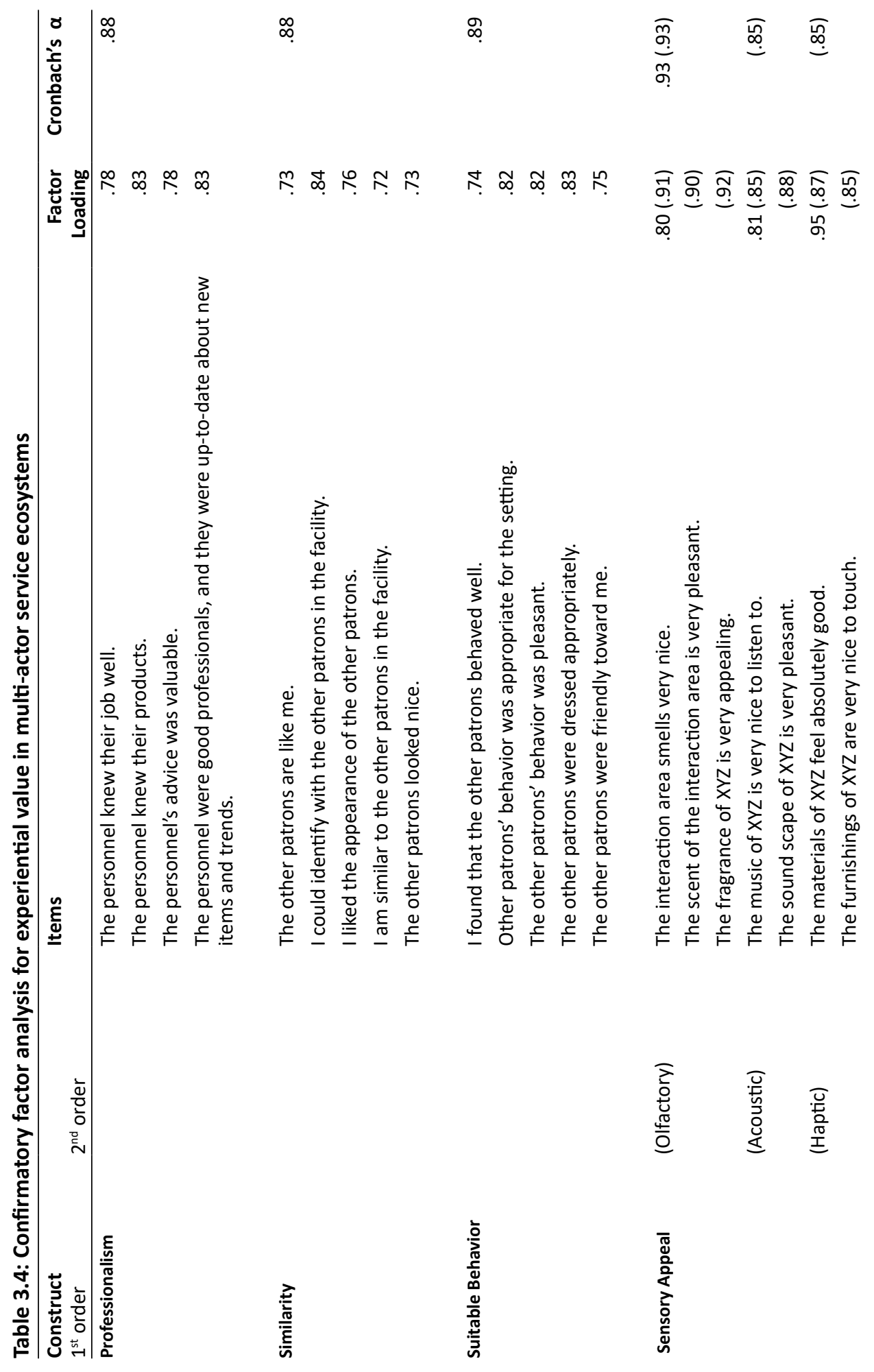




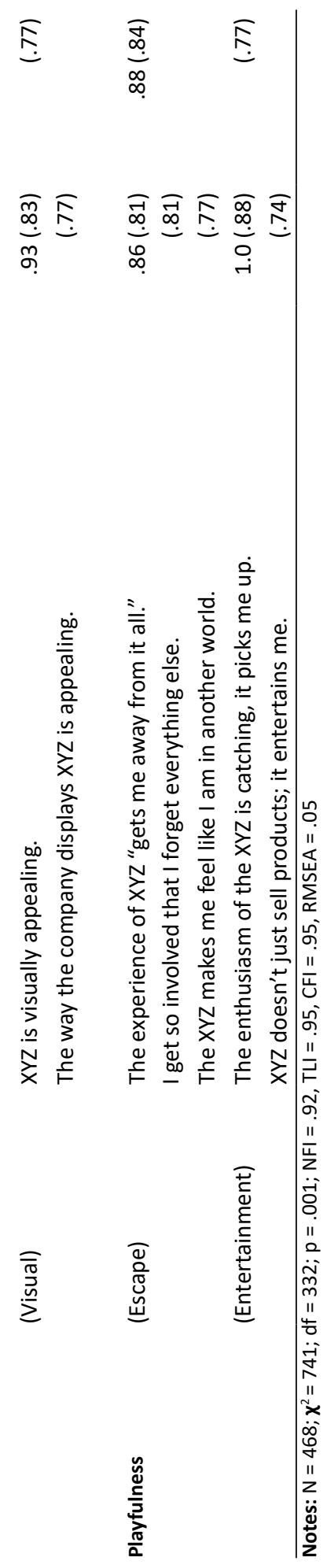


Table 3.5: Validity matrix (complete model)

\begin{tabular}{|c|c|c|c|c|c|}
\hline Dimension & CR & AVE & $\begin{array}{l}\text { Interaction } \\
\text { Attitude }\end{array}$ & $\begin{array}{l}\text { Inter-Customer } \\
\text { Helping Behavior }\end{array}$ & $\begin{array}{l}\text { Experiential } \\
\text { Value }\end{array}$ \\
\hline Interaction Attitude & .801 & .513 & .716 & & \\
\hline Inter-Customer Helping Behavior & .881 & .649 & $.359 * * *$ & .806 & \\
\hline Experiential Value & .891 & .620 & $.655^{* * *}$ & $.419 * * *$ & .787 \\
\hline
\end{tabular}

In comparison to the new model, the Mathwick et al. (2001) model only achieved a chisquare statistic $(X 2=1,175, \mathrm{df}=270)$ and fit indices as follows: $\mathrm{SRMR}=0.074, \mathrm{NFI}=0.82, \mathrm{IFI}$ $=0.86, \mathrm{CFI}=0.86, \mathrm{RMSEA}=0.09$.

After the overall model fit was approved, hypotheses were tested via structural equation modeling. The structural equation model's standardized path coefficients were used to evaluate the hypotheses (see Figure 3.2).

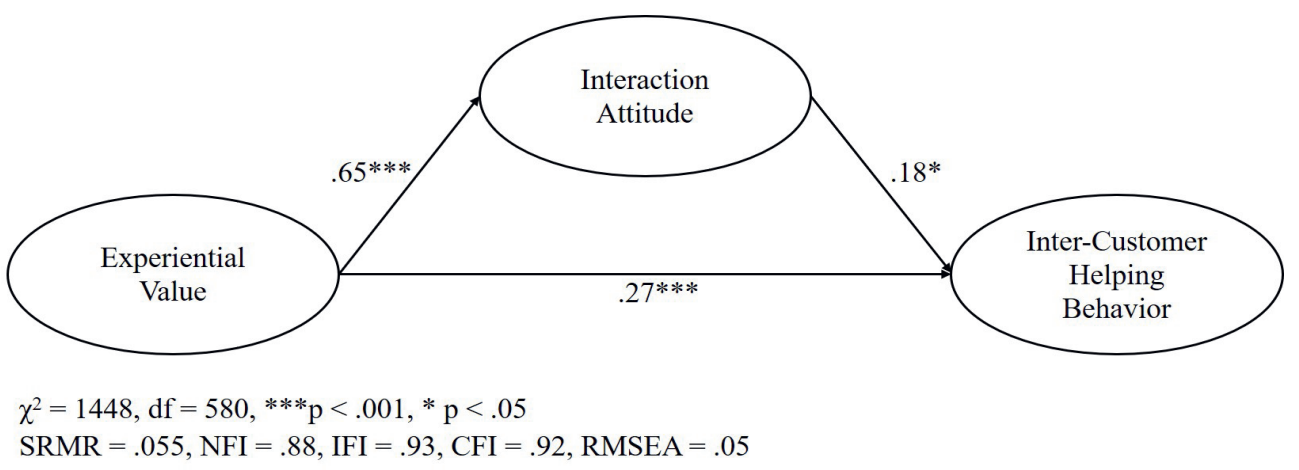

Figure 3.2: Results of the structural equation model

$\mathrm{H}_{1}$ predicts that experiential value in multi-actor service ecosystems positively influences a customer's interaction attitude. As presented in Table 3.6, the hypothesis is strongly supported. The standardized path coefficient between experiential value and interaction attitude is $\beta=0.65, C R=12.08$, and $p<0.001$.

The second hypothesis $\left(\mathrm{H}_{2}\right)$ suggests that interaction attitude in multi-actor service ecosystems positively influences inter-customer helping behavior. For this path, with a standardized path coefficient of $\beta=0.18, C R=2.480$, and $p<0.05$, the hypothesis was also supported.

The third hypothesis $\left(\mathrm{H}_{3}\right)$ suggests that experiential value in multi-actor service ecosystems positively influences inter-customer helping behavior. For this path, with a standardized path coefficient of $\beta=0.27, C R=3.637$, and $p<0.001$, the hypothesis was also supported.

Considering that both $\mathrm{H}_{1}$ and $\mathrm{H}_{2}$ have been supported, point in the same direction, and are significant, we suspect that interaction attitude mediates the relationship between experiential value and inter-customer helping. The indirect effect of experiential value on 


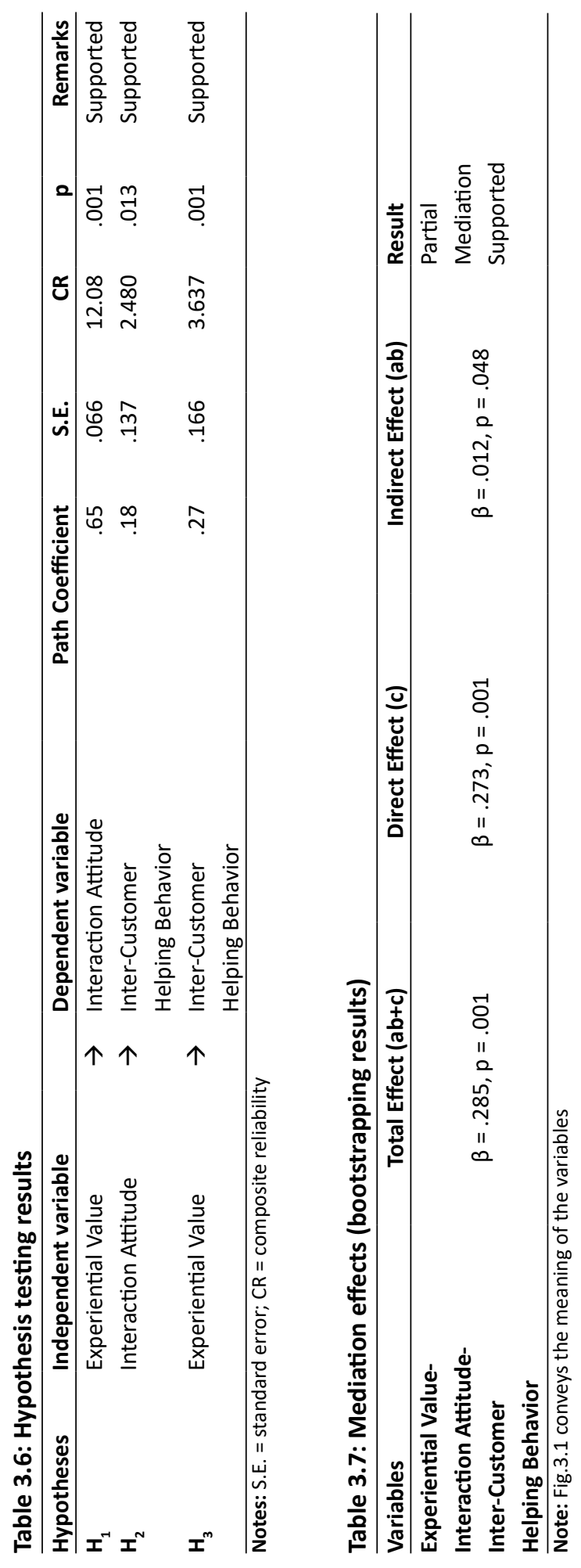


inter-customer helping behavior must be significant to establish the mediation effect. We used the state-of-the-art approach for mediation analysis as suggested by Zhao et al. (2010) and performed a bootstrapping procedure with 2,000 bootstrap samples and used the $90 \%$ bias-corrected confidence level. The results of the analysis revealed a significant indirect effect of experiential value on inter-customer helping behavior via interaction attitude $[\beta$ $=0.012, \mathrm{p}=0.048$, standard deviation $(\mathrm{SD})=3.02,95 \% \mathrm{Cl}(0.05,0.52)]$, supporting partial mediation of interaction attitude. The mediated effect $(a \times b)$ and the direct effect $(c)(\beta=$ $0.273, p=0.001, S D=3.46$ ) point in the same direction, indicating complementary mediation (Zhao et al., 2010). The total effect, direct effect, and the indirect effect are presented in Table 3.7.

\subsection{DISCUSSION}

The aim of this study was to identify which elements of the multi-actor service ecosystem contribute to a customer's experiential value and investigate its relation to a customer's interaction attitude and inter-customer helping behavior. To achieve this objective, we applied a scale-development procedure and explored the underlying experiential value dimensions in a multi-actor ecosystem. Thereafter, a structural model was tested.

This study implied certain cause-and-effect relationships between the independent and dependent variables. However, we are aware that in order to establish causality, we would need three conditions to be fulfilled: Concomitant variation between the supposed independent and the supposed dependent variable, temporal precedence of the independent variable, and exclusion of other plausible alternative explanations. In the proposed model, the standardized path coefficients (of $\mathrm{H}_{1}, \mathrm{H}_{2}$, and $\mathrm{H}_{3}$ ) are equal to the correlation. As evidenced by their magnitude, the first condition (concomitant variation) can be assumed. Simultaneously, this correlation is clear evidence of the external validity of the experiential value scale. The scale is evidence for the-formerly ignored-relevance of interactions between customers for the experiential value. However, if that is the case, it is not implausible to assume a reversed causal effect, that is, that inter-customer helping behavior may also affect experiential value (in the sense that helping others creates value in itself). Hence, temporal precedence is still strongly suspected but cannot be asserted with absolute certainty. As already pointed out, we decided that given the described lack of a scale, scale development and investigating the correlation had to precede testing for causation and running experiments. This choice of research design limits our ability to fully exclude other plausible alternative explanations at this point, as the best method for this would be conducting "a carefully designed experiment" (Moore et al., 2012, p. 330). In summary, our results indicate a high degree of external validity and a valid new scale. The findings of our study support the following conclusions:

First, experiential value in multi-actor ecosystems comprises five dimensions. It is based on the functional value of personnel (professionalism), the perception of other customers' appearance (similarity), the perception of other customers' behavior (suitable 
behavior), multisensory stimuli (sensory appeal), and a customer's enjoyment (playfulness). Our findings highlight the importance of adopting a holistic approach toward experiential value in multi-actor service ecosystems. The personal interaction between customers and employees and interactions among customers in multi-actor service ecosystems account for three out of five relevant experiential value dimensions. Managers may use this finding and invest in proper coaching and training activities for employees with direct customer contact, who might not have the necessary skills and knowledge required nor be aware of their importance. This is particularly important because the appropriate level of social interaction (i.e., interaction intensity, frequency, etc.) largely depends on the type of service and must align with a customer's expectation. Our findings also suggest that perceptions of other customers' appearance and behavior impact a customer's experiential value. Managers need to be aware of and accept the fact that there are drivers of experiential value outside of their direct sphere of influence. One possible way to counteract the risks associated with other customers' appearance and behavior is by attempting to limit the appeal of an offering (e.g., product or service) or an event (e.g., experiential event, promotion, or campaign) to a preferred customer clientele. Clearly, this comes at a cost that managers must consider. For example, advertising and promoting sweepstakes is a common method to increase instore customer frequency. However, this entails the risk that "sweepstakes hunters," who are very different in appearance and behavior from the "usual clientele," might negatively influence the experiential value of other customers present in the ecosystem. Furthermore, our analysis confirmed that multi-actor service ecosystems are in fact multisensory and that the sensory appeal is formed by olfactory, acoustic, haptic, and visual stimuli. This is not an entirely new finding. However, while some companies have achieved substantial competitive advantage via the creation of a multisensory customer experience, the most acknowledged and successful "multisensory store redesigns have been [extremely] expensive" (Spence et al., 2014, p. 483). Managers need to be aware of these facts and consciously weigh increased experiential value-through optimized multisensory appeal-against high investments with uncertain return on investment. Furthermore, our analysis points to the importance of playfulness for the EX-MAS. Designing an experience such that it entertains and functions as a temporary escape from the daily routine might prove challenging for two reasons. First, it might be in conflict with a company's objective to communicate information (e.g., product or service specifications, price). Managers must weigh providing a fun and exciting experience against their own goals with regard to the messages they want to convey. Second, depending on the product or service, customers might expect different levels of playfulness. This is challenging because, in most cases, multiple products or services are displayed simultaneously. Because the possibility to stage products/services in a certain way is limited due to limited budgets or availability of physical space, managers probably have to prioritize some over others. Researchers can greatly benefit from these findings, as the developed scale can be used to measure experiential value more accurately than before, especially in cases of multi-actor ecosystems. 
Second, our analysis supported the hypotheses that experiential value relates to a customer's interaction attitude and inter-customer helping behavior. The direct relation to interaction attitude is relevant for several reasons. For example, managers can use this information to increase the number of interactions between customers and employees. This adds potential for customer acquisition but also the potential to increase revenue from existing customers (e.g., cross-selling, up-selling). Furthermore, companies can utilize a customer's direct feedback for product improvement and new product development. Customers, in contrast, might benefit from interaction with employees through an increase in knowledge about current and future offerings (e.g., products, services, deals), which potentially increases customer satisfaction. Knowledge about the positive influence of experiential value on inter-customer helping behavior is also highly relevant to companies. Managers considering a reduction of service personnel can attempt to utilize customers as "pseudo employees" to compensate for such downsizing. However, professionalism is also a part of experiential value; therefore, managers must identify the optimal ratio of employees in relation to "pseudo employees".

Third, our analysis supports the positive effect of interaction attitude on inter-customer helping behavior and the mediating effect of interaction attitude between experiential value and inter-customer helping behavior. This strengthens the importance of correctly identifying and influencing experiential value because it shows a significant direct and indirect relation to inter-customer helping behavior.

\subsection{LIMITATIONS AND FUTURE RESEARCH}

This study is the first to make an effort to identify experiential value in multi-actor service ecosystems. Unlike previous studies, we simultaneously considered a customer's interaction with the multisensory physical environment-as well as personal interaction with employees and between customers-as sources of experiential value. The 28 items of the proposed scale demonstrate that experiential value is based on the functional value of personnel (professionalism), perception of other customers' appearance (similarity), perception of other customers' behavior (suitable behavior), multisensory stimuli (sensory appeal), and visitors' enjoyment (playfulness). Our study provides empirical validation for some of the findings of other researchers (e.g., Mathwick et al., 2001; Sánchez et al., 2006; Varshneya \& Das, 2017; Wiedmann et al., 2018). While it succeeds in answering the question on which elements of multi-actor service ecosystems contribute to a customer's experiential value and in investigating its relation to a customer's interaction attitude and inter-customer helping behavior, due to our research setting, we had the fortune (or misfortune) of having a "competitor-free environment." However, in multi-actor service ecosystems without full constructional separation (e.g., shop-in-shop), there might be additional influences on a customer's experiential value (e.g., employees of the competition, multisensory stimuli). Researchers and practitioners are invited to validate the EX-MAS scale in those cases where other companies noticeably compete for a customer's attention. 
The goal of this study was to contribute similarly to theory and practice by developing an experiential value scale for multi-actor service ecosystems and investigating the correlations between experiential value, interaction attitude, and inter-customer helping behavior. This study used correlational and (customers') self-reported data. Going forward, we suggest an experimental design examining the hypothesized relationships to support causal conclusions. Additionally, future research can try to observe actual customer behavior and compare it to the self-reported data from this study. It is necessary to validate the scale and investigate its applicability across different countries, cultures, and industries.

Furthermore, our research employed a cross-sectional survey design. Although our study established a substantial correlation between experiential value, interaction attitude, and inter-customer helping behavior, we encourage future research to explore the longitudinal effects. Specifically, it could be interesting to investigate whether inter-customer attitude needs to be reinforced once "generated" and, if so, at which intervals and which intensity. In addition future research should address and control for potential endogeneity.

We identified a complementary mediation in our proposed model. The significant direct effect of experiential value on inter-customer helping behavior "points to the possible existence of some omitted second mediator" (Zhao et al., 2010, p. 201). Future research is invited to continue with the investigation of additional mediators. For example, it may prove insightful to take a closer look at individuals' perceived responsibility. There is some evidence that perceived responsibility mediates the relationship between an experience in the presence of others (multi-actor service ecosystem) and inter-customer helping behavior (e.g., Yi \& Kim, 2017).

This study focused on experiential value and on evaluating its impact on a customer's interaction attitude and inter-customer helping behavior. Future research may continue with the investigation and contribute to the literature by studying whether experiential value can also be used to foster other prosocial behaviors, dimensions of the CCB (e.g., feedback, advocacy, tolerance) or customer participation behavior and how that can be done both effectively and efficiently. 


\section{Chapter 4}

INFORMATION MANAGEMENT CAN'T BE ALL FUN AND GAMES, CAN IT? HOW GAMIFIED EXPERIENCES FOSTER INFORMATION EXCHANGE IN MULTI-ACTOR SERVICE ECOSYSTEMS 
Information exchange behavior-that is, information-seeking and information-sharing behavior, or rather, the targeted search for information, and the provision of information to others-is a vital part of customer participation behavior. This chapter investigates whether and how gamified experiences in a multi-actor service ecosystem can be used to encourage customers' information exchange behavior. To this end, a quantitative research approach (structural equation modeling) was used.

\section{Publication history:}

A version of the paper, written together with Prof. Dr. Goetz Greve, Prof. Dr. Kenneth Bates, and Prof. Dr. Jörg Henseler, was submitted to and accepted for publication in the International Journal of Information Management (IJIM).

Weretecki, Patrick; Greve, Goetz; Bates, Kenneth, Henseler, Jörg. 2021. “Information management can't be all fun and games, can it? How gamified experiences foster information exchange in multi-actor service ecosystems." International Journal of Information Management, doi:10.1016/j.ijinfomgt.2021.102391.

The following chapter is largely based on the paper published in the IJIM. 


\section{ABSTRACT}

This chapter investigates whether gamified experiences in a multi-actor service ecosystem can be used to encourage customers' information exchange behavior. Furthermore, it examines the impact of customers' knowledge sharing attitude on the relationship between experiential value and customers' information exchange behavior. Structural equation modeling was used to assess these dynamic relationships and provide a scalable measurement instrument that can be applied to gamified experiences ranging from simple customer-interface interactions, all the way up to multi-actor service ecosystems. Our findings support the notion that managers can use gamification to foster information exchange and thereby value co-creation between customers and employees directly, without necessarily having to change customers' attitudes first. The findings also suggest that gamification can be applied successfully in cases of large groups of people with widely varying characteristics, backgrounds, and motivations. Additionally, our research indicates that experiential value is a suitable candidate for a consistent measurement instrument for gamification. This study is the first to apply a holistic experiential value approach to a gamified experience that simultaneously accounts for customers' interactions with a multisensory physical environment, their personal interactions with employees, and their interactions with other customers.

Keywords: Gamification, Experiential value, Multi-actor service ecosystem, Knowledge sharing attitude, Information exchange behavior 


\subsection{INTRODUCTION}

While modern customers are becoming increasingly knowledgeable (e.g., Bagheri et al., 2019; Prahalad \& Ramaswamy, 2004; Verhoef et al., 2015), companies increasingly face the challenge of acquiring customer-related knowledge, as it is considered to be crucial for the provision of products and services that meet customer demands (Bagheri et al., 2019). Customers' willingness and ability to engage in information seeking and information sharing is considered necessary for any value creation to occur (e.g., Delpechitre et al., 2018; Groth, 2005; Revilla-Camacho et al., 2015; Yi \& Gong, 2013). Therefore, information management must now move beyond merely managing activities around collecting and storing information to concentrate more on facilitating customer exchange behaviors. Among the many methods used to influence customers' behavior, gamified experiences have proven to be very successful in achieving high levels of engagement (e.g., Hamari \& Koivisto, 2014; Harwood \& Garry, 2015; Kuo \& Chuang, 2016), and gamification increasingly draws the attention of both academics and practitioners due to its power to generate experiential value for customers (e.g., Eppmann et al., 2018; Hammedi et al., 2017; Leclercq et al., 2020).

The concept of gamification has been explored previously in areas such as marketing (e.g., Berger et al., 2018; Hofacker et al., 2016; Müller-Stewens et al., 2017) and retailing (Poncin et al., 2017), and there is evidence that gameful experiences can influence customer behavior (Rodrigues et al., 2016) or foster behavioral engagement (Jang et al., 2018). However, there is also evidence that gamification does not always works as intended (e.g., Leclercq et al., 2020; Wolf et al., 2020). In fact, some researchers even caution against the use of gamification, highlighting potential challenges (e.g., inability to participate due to absence of skills) and drawbacks (e.g., over-participation) (Hammedi et al., 2017) or even customer disengagement (Leclercq et al., 2018). Considering that gamified experiences may be applied in a number of different ways, we believe an investigation into successful parings between experiential and behavioral outcomes is necessary (Liu et al., 2017).

In the current research we operationalize gamification as a process of supporting a customer's "overall value creation" (Huotari \& Hamari, 2017, p. 25) through gameful experiences that can occur either individually or within a "socially interactive" (Howard \& Gengler, 2001, p. 189) setting where multiple employees and customers share the same physical environment. This is particularly important because any individual customer's reaction to an experience can influence the value of the interaction for other participating customers (Grove \& Fisk, 1997).

Therefore, in multi-actor service ecosystems it is necessary to shift the focus from dyadic interactions toward interactions occurring between and within groups of actors ( $\mathrm{Li}$ et al., 2017). Although companies increasingly use gamification to achieve their goals (e.g., engage customers) and despite the growing body of literature on that topic, considerable knowledge gaps inhibit the design and subsequent deployment of effective gamification approaches (Leclercq et al., 2018; Morschheuser et al., 2018; Wünderlich et al., 2020). We have highlighted three gaps, which in our opinion need immediate attention. 
First, gamification research and applications have typically centered around the potential influence on human behavior without much consideration for the antecedents to the effects of gamification (Koivisto \& Hamari, 2019). While research has started to investigate gamification and its relation to an actor's motivation and behavior, research is still not able to match specific gamification elements to specific motivational and/or behavioral outcomes (Warmelink et al., 2020). Instead of predominantly focusing on measuring the effects of gamification, future research is asked to shift its focus toward aspects "that precede the effects of gamification on human behavior and motivation, such as attitudes" (Koivisto \& Hamari, 2019, p. 205).

Secondly, research is sparse regarding the challenge of stimulating engagement in multi-actor ecosystems (Koivisto \& Hamari, 2019). As mentioned previously, a gamified experience can take place in socially interactive settings among the presence of other known or unknown actors. There are examples from practice of successfully implemented gamification approaches in such interactive settings, for example, "piano staircase" (Peeters et al., 2013) or "all eyes on Samsung S4" (Busch, 2013). However, research regarding those applications thus far has been limited.

Third, it has been difficult to compare results across research studies due to the lack of a consistent and validated measurement instrument that can be applied to gamified experiences (Koivisto \& Hamari, 2019). However, it is of utmost importance for information management to understand and measure both the antecedents and consequences of gamification in socially interactive settings. This will help managers to (1), influence their customers to engage in information exchange behaviors and (2), enable decision makers to improve their strategies regarding the application of gamified experiences.

Thus, the purpose of this study is to investigate whether the experiential value, generated through the gamified experience in a multi-actor service ecosystem, can be used to encourage customers' information exchange behavior. Furthermore, our research examines the impact of customers' knowledge sharing attitude on the relationship between the experiential value of a gamified experience and customers' information exchange behavior. Finally, our study examines the role of customers' attitudes as an antecedent to the effects of gamification. We use structural equation modeling to assess these dynamic relationships and provide a scalable measurement instrument that can be applied to gamified experiences ranging from simple customer-interface interactions, all the way up to multi-actor service ecosystems. In contrast to prior research, this study is the first to apply a holistic experiential value approach to a gamified experience that simultaneously accounts for customers' interactions with a multisensory physical environment, their personal interactions with employees, and their interactions with other customers. This will be useful to researchers in understanding the interplay between customers' knowledgesharing attitude and the actual information exchange behavior. However, it is also highly relevant for managers, as it sheds light on the possibility of behaviors that can be directly influenced without first needing to change a customer's attitude. 


\subsection{THEORETICAL BACKGROUND AND HYPOTHESES DEVELOPMENT}

\subsubsection{Gamified experiences}

The gamified experience has been defined as a "psychological state resulting from the interaction of [...] perceiving presented goals to be non-trivial and achievable, being motivated to pursue those goals under arbitrary externally-imposed constraints, and [the belief that] actions within these constraints [are] volitional." (Landers et al., 2019, pp. 83-84). In other words, the gamified experience is the "psychological consequence" (Eppmann et al., 2018, p. 99) of using a successfully gamified service. Gamified experiences, also referred to as "game-like" (Hammedi et al., 2017, p. 3) or "gameful" (e.g., Leclercq et al., 2020, p. 2; Wolf et al., 2020, p. 9) experiences, are experiences infused with gameful affordances, in a typically non-game context, to deliver experiences similar to those created through games (Deterding et al., 2011; Huotari \& Hamari, 2017; Warmelink et al., 2020).

Gamified experiences are co-created in interactions between the user(s) and the gamified service (Högberg, Hamari, et al., 2019; Huotari \& Hamari, 2017). From a business perspective, the ultimate goal of creating gamified experiences is to motivate "firmbeneficial user behavior" (Wolf et al., 2020, p. 1). Some examples of such behaviors are customers' willingness to accept higher prices and customer loyalty (Wolf et al., 2020) or engagement (e.g., Högberg, Ramberg, et al., 2019; Jang et al., 2018).

Among the various elements and mechanics that structure games, research indicates that achievement and progression-oriented affordances (e.g., points, badges, and rankings) are a more common way to gamify experiences than social-oriented (e.g., competition, cooperation), immersion-oriented (e.g., avatar, virtual identity), real world-related (e.g., physical objects, prizes), and miscellaneous elements (e.g., virtual currency, notifications) (Koivisto \& Hamari, 2019).

\subsubsection{Information exchange}

Information enables both customers and companies alike to make (the right) decisions and solve problems (Guo, 2011). Within multi-actor service ecosystems, actors engage in information exchange by seeking information but also sharing information (with each other) (Wilson, 1999). Information-seeking behavior is defined as the "purposive acquisition of information from selected information carriers" (Johnson et al., 1995, p. 275). It refers to an actor's way of gathering and utilizing information (Kakai et al., 2004). Information-seeking, or rather, the information received through the activity, is important to customers because it enables them to successfully co-create value with other actors of the ecosystem (Yi \& Gong, 2013).

Information-sharing behavior includes the provision of information to other actors and confirming that the recipient(s) has (have) received and understood that information (Sonnenwald, 2006). Information sharing is key to successful value co-creation (Yi \& Gong, 2013) as customers can ensure that the service they receive matches their individual needs (Ennew \& Binks, 1999). 
There are three different ways to model the relationship between information seeking and sharing. While the indirect approach "conceptualizes information seeking and sharing as discrete activities connected by an intermediating factor, [...] the sequential approach assumes that information seeking precedes information sharing" (Savolainen, 2019, p. 518). This study approaches information exchange from the viewpoint of the interactive approach; hence, information seeking and sharing are interpreted as activities that have no fixed temporal order, and both activities (can) influence each other so that transmitted information (information-sharing) leads to new questions (information-seeking), which then might lead to another round of information sharing and seeking (Savolainen, 2019).

\subsubsection{Multi-actor service ecosystems}

A multi-actor service ecosystem is "a relatively self-contained, self-adjusting system of resource integrating actors connected by shared institutional arrangements and mutual value creation through service exchange" (Vargo \& Lusch, 2016, pp. 10-11). As evidenced by the growing body of literature on this topic, research investigating service encounters has progressed from the focus on dyadic customer-service-provider interactions, toward interactions in multi-actor service ecosystems (e.g., Chen et al., 2020; Datta, 2020; Hartmann et al., 2018; Ho et al., 2020; Holmqvist et al., 2020; Iden et al., 2020; Pathak et al., 2020; Pinna et al., 2020). In an increasingly networked environment, it has become important to focus on the "intersection of the digital, physical and social realms" (Bolton et al., 2018, p. 776) of the customer experience, instead of investigating these realms in isolation.

\subsubsection{Value, attitude, and behavior in multi-actor service ecosystems}

In order to answer the question of whether gamification can be used to encourage customers' information exchange behavior, it is necessary to understand the causal chain that leads to the desired outcome. Prior research suggests that behaviors are generally driven by customers' attitudes toward a company (e.g., Bergel et al., 2019; Petersen et al., 2018), and specifically for information management, there is evidence that a customers' knowledge sharing attitude may influence information-seeking behavior and informationsharing behavior (Yang, 2008). However, gamification research thus far has not yet investigated the relationship between gamified experiences and customers' attitudes and the subsequent influence on customers' behavior (Koivisto \& Hamari, 2019). To understand how an experience stemming from gamification affects a customers' knowledge sharing attitude and his or her information-seeking and sharing behavior, we draw upon the value-attitude-behavior (VAB) model, as others have before us (e.g., Hansen, 2008; Vaske \& Maureen, 1999; Kang et al., 2015; McCarty \& Shrum, 1994; Shamim et al., 2017; Shim \& Eastlick, 1998). According to this framework, values have a direct as well as an indirect influence on behavior (Homer \& Kahle, 1988), while attitudes play a mediating role between values and behaviors (e.g., Jayawardhena, 2004; Kautish \& Sharma, 2019; Razali et al., 2021; Shamim et al., 2017; Shim \& Eastlick, 1998). 


\subsubsection{Value of gamified experiences in multi-actor service ecosystems}

Recent gamification research has pointed out that "researchers and managers risk missing performance-relevant aspects if they only consider experiences in isolation" (Wolf et al., 2020, p. 354), and multi-actor service ecosystems, in particular, are largely characterized by interactions occurring among groups of actors simultaneously experiencing a given environment. Hence, it is necessary to investigate gamified experiences in multiactor service ecosystems holistically. As previously mentioned, gamification can be used to enhance a service and support actors in the value co-creation process (Huotari \& Hamari, 2017), and the value derived via "interactions involving either the direct usage or [indirect observation] of goods or services" (Mathwick et al., 2001, p. 41) can be captured through experiential value. Therefore, we focus our attention on the experiential value derived through a gamified experience in a multi-actor service ecosystem. This value must account for customers' interactions with the gamified physical environment, their personal interactions with employees, and interactions among participating customers. Mathwick et al. (2001) developed a four-dimensional scale comprising aesthetics, playfulness, service excellence, and customer return on investment. The scale was tested and validated in a catalog and internet shopping context. However, while this experiential value scale is probably the most widely used, it has been argued that due to its context-specificity, it is not sufficient to capture experiential value in multi-actor service ecosystems (see Chapter 3). There is compelling evidence that the four-dimensional experiential value scale (EVS) needs to be adjusted depending on the context.

For instance, aesthetics, in the EVS, are limited to visual appeal and entertainmentrelated factors (Mathwick et al., 2001). However, there is evidence that visual, acoustic, haptic and olfactory elements are significantly relevant (Wiedmann et al., 2018) in terms of the overall experience and therefore should be addressed within a marketing concept. Furthermore, service excellence reflects customers' general assessment of the performance displayed by the service provider (Mathwick et al., 2001) but neglects the functional value of the contact personnel within a service ecosystem. Sánchez et al. (2006) provided evidence for the relevance of the professionalism of contact personnel in multi-actor service ecosystems. Finally, due to its context, the EVS does not account for the impact of other customers on experiential value. Brocato et al. (2012) found evidence for the relevance of the other customer perception (OCP) dimensions "similarity" to other customers and the "physical appearance" and "suitable behavior" of other customers in a multi-actor service ecosystem.

\subsubsection{Knowledge sharing attitude in multi-actor service ecosystems}

Knowledge sharing revolves around the exchange of existing and subsequent creation of new knowledge between at least two parties (van den Hooff \& de Ridder, 2004). Hence, knowledge sharing (KS) behavior consists of both providing and receiving knowledge. KS is not performed regularly or habitually, so research has investigated ways to motivate and 
encourage individuals to engage in the process (Cabrera \& Cabrera, 2005; Razmerita et al., 2016).

Social exchange theory suggests that individuals will engage in KS with others with the expectation of a benefit being received in return for their participation, and individuals tend to perform behaviors where they are able to maximize benefits and minimize their costs (Blau, 1964). Self-determination theory posits that behaviors can be extrinsically and/ or intrinsically motivated (Ryan \& Deci, 2020). In contrast to extrinsic motivation, which is triggered by external benefits, for example, rewards or being appreciated by others (Lee et al., 2006) - intrinsic motivation refers to the drive of doing an activity for the "inherent satisfactions" (Ryan \& Deci, 2020, p. 2) it provides. According to the analysis of Lee et al. (2006), effort, time, and a lack of reward are the key barriers inhibiting customer knowledge sharing while enjoyment and fun of helping others induces KS behavior.

There is also evidence from information science that intrinsic motivational variables such as enjoyment positively influence knowledge sharing attitude (Lin, 2007) and actual knowledge sharing behavior (Phung et al., 2019).

Developing similar experiences as the ones created by games (e.g., sense of enjoyment, flow, autonomy) so that individuals engage with the system simply for the sake of using it, is at the core of information systems gamification tactics (Koivisto \& Hamari, 2019). Therefore, this study hypothesizes the following:

$\mathrm{H}_{1}$ : The experiential value of a gamified experience in a multi-actor service ecosystem positively influences customers' knowledge sharing attitude.

Although the discussion about the exact link between attitude and behavior has varied dramatically and has certainly become more nuanced over the years, the existence of a relationship between attitude and behavior remained undisputed (Guyer \& Fabrigar, 2015). Research has discussed (the lack of) a direct relationship between both constructs (Wicker, 1969): one that is mediated by intention (Fishbein et al., 1975) and one where the perceived behavioral control plays an important role in the relationship (Ajzen, 1991). However, to date, none of the afore mentioned models has been able to prevail over the others, and the value-attitude-behavior model is still up-to-date and frequently used (e.g., Cheung \& To, 2019; Shin et al., 2017).

Prior research has demonstrated the positive effect of knowledge sharing attitude on the intention to share information (e.g., Bock et al., 2005; So \& Bolloju, 2005). Furthermore, it has been argued that "customers displaying positive attitudes towards knowledge sharing are more likely to both seek and share information" (Shamim et al., 2017, p. 595). Therefore, this study hypothesizes the following:

$\mathrm{H}_{2}$ : Customers' knowledge sharing attitude in a multi-actor service ecosystem positively influences customers' information-sharing behavior. 
$\mathrm{H}_{3}$ : Customers' knowledge sharing attitude in a multi-actor service ecosystem positively influences customers' information-seeking behavior.

\subsubsection{Information exchange behavior in multi-actor service ecosystems}

As already pointed out, information-seeking - that is, the information received through the activity-is important to customers because it enables them to successfully co-create value with other actors of the ecosystem (Yi \& Gong, 2013). Information-sharing behavior includes the provision of information to other actors and confirming that the recipient(s) has (have) received and understood that information (Sonnenwald, 2006). Information sharing is key to successful value co-creation as customers can ensure that the service they receive matches their individual needs (Ennew \& Binks, 1999; Yi \& Gong, 2013).

Similar to games, gamification aims for customers to feel positive emotional arousal and develop a need for social comparison or for bonding with others (Koivisto \& Hamari, 2019).

Bardi and Schwartz (2003) found evidence that stimulation values (e.g., excitement and novelty) relate strongly to the behaviors that express them. Furthermore, hedonism (e.g., pleasure, sensuous gratification), power (e.g., status, prestige), and universalism (e.g., understanding, social justice) relate at least moderately to the expressing behaviors (Bardi \& Schwartz, 2003).

Studies show that gamified experiences can influence participation behavior (e.g., information exchange behavior) in terms of the quantity and/or quality of the contributions (e.g., Barata et al., 2013; Choi et al., 2014). Therefore, this study hypothesizes the following:

$\mathrm{H}_{4}$ : The experiential value of a gamified experience in a multi-actor service ecosystem positively influences customers' information-sharing behavior.

$\mathrm{H}_{5}$ : The experiential value of a gamified experience in a multi-actor service ecosystem positively influences customers' information-seeking behavior.

We expect that (in line with the VAB model) knowledge sharing attitude mediates between the experiential value of the gamifies experience and the resulting behavior. The five hypotheses are depicted in Figure 4.1. 


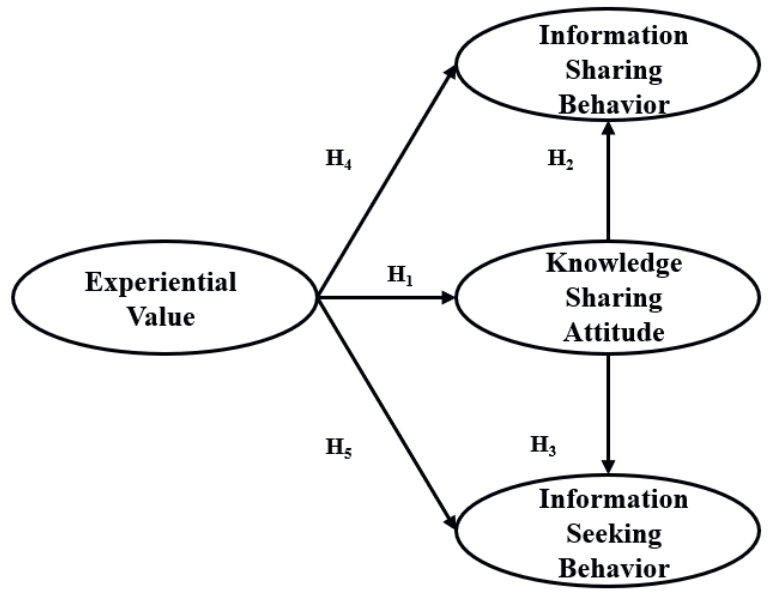

Figure 4.1: Conceptual model

\subsection{METHODOLOGY AND SAMPLE}

\subsubsection{Measures}

The measurement for the value must account for customers' interactions with the gamified physical environment, their personal interactions with employees, and interactions between customers. Therefore, we used the EVS for multi-actor service ecosystems, which is based on the functional value of personnel (professionalism), the perception of other customers' appearance (similarity), the perception of other customers' behavior (suitable behavior), multisensory stimuli (sensory appeal), and customers' enjoyment (playfulness) (see Chapter 3). Professionalism, the functional value of the contact personnel, is measured by four items loading on a single factor (Sánchez et al., 2006). Professionalism value may be interpreted as the value that customers derive from a personal interaction experience based on perceived knowledge, competence, and valuableness of information. Similarity reflects the degree to which customers feel similar and can relate to other customers in the service ecosystem (Brocato et al., 2012). Customers seek social support from others who are in a similar situation. Social support is most effective when it is offered by actors who can relate because they have had the same experience(s) (Hanks et al., 2020). Suitable behavior of other customers is judged (by their peers) based on what is considered to be appropriate within the context of the service ecosystem (Brocato et al., 2012). Other customers' behaviors can have a tremendous influence on a customer's experience as it has been shown to influence the level of expectation, set social rules, function as a standard for comparison, entertain, and help participation (Camelis et al., 2017). Sensory appeal relates to the influence of the multisensory environment (olfactory, acoustic, haptic, and visual stimuli) on experiential value. Addressing multiple senses simultaneously and in a coordinated way, can influence the customer's experience positively (Soars, 2009). Playfulness refers to the customer's enjoyment that comes from engaging in entertaining activities. Furthermore, escapism is 
the aspect of playfulness that allows the customer to temporarily escape their daily routine. Prior research has reported the importance of entertainment and escapism for experiential value (e.g., Keng et al., 2007; Mathwick et al., 2001). The scale was developed and validated in a multi-actor service ecosystem, and the items used to measure experiential value are based on a unique combination of prior literature on experiential value in the fields of service marketing, brand management, retail, and tourism management.

Customers' knowledge sharing attitude is part of the customer value co-creation attitude and therefore can be measured using that scale (Shamim et al., 2017). Knowledge sharing attitude is measured by three items loading on a single factor.

As noted, both the information-seeking and information-sharing behavior are required for successful value co-creation in multi-actor service ecosystems. This required participation by the customer can be measured using the customer value co-creation behavior scale (Yi \& Gong, 2013). Information-seeking is measured by three and information sharing by four items each loading on a single factor. Table A.4.1 provides an overview of all the constructs and measurements.

\subsubsection{Sample and data collection}

The customer survey was conducted at IFA 2018, the world's leading experiential event for consumer electronics and home appliances. The multi-actor service ecosystem was gamified through a combination of achievement/progression-oriented, social-oriented, immersion-oriented, and real-world-related affordances. After initial registration, customers received a personalized link on their cellphone leading them to their personal badgebook, which displayed their virtual identity including chosen username, collected points, achievements, and additional performance statistics. Depending on their performance (visible leaderboards) in the challenges and competitions against other actors and computer programs, customers had the chance to win real-world prizes.

Gamification at this event was primarily used to have customers experience and learn more about new $5 \mathrm{G}$ technologies in a socially interactive, innovative, and fun way. For example, a multiplayer drone race was developed to allow customers a playful way to experience the advantages of a $5 \mathrm{G}$ network. Up to five players at a time were able to fly a customized/personalized drone through a futuristic city, all while being displayed on a 4.5 x 6.0-meter LED wall (Demodern, 2018). Players flew through four different environments, collecting power-ups based on $5 \mathrm{G}$ features such as speed, latency, coverage, and capacity, which added variation to game rhythms and influenced player performance while making salient the technological advantages of $5 G$ (Demodern, 2018). Players received badgebook points for their performance within the game, but they decided on their own whether to behave competitively or cooperatively during the game experience. On average, customers had the gamified experience for 16.6 minutes.

Customers of the experiential event were intercepted and screened for appropriateness after their visit, near the exits of a 5,000 square-meter experience area. The qualifying 
criteria for the participants required active participation and interaction with the experiential offerings. Computer-assisted self-interviewing was used. Data were collected from August 31 to September 5, 2018. A total of 468 valid completed questionnaires were obtained from 632 qualified respondents, representing a valid response rate of more than $74 \%$. The decision to discard some of the filled questionnaires was based on obvious outliers and incomplete answers. Among the 468 respondents, most of the respondents were male (66.8\%), in their twenties (34.3\%), employed (71.5\%), and had either a high school degree (41\%) or a degree from a university (41.9\%). Table 4.1 provides a detailed overview of the sample.

Table 4.1: Demographic profile of the sample

\begin{tabular}{|c|c|c|c|}
\hline Variable & Characteristics & Cases & $\%$ \\
\hline \multirow[t]{7}{*}{ Age } & $16-19$ years & 71 & 15.2 \\
\hline & 20-29 years & 160 & 34.3 \\
\hline & 30-39 years & 71 & 15.2 \\
\hline & $40-49$ years & 60 & 12.7 \\
\hline & $50-59$ years & 64 & 13.6 \\
\hline & $60-65$ years & 24 & 5.1 \\
\hline & 66 years and older & 18 & 3.9 \\
\hline \multirow[t]{2}{*}{ Gender } & Female & 155 & 33.2 \\
\hline & Male & 313 & 66.8 \\
\hline \multirow[t]{3}{*}{ Education } & High School & 192 & 41.0 \\
\hline & University & 196 & 41.9 \\
\hline & Without higher education & 80 & 17.1 \\
\hline \multirow[t]{2}{*}{ Occupation } & Full time/part time & 335 & 71.5 \\
\hline & Unemployed & 133 & 28.5 \\
\hline \multirow[t]{5}{*}{ Occupation (if unemployed) } & Pupil & 138 & 29.5 \\
\hline & Student & 162 & 34.5 \\
\hline & Pensioner & 121 & 25.9 \\
\hline & Housewife/husband & 17 & 3.6 \\
\hline & Other & 30 & 6.5 \\
\hline
\end{tabular}

Note: $\mathrm{N}=468$

\subsubsection{Measurement model}

Prior to the investigation of the structural model, confirmatory factor analysis (CFA) was conducted applying the software AMOS v.25. The constructs used for the CFA, including the higher-order experiential value, are depicted in the Appendix in Table A.4.1. The CFA achieved acceptable fit (SRMR $=.06, \mathrm{NFI}=.89, \mathrm{IFI}=.94, \mathrm{CFI}=.94, \mathrm{RMSEA}=.05, \mathrm{CMIN}$ / $\mathrm{DF}=2.064)$. The validity and reliability of the constructs have been assessed. Convergent validity was assessed based on the AVE, with a recommended cut-off of .5 (Hair et al., 2018). As an exception to this rule, convergent validity may also be concluded in cases of an AVE below .5 but with composite reliability (Fornell \& Larcker, 1981). Discriminant validity was evaluated by checking whether the AVE of each construct was greater than the inter- 
construct correlations (Hair et al., 2018). Composite reliability was used to evaluate internal consistency, with a threshold of 0.7 for the $C R$ values. The reliability for each construct was assessed based on Cronbach's $\alpha$. As evidenced by Table 4.2, the model is valid and reliable.

\subsubsection{Structural model}

The structural model was tested. The overall model fit was almost identical to the model fit of the measurement model and therefore satisfactory. The model resulted in a chi-square statistic $\left(\chi^{2}=1205, \mathrm{df}=579\right)$ and acceptable fit indices (SRMR $=.06, \mathrm{NFI}=.89, \mathrm{IFI}$ $=.94, \mathrm{CFI}=.94, \mathrm{RMSEA}=.05)$. After the overall model fit was approved, hypotheses were tested via structural equation modeling. The structural equation model's standardized path coefficients were used to evaluate the hypotheses (see Figure 4.2).

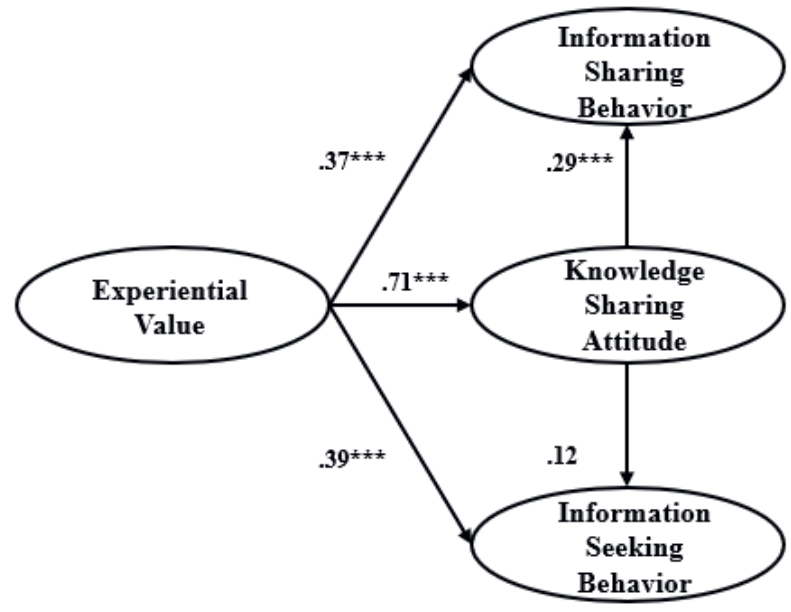

$\chi^{2}=1205, \mathrm{df}=579, * * * \mathrm{p}<.001, *$

SRMR $=.06, \mathrm{NFI}=.89, \mathrm{IFI}=.94, \mathrm{CFI}=.94, \mathrm{RMSEA}=.05$

Figure 4.2: Results of the structural equation model

\subsection{RESULTS}

$\mathrm{H}_{1}$ predicts that the experiential value of a gamified experience in a multi-actor service ecosystem positively influences customers' knowledge sharing attitude. As presented in Table 4.3, the hypothesis is strongly supported. The standardized path coefficient between experiential value and knowledge sharing attitude is $\beta=.71, C R=11.87$, and $p<.001$.

$\mathrm{H}_{2}$ predicts that the customers' knowledge sharing attitude in a multi-actor service ecosystem positively influences customers' information-sharing behavior. As presented in Table 4.3, the hypothesis is strongly supported. The standardized path coefficient between customers' knowledge sharing attitude and customers' information-sharing behavior is $\beta$ $=.29, \mathrm{CR}=3.31$ and $\mathrm{p}<.001$. 


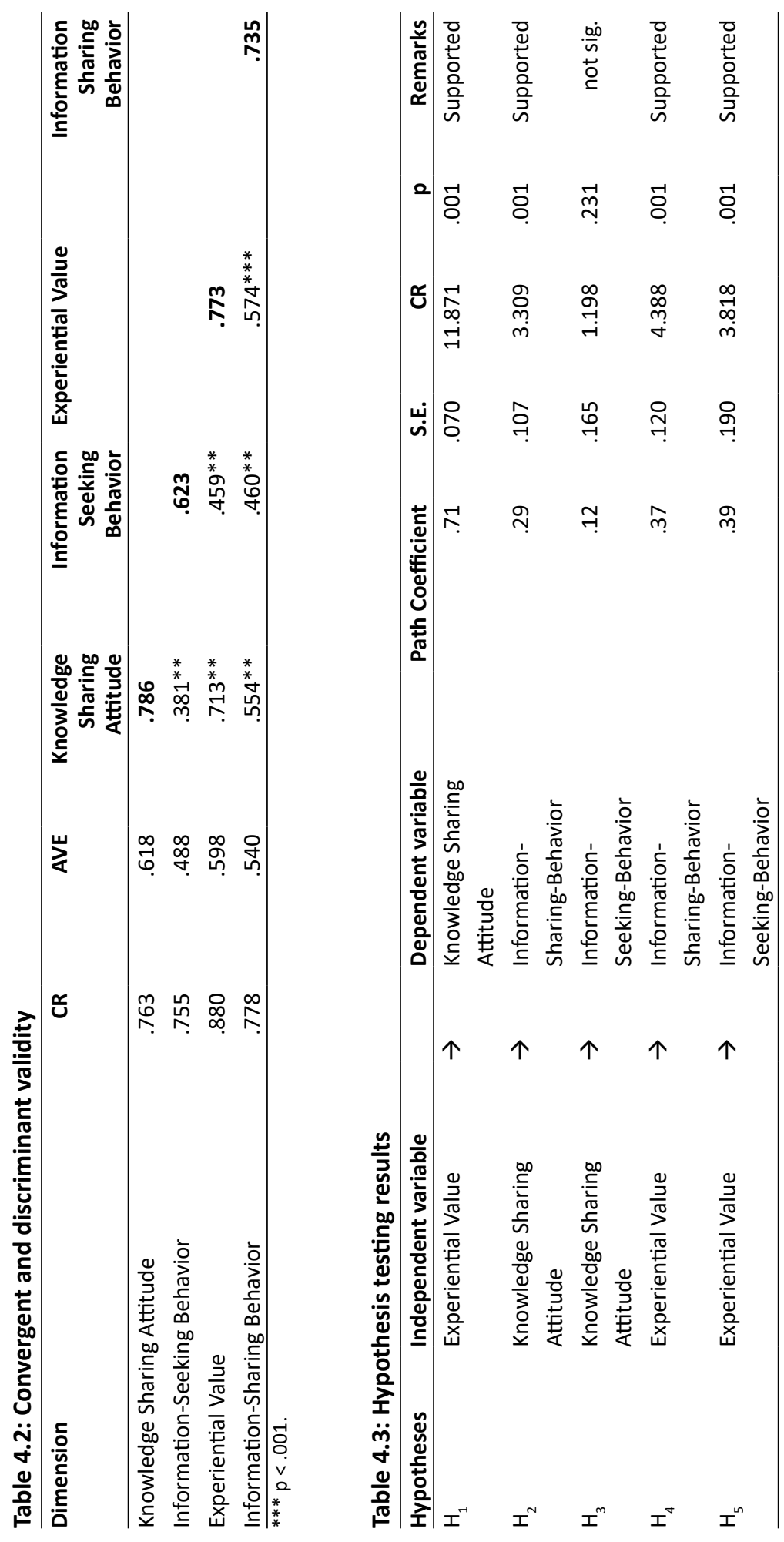


$\mathrm{H}_{3}$ predicts that the customers' knowledge sharing attitude in a multi-actor service ecosystem positively influences customers' information-seeking behavior. As presented in Table 4.3, the effect is not significant and therefore the hypothesis is not supported.

$\mathrm{H}_{4}$ predicts that the experiential value of a gamified experience in a multi-actor service ecosystem positively influences customers' information-sharing behavior. As presented in Table 4.3, the hypothesis is strongly supported. The standardized path coefficient between experiential value and information-sharing behavior is $\beta=.37, C R=4.39$, and $p<.001$.

$\mathrm{H}_{5}$ predicts that the experiential value of a gamified experience in a multi-actor service ecosystem positively influences customers' information-seeking behavior. As presented in Table 4.3, the hypothesis is strongly supported. The standardized path coefficient between experiential value and information-seeking behavior is $\beta=.39, C R=3.82$, and $p<.001$.

Research has pointed out that "the main feature of the VAB model is its emphasis on the mediating role of attitudes [between] values and behaviors" (Milfont et al., 2010, p. 2792). Several other researchers have reported findings of this feature (e.g., Cai \& Shannon, 2012; Jayawardhena, 2004; Shamim et al., 2017; Shim \& Eastlick, 1998). Against this background and considering that both $\mathrm{H}_{1}$ and $\mathrm{H}_{2}$ have been supported, point in the same direction, and are significant, we suspect that knowledge sharing attitude mediates the relationship between experiential value and information-sharing behavior. The indirect effect of experiential value on and information-sharing behavior must be significant to establish a mediation effect. We performed a bootstrapping procedure with 2,000 bootstrap samples and used the $90 \%$ biascorrected confidence level. The results of the analysis revealed a significant indirect effect of experiential value on information-sharing behavior via knowledge sharing attitude $(\beta=$ $.293, p=.005)$, supporting partial mediation of knowledge sharing attitude. The mediated effect $(a \times b)$ and the direct effect (c) point in the same direction, indicating complementary mediation (Zhao et al., 2010). The total effect, direct effect, and indirect effect are presented in Table 4.4 .

Table 4.4: Mediation effects (Bootstrapping Results)

\begin{tabular}{|c|c|c|c|c|}
\hline Variables & Total effect $(a b+c)$ & Direct effect (c) & Indirect effect (ab) & Result \\
\hline Experiential Value- & & & & Partial \\
\hline $\begin{array}{l}\text { Knowledge Sharing Attitude- } \\
\text { Information-Sharing Behavior }\end{array}$ & $\beta=.667, p=.001$ & $\beta=.374, p=.001$ & $\beta=.293, p=.005$ & $\begin{array}{l}\text { Mediation } \\
\text { Supported }\end{array}$ \\
\hline
\end{tabular}

\subsection{DISCUSSION}

The aim of this study was to investigate whether experiential value generated through a gamified experience in a multi-actor service ecosystem can be used to encourage customers' information exchange behavior. Furthermore, our research had the goal of examining the impact of customers' knowledge sharing attitude on the relationship between the experiential value of a gamified experience and customers' information exchange behavior. We applied structural equation modeling to achieve this objective, and we believe our study 
has augmented the literature on gamification and multi-actor ecosystems in a number of ways.

First, this study makes a substantial contribution regarding the characteristics that precede the effects of gamification on customer behavior. Prior research already has demonstrated the moderating role of demographic factors (e.g., Bittner \& Schipper, 2014; Koivisto \& Hamari, 2014) and the relevance of certain personality traits (Butler, 2014); however, to our knowledge, this is the first study that has investigated attitude as a predecessor of the effects of gamification. This is important for several reasons. First, it is highly unlikely that the maximum efficiency of gamification will be achieved without a clear understanding of both consequences and antecedents. Additionally, it has the potential to put a new spin on prior findings. For instance, it may not be that demographics moderate the effects of gamification, as suggested by Bittner and Schipper (2014), but rather that certain attitudes occur more often within some demographic groups.

Second, this study investigated a gamified experience that had the goal of stimulating engagement among large groups of people with widely varying characteristics and backgrounds. As evidenced by Table 4.1, the demographic profile of the sample was highly diverse. Interestingly, neither the organizer of the event nor the researchers saw any significant variance among the answers of members of different demographic groups. After conferring with the organizer of the event we traced this back to the following three reasons. First, all gamified experiences were kept simple in terms of handling and necessary prior (technical) knowledge. The goal was to deliver experiences with low barriers to entry. Second, the possibility of winning real-world prizes seemed to appeal to all customers. Third, while the experiential event attracted customers with different characteristics and backgrounds from all over the world, all of them likely shared a common interest in innovations in consumer electronics. Therefore, it is certainly a possibility that a shared common interest among customers is more important for successful gamification than similarities in demographic backgrounds.

Third, this study aimed to identify a consistent and validated measurement instrument that can be applied to (any) gamified experiences. This is highly relevant, as it enables researchers to compare research results despite differences in context, industry, or implementation (Koivisto \& Hamari, 2019). Although the implementation of gamification tactics can vary greatly, the experiential value they create is the common goal among them. Considering that there already exists a scalable measurement instrument that can be applied to gamified experiences ranging from simple customer-interface interactions, all the way up to multi-actor service ecosystems, we believe this avenue is worth pursuing. 


\subsection{CONTRIBUTIONS AND IMPLICATIONS}

\subsubsection{Theoretical contributions and implications}

As described above, this study makes several contributions. However, we feel that two specific theoretical contributions are especially relevant, as they pave the way for future research.

First, in order to understand how an experience stemming from gamification affects a customers' knowledge sharing attitude and his/her information-seeking and sharing behavior, we drew upon the value-attitude-behavior model. To our knowledge, this is the first study to apply the VAB model in the gamification context. Our results indicate that it certainly fits the intended purpose. That is good news for gamification researchers, as it provides a possible approach toward unlocking more of the mechanics of successful gamification applications.

Second, this study found that knowledge sharing attitude mediates the relationship between experiential value and information-sharing behavior. At the same time, we identified a complementary mediation effect in our proposed model. The significant direct effect of experiential value on information-sharing behavior "points to the possible existence of some omitted second mediator" (Zhao et al., 2010, p. 201). Therefore, we not only provided the first evidence for the importance of attitude (in general) as an antecedent to the effects of gamification, but our findings also suggest that there may be additional mediators (i.e., other attitudes) worth investigating.

\subsubsection{Implications for practice}

First, the experiential value of a gamified experience positively influences both customers' information-sharing and information-seeking behaviors. This direct influence on customers' information exchange behavior will be particularly interesting to managers, as our findings support the notion that gamification may be used to foster information exchange and value co-creation between customers and employees directly, without necessarily having to change customers' attitudes first. This probably will result in gamification becoming even more attractive to managers, as it presents itself as an easy way to influence such an important customer behavior. However, such expectations need to be tempered somewhat, as our investigation also revealed that customers' knowledge sharing attitudes precede information-sharing behavior. Additionally, we find that knowledge sharing attitude mediates the relationship between experiential value and information-sharing behavior. Hence, managers need to be aware that there also is a significant indirect effect on information-sharing behavior to be considered. This should encourage the development of gamified experiences that extend beyond entertainment and stimulate conversation among actors. For example, in our study, the gamification context embedded content related to $5 \mathrm{G}$ technologies. This allowed for participants to not only increase individual knowledge, but also consider the relevance of $5 \mathrm{G}$ capabilities to their own lives. This allows the customer 
to know what questions to ask or experiences to share and can ultimately increase the capability of value co-creation.

Secondly, our findings suggest that gamification can be applied in cases of large groups of people with widely varying characteristics, backgrounds, and motivations. Applying the EVS for multi-actor service ecosystems revealed that in such a case, a customer's perception of the other actors of the ecosystem (e.g., employees and other customers) has a significant influence on the overall experiential value of the gamified experience. This is of high importance to management. In cases of gamification deployed in the virtual world (e.g., websites or apps), other actors largely stay anonymous. However, in real-world multi-actor service ecosystems, all participants, their behaviors, and their characteristics are directly visible to other participating actors. Therefore, actors within this environment will influence one another's perceptions and impact the potential customer experiential value. Managers need to be made aware of this important difference between gamification in the virtual world and in multi-actor service ecosystems before executing any gamification strategies. Thus, strategies should extend beyond game mechanics to also include game administration and training of employees to promote consistency within the customer experience.

\subsection{LIMITATIONS AND FUTURE RESEARCH}

This study is the first to apply a holistic experiential value approach to a gamified experience that simultaneously accounts for customers' interactions with a multisensory physical environment, their personal interactions with employees, and their interactions with other customers. It succeeds in answering the question of whether gamified experiences in a multi-actor service ecosystem can be used to encourage customers' information exchange behavior, and it successfully investigates the impact of customers' knowledge sharing attitude on the relationship between experiential value and customers' information exchange behavior. However, it is not without its limitations.

Information exchange between different actors (e.g., between customer and employee) is certainly necessary; however, providing "the 'right' information, at the 'right' time, in the 'right' place, in the 'right' way, to the 'right' person" (Fischer, 2012, p. 1) is far more important than sheer information quantity. After all, increased information (quantity) is not useful if it is lacking the aforementioned qualities. Therefore, future research should also focus on the quality of the exchanged information in gamified multi-actor service ecosystems. A comparison between the information quality of "naturally" occurring information exchange versus the one fostered through a gamified experience would certainly be interesting.

As indicated, the multi-actor service ecosystem in this study was gamified through a combination of achievement and progression-oriented, social-oriented, immersionoriented, and real-world-related affordances. Based on the results of our study, we believe that it is safe to say that the affordances have been combined successfully. However, our results do not allow conclusions on the relevance of individual affordances or their manifestations (e.g., cooperatively vs. competitively) for different actor groups. Considering 
that the drivers of behaviors can (depending on the actor) be diverse (Koivisto \& Hamari, 2019), future research could also investigate if certain affordances are more suitable to influence certain actor groups than others. This study investigated a gamified experience at an experiential event in the electronics industry. The nature of the event allowed for a large and immersive audiovisual experience within a context that participants were exposed to other entertainment and experiential displays and encounters. While we believe our findings are robust, in order to generalize our research, it is necessary to investigate other (less experience- and entertainment-focused) contexts and industries. It would be interesting to see if a gamified experience such as the one in our study would elicit different effects when encountered as a more novel engagement outside of other gamified efforts.

\subsection{CONCLUSION}

This study's starting point, was a general question: “Information management can't be all fun and games, can it?" As the title of the chapter indicates, it might be hard to believe that something important, such as information management, could accompany something insignificant, such as games or game-like experiences. To answer the question, this research investigated whether gamified experiences can be used to encourage customers' information exchange behavior. We believe that they can, even in cases of large groups of people with widely varying characteristics, backgrounds, and motivations. However, we feel that this is only half the story. From our perspective, the real challenge for businesses will not be the design of gamified experiences that foster information exchange between the actors in multi-actor service ecosystems but to ensure that the actors still provide the "right" information, at the "right" time, in the "right" place, in the "right" way, and to the "right" person. Against this background, our initial question should be best answered as follows: Information management can be all fun and games, as long as all quality attributes of information exchange are adhered to. 
Chapter 5

PUTTING THE RETAIL

APOCALYPSE OUT OF BUSINESS 
Failure to appropriately address and co-create value with modern customers is one of the primary reasons for the ongoing retail apocalypse. This chapter investigates how companies from different industries deal with the threat of the ongoing retail apocalypse and achieve sales ecosystem well-being. To this end, qualitative research (case study research) was conducted. The chapter provides inspiring examples of company-designed functional approaches toward ecosystem well-being.

\section{Publication history:}

A shortened version of this chapter is currently finalized, in order to be suitable for submission to a practitioner's journal, most likely to the MIT Sloan Management Review. 


\section{ABSTRACT}

Failure to appropriately address and co-create value with modern customers is one of the primary reasons for the ongoing retail apocalypse. This article identifies best practices and key levers used by three successful retailers to achieve sales ecosystem wellbeing by successfully addressing the needs and desires of modern customers. The levers are employees' mindset (i.e., self-conception and customer-centricity), resource delivery (i.e., customization, third parties, knowledge bridges, subject matter experts, coherent experience, and accessibility) and customer empowerment (i.e., helping customers help themselves and co-ideation/brainstorming). The presented actionable insights broaden the minds of managers and enable both intra-industry and inter-industry learning.

Keywords: Sales ecosystem, Multi-actor, Retail apocalypse, Value co-creation, Well-being 


\section{$5.1 \quad$ INTRODUCTION}

Nothing is more constant than change. The practice of selling, which has advanced considerably, is no exception to this rule. A transactional selling orientation that emphasizes short-term outcomes has been superseded by relationship selling with a focus on longterm partnerships and (more recently) by consultative and enterprise selling approaches that consider salespeople to be co-developers of long-term relationships with customers, leading to long-term benefits for companies (Hartmann et al., 2021). Consequently, the understanding of salespeople's jobs has evolved from creating value for the customer toward co-creating solutions with and for actors in the entire multi-actor ecosystem (Friend \& Malshe, 2016). Achieving sales ecosystem well-being-that is, the successful "blending [of] value co-creation and sales ecosystem elements and practices" (Ranjan \& Friend, 2020, p. 234)-has become increasingly challenging for companies as they face a new type of customer. This "modern" customer has educated him or herself about the product or service online, via social media, or by conferring with their network (e.g., family, friends, colleagues). The customer has price transparency, knows about competitors' offerings, and enjoys the convenience of online shopping. The ongoing retail apocalypse-that is, the rise of store closings and filings for bankruptcy with just a small number of examples of retailers that are succeeding and expanding-is evidence that the majority of brick-and-mortar retailers still struggle to address this modern customer and showcase their advantages against online. MarketWatch reported that in 2020, retail bankruptcies in the U.S. hit their highest level since the financial crisis of 2009 (Garcia, 2020). Among the victims of this development are some of the most famous and established names from all industries; for example, Pier 1 Imports (home furnishings), JCPenney (department store), Brooks Brothers (apparel), GNC (health and nutrition), and Guitar Center (musical instruments) (Thomas, 2020). The COVID-19 pandemic and the worldwide temporary shutdowns of physical stores further accelerated an already existing trend from physical brick-and-mortar stores toward online shopping so this trend may soon reach a head. Retailers' position with regard to the retail apocalypse can be determined on a continuum, with filing for bankruptcy and closing most or all of their stores representing one end of that continuum and expanding physical retail store quantity and/or quality at the other end. While the mandatory shutdowns of physical stores admittedly took a toll on the financial situation of those companies, they were already struggling before the pandemic. Somewhere along that continuum are retailers from all industries - for example, GameStop (video game retailer), Victoria's Secret (apparel) and Sears (department store)-under immense pressure, trying to avoid such an outcome primarily by closing stores and cutting costs. For instance, both Victoria's Secret and GameStop will have permanently closed approximately 1,000 stores worldwide by the end of the fiscal year 2020 (L. Gray, 2020; Whiteman, 2021).

However, some retailers seem to be immune to the retail apocalypse. For instance, Lululemon Athletica (apparel) is continuously expanding its physical retail store footprint. As of December 2020, there were 515 company-operated stores worldwide and the company 
reported plans to open 30-35 stores in 2021, similar to the number of stores they opened in 2020 (A. Gray, 2020).

Amazon, the formerly pure play-online retailer, started opening its first physical retail stores in 2015 and now operates five different types of retail store formats. As of January 2021, there were 24 Amazon bookstores, 28 Amazon 4-star stores, five Amazon Fresh stores, four Amazon Go stores and even an Amazon Go Grocery store in the U.S. The company has already announced concrete plans to expand internationally by opening up to 30 physical stores in the UK (Wilson, 2020).

Deutsche Telekom, the largest European telecommunications provider, has a different approach. Instead of opening additional locations, the company announced in 2020 that it would redesign and repurpose all 400 of its German-based stores (Kral, 2020). Deutsche Telekom has doubled its financial investment in its physical retail stores in 2020 and started closing small stores with limited space in favor of larger experience stores (Kral, 2020).

This raises an interesting question: How exactly are Lululemon, Deutsche Telekom and Amazon achieving retail sales ecosystem well-being, and can their models be transferred to other businesses?

Our analysis revealed that within their retail stores, these companies rely on three different levers to achieve sales ecosystem well-being by successfully addressing the needs and wants of the modern customer. By studying one native brick-and-mortar retailer that expands its physical retail spaces but also explores the opportunities of the online world (Lululemon), a service provider (Deutsche Telekom) invested in multiple sales channels, and a native online retailer expanding offline (Amazon), this study presents a collection of best practices from different industries and provides actionable insights in order to broaden the minds of managers from all industries and enable both intra-industry and inter-industry learning.

\subsection{THEORETICAL BACKGROUND}

\subsubsection{Retail sales ecosystem}

Sales ecosystems, in general, consist of actors (i.e., every individual involved in the service-for-service exchange), resources (e.g., knowledge, CRM platforms), and institutions, i.e., a wide range of coordinating heuristics (Hartmann et al., 2021) that create and alter sales ecosystem practices, which then affect sales ecosystem outcomes, and vice versa (Ranjan \& Friend, 2020). From an ecosystem perspective, sales ecosystems cover the entire "spectrum of ecosystem levels-e.g., micro-level (e.g., buyer-seller), meso-level (e.g., buying center-selling center), and/or macro-level (e.g., buyer-seller organization)" (Ranjan \& Friend, 2020, p. 242). This study evaluates best practices in retail sales ecosystems through the lens of the micro level. Hence, typical actors include multiple frontline employees (FLE) with different skill sets and expertise (e.g., sales and customer service) and customers with different relationships to the company (e.g., former, new, and potential customers). These actors integrate and exchange their resources (e.g., special skills and knowledge) within 
the environment of the retail store, leading to co-created value for all actors within the ecosystem (including themselves) (Hartmann et al., 2018).

Within sales ecosystems, eight different co-creation practices (Frow et al., 2016; Ranjan \& Friend, 2020) - which are based on the activities of sensing, assessing and internalizingbind together actors, resources, and institutions and contribute to value co-creation (VCC) i.e., value co-production (VCP) and value-in-use (ViU), ultimately improving the well-being of the system (Ranjan \& Friend, 2020). Because these practices are highly interdependent, a holistic approach is advisable. Based on the aforementioned consideration and in line with Ranjan \& Friend (2020), Figure 5.1. presents the eight interdependent co-creation practices (in bold) and the respective potential measures for VCC.

\subsection{METHODOLOGY AND SAMPLE}

\subsubsection{Research approach}

As indicated above, this study focuses on identifying, analyzing, and emphasizing the best sales ecosystem practices employed by Lululemon, Deutsche Telekom, and Amazon. This study strives to provide actionable insights and broaden the minds of managers from all industries and enable both intra-industry and inter-industry learning. This research followed the suggestion of Yin (2013) and selected the research method based on "(a) the type of research question posed, (b) the extent of control [the team of researchers had] over actual behavioral events, and (c) the degree of focus on contemporary as opposed to entirely historical events" (p.9). As this study primarily focused on the "how" exactly are the three companies achieving retail sales ecosystem well-being, as opposed to "who, what, where, how many, how much", surveys and archival analysis have been excluded from the list of potential research methods. The lack of control over the observed phenomenon led to the exclusion of experiments as a research method. Finally, this study's focus on contemporary events led to case study research (Eisenhardt, 1989) as the fitting research method. The three selected cases complement each other well; because they differ from each other (i.e., a natively brick-and-mortar retailer that expands its physical retail spaces but also explores opportunities in the online world, a service provider and a native online retailer expanding offline), and they cover a broad spectrum. In the context of this study, best practices, in contrast to regular practices, represent the company's most effective and/or efficient ways (i.e., manifestations of sales ecosystem practices) of achieving sales ecosystem well-being, as evidenced by attaining value co-creation measures (see Figure 5.1). However, because value in sales ecosystems (at the micro level) is created in collaboration between multiple actors (e.g., customers, frontline employees) but perceived individually and possibly differently, a holistic evaluation of best practices must include at least an internal (company) and an external (customer) perspective. Data collection for the internal perspective consisted of a broad range of sources (e.g., company presentations, reports, press releases, news articles, interviews, the website(s), and company-operated social media accounts). The customers' perspective was analyzed primarily based on authentic customer experience reports in 


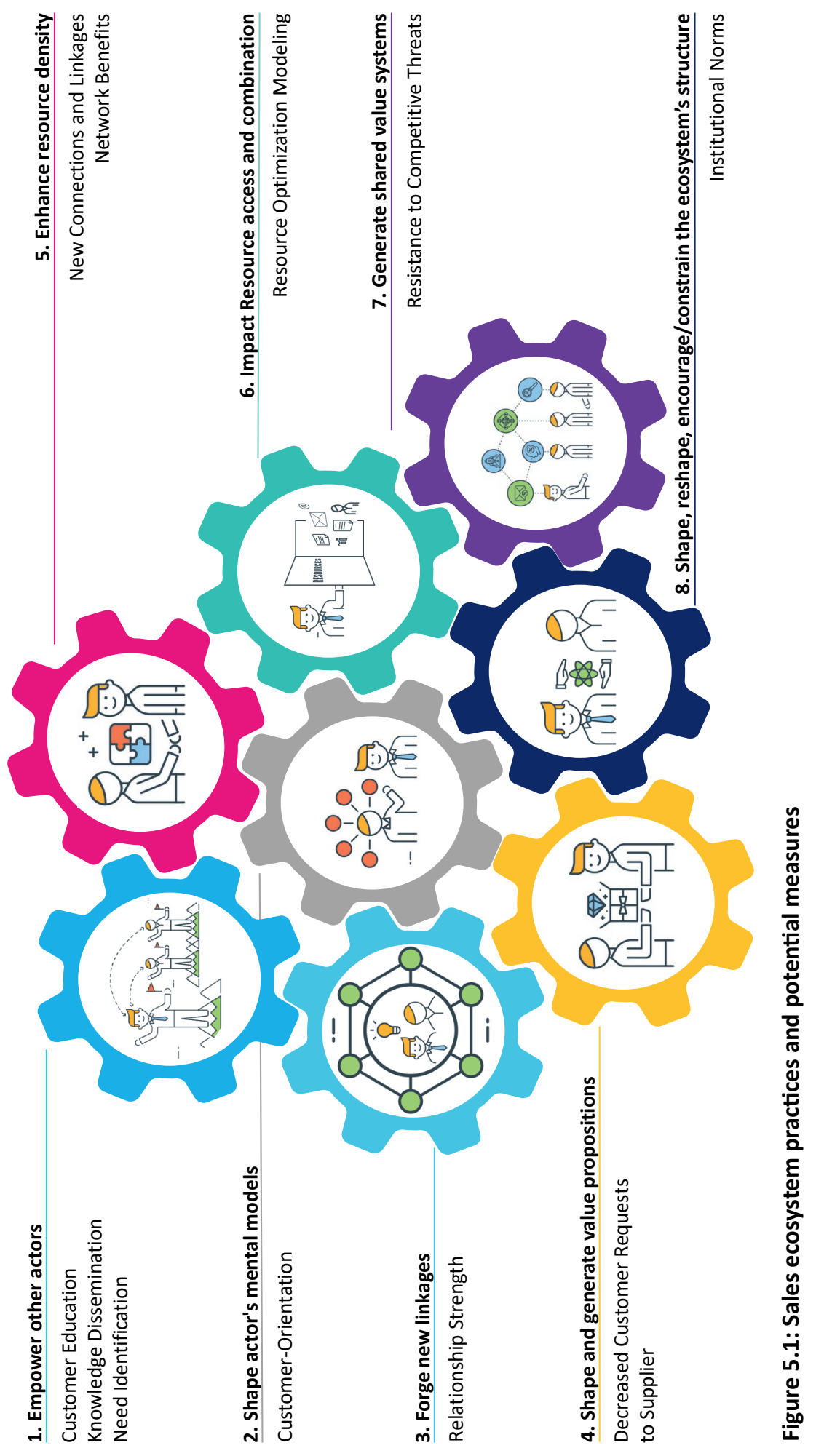


social media channels (e.g., comments, videos, vlogs) and complemented by insights from personal interviews with customers, all of which were unpaid. Furthermore, the insights from store visits and personal observations in physical stores were used to add an additional and impartial layer to the data collection.

The data analysis consisted of individual within-case analysis followed by cross-case analysis (Eisenhardt, 1989). First, each of the cases was analyzed independently based on the eight different sales ecosystem practices (Ranjan \& Friend, 2020), starting with the internal perspective and followed by an analysis of the external perspective. Case writeups consisting of the identified intersections between the perspectives were created. Subsequently, field observations were used to validate the findings and impartially observe and evaluate the practices. The up-close firsthand observations facilitated the subsequent cross-case analysis. Therefore, identifying cross-case similarities and differences in the design and application of the practices was more effective. This study showcases the aggregated results of the cross-case analysis, with a focus on similarities and differences between the three companies; specifically, the way they achieve sales ecosystem well-being.

\subsubsection{Lululemon}

The Canadian-based company Lululemon was founded in 1998 and primarily offers "yoga-inspired, technical athletic apparel for women and men" (Lululemon, 2016). It is particularly successful at the intersection of athletic and leisure (athleisure) apparel. The company prides itself on the continuous improvement of its stylish products based on community (e.g., customers, ambassadors, and elite athletes) feedback (Lululemon, 2020d). Most recently, Lululemon also ventured into the home fitness market by acquiring Mirror (Maheshwari, 2020). In addition to the investment in physical retail stores, Lululemon has also invested heavily in digital technology. The company tries to utilize the individual strengths of each customer's touchpoint, and this omnichannel strategy has already paid off. The company's website and app enable them to conduct simple business transactions, such as purchasing, virtual waitlists, or click and collect, as well as more complex tasks such as live video appointments with digital educators (Anderson, 2021). Physical stores are critical in driving the Lululemon customer experience. According to SGB Executive (2021)'s summary of Lululemon's presidents' talk at the NRF (National Retail Federation) Big Show, the CEO of Lululemon argued that the strengths of the physical stores come from the quality of the people working in the stores, the quality of the connections established with the communities, and the guest interactions that the company can create.

\subsubsection{Deutsche Telekom}

The German telecommunications company, which was privatized in 1995, is present in more than 50 countries and has its own infrastructure in Germany, Europe and the US. (Kespohl, 2020). Internationally, most of its physical retail stores are operated under the T-Mobile brand. Depending on the country, the company offers "fixed-network/ 
broadband, mobile communications, Internet, and Internet-based TV products and services for consumers, and [information and communication technology] solutions for business customers and corporate customers" (Deutsche Telekom AG, 2021). Physical retail stores in Europe-including Austria, Poland, Slovakia, the Netherlands, and the Czech Republic-are operated locally with continuous monitoring of the brand experience in the stores by the headquarters (HQ) in Bonn. While retail store experience innovation, in terms of layout and practices, is primarily $\mathrm{HQ}$ driven, the company facilitates a constant open exchange of best practices between country subsidiaries. In contrast to Lululemon and Amazon, Deutsche Telekom offers franchises. Depending on the expected profit margins, expected customer frequency, and anticipated risks, the company operates using different business models (e.g., own-shop, Telekom Shop Partner, Telekom exclusive Partner, Telekom Partner) (Telekom Deutschland $\mathrm{GmbH}, 2021$ ). Deutsche Telekom revises its physical retail store formats, both for its own and franchise stores, on a regular basis. The latest iteration, the "Magenta Shop 2020" store concept, was piloted in different European markets in 2019, and in 2020 the company announced a rollout of the new format wherever possible (Kral, 2020). The new concept includes interactive experience corners, digital touchpoints, and event and workshop rooms (Kral, 2020).

\subsubsection{Amazon, inc.}

The Seattle-based e-commerce company, founded in 1994, started as an online marketplace for books (Amazon Autor, 2018). Today, the company is one of the most valuable brands in the world and collects revenue streams from a broad range of digital businesses, for example, "e-commerce operations, cloud services, digital advertising" (Reiff, 2021) but also from video and music content, as well as from sales in physical retail operations (Reiff, 2021). Amazon addresses different market segments and consumer demands with individually developed physical retail store formats. While Amazon Go focuses on "readyto-eat options for breakfast, lunch and snack options" (Amazon, 2020), Amazon Go Grocery offers fresh produce, meat, and fish but also cooking essentials (Amazon, 2020). Amazon Fresh offers a product range that is similar to the upscale, organic-focused, Whole Foods (purchased by Amazon in 2017) but at a lower price point (Amazon, 2020). Amazon Books primarily offers "a highly curated [and at least 4-star rated] selection of books" (Amazon, 2021b) as well as the opportunity to learn more about Amazon devices and smart home accessories (Amazon, 2021b). The Amazon 4-star format goes yet a step further, featuring a selection of the most popular and highest-rated products from different categories, e.g., "devices, consumer electronics, toys, games, books, kitchen, home" (Amazon, 2021a). Despite the differences between the stores, there is one overarching similarity: all stores rely, in different ways, on (a combination of) state-of-the-art technologies (e.g., cameras, sensors, computer vision, deep learning, artificial intelligence, or big data analytics) to improve the customer experience (Gross, 2019). 


\subsection{RESULTS}

\subsubsection{Empowering other actors}

The analysis of how Lululemon, Amazon, and Deutsche Telekom educate and empower their customers revealed that they mainly rely on two components: the employee mindset and customized knowledge transfer.

\subsubsection{Employee mindset}

It all starts with a basic requirement: the mindset of the frontline employees (FLEs) and their self-conception. The frontline employees are asked to focus on connecting, interacting, and educating customers instead of closing sales at all costs. For example, Lululemon does not hire salespeople for their stores; they hire "Educators." The company describes this approach as follows: "Their main role is to effectively educate our guests on the fabrics, features, fit and function of our product, our culture and the communities we belong to. Our goal is to have guests leave our store having learned something, rather than having purchased something. By educating guests we empower them to make decisions for themselves based on the facts that we offer them" (Goel, 2021). However, the overall management of employees must fit with this goal. For instance, if employee compensation is mostly based on commission, this raises a conflict of objectives, and the desired mindset cannot be achieved. Lululemon tries to minimize the effect of sales commissions on the employee mindset by linking the commission to a store's overall performance, not to individual sales. Deutsche Telekom and Amazon, in contrast, simply limit sales commissions or cancel them altogether. Manifestations of such mindsets can be observed by frontline employees helping customers order online. For example, Deutsche Telekom has realized that it is not cost-efficient to carry the entire range and variety of accessories in the physical stores and therefore installed virtual shelves. Since employees' salaries are largely independent of store sales, employees are happy to help customers order the product from the Telekom website. Employees at Amazon Books encourage customers to use their smartphone in the store (e.g., check prices, read reviews) and to order directly from the website if the customers prefer the convenience of shipping to carrying their purchases.

\subsubsection{Customized knowledge transfer}

Customized knowledge transfer (CKT) refers to offerings to a customer that go beyond what is typically expected in a physical retail store (e.g., a dyadic sales/service conversation between FLE and customer) and that are tailored to customers' individual information needs. Both Lululemon and Deutsche Telekom focus on in-person events and workshops in their physical retail stores. Lululemon regularly offers free yoga classes to their customers and/or the interested public, designed to fit specific segments, groups, and experience levels (Quiroz, 2019). For instance, Lululemon offers "beginner" yoga classes (Fisher, 2020) in which interested individuals (potential customers) can borrow the necessary equipment (e.g., yoga mat, clothes) (Patton \& Rastello, 2019). In this way, the company removes 
obstacles and facilitates firsthand experiences. Deutsche Telekom also regularly offers (usually) complimentary workshops in their stores (Telekom Deutschland GmbH, 2020a). The workshops are offered to customers who are facing difficulties in using products and/or services but are also open to the interested public. The workshops are held either by a senior salesperson from the store-to foster community building-or by a partner in the case of device-specific workshops (e.g., Samsung). Topics focus on the Telekom product or service portfolio and include, but are not limited to, how to improve a Wi-Fi connection, how to use the camera, how to operate Android phones, and how to master smart homes (Telekom Deutschland $\mathrm{GmbH}, 2020 \mathrm{a}$ ). Within the workshops, the experts share inimitable knowledge with a group of up to 10 participants (depending on the physical space available in the respective store) and enable them "to champion co-creation of value" (Ranjan \& Friend, 2020 , p. 243). The informal and bilateral exchange of information between experts and the participants helps employees learn about the problems and critical needs of customers through firsthand experience. This information is used by the company to improve products and services as well as the sales approach itself. In contrast to the in-person CKT, Amazon relies on advanced technologies. Amazon Books uses customer insights, based on the analysis of millions of transactions at Amazon.com, customers' wish lists, and so on to offer individual, customized knowledge to customers (Amazon, 2021b). In-store product displays and advertising such as "If you liked this book, you will love these" or "Most wished for in your area" are excellent examples of how Amazon engages in technology-based customer education and empowerment without the necessity of in-person customized knowledge transfer.

\subsubsection{Shape actor's mental models}

The best practices in terms of successfully shaping retail store customer mental models revolve around a focus on customer-centricity. Similar to the approach toward CKT, Lululemon bets on customer-facing employees and their personal interactions with customers, while Deutsche Telekom and Amazon achieve this through a combination of customer-facing employees and data analysis.

\subsubsection{Customer centricity}

Lululemon's approach toward shaping customers' mental models is threefold. First, the company assumes that the authenticity of the FLE is key to creating meaningful connections between educators and customers. Therefore, the company requires that its educators are "speaking authentically about product use through their own experiences" (Lululemon, 2021a).

Second, the educators take customers' names (at the latest in the dressing room) and subsequently address them on a first-name basis (Gajsek, 2020). This changes the dynamic of the relationship between educators and customers. The relationship evolves from a professional business relationship to a more personal one. Third, Lululemon ensures that 
customers feel valued. To this end, customers can book one-on-one time with educators at their nearest retail store in advance, for a personal or gift-shopping experience (Lululemon, 2020a). This makes the shopping experience more exclusive, as customers determine the when, where, and what.

Similar to Lululemon, Deutsche Telekom also tries to shape customers' mental models through the dedication of face time with customers. The moment customers enter a Deutsche Telkom retail store, they are approached by a concierge with the purpose of identifying their needs as quickly as possible and making them feel welcome (Invidis Redaktion, 2021). Through needs-based servicing, Deutsche Telekom can significantly raise customer satisfaction levels. For instance, customers in a hurry or with small requests can be fast-tracked, leaving the company to dedicate more resources to the customers who require more time and have voiced more interest. Deutsche Telekom also offers a sophisticated online appointment scheduling feature. In contrast to Lululemon, Deutsche Telekom requests customer-identifying properties (e.g., phone number) which, according to their conditions, are used to prepare the appointment (Telekom Deutschland $\mathrm{GmbH}$, 2019a). In cases of existing customer relationships, this enables Deutsche Telekom to pull relevant customer data (e.g., customer status, monthly rates, payment behavior) before the appointment. Hence, employees already know a considerable amount about the customers they meet and do not have to pepper them with questions, which in turn makes customers feel valued and viewed as individuals.

According to its mission statement, Amazon aims "to be Earth's most customer centric company" (About Amazon Staff, 2018). Hence, Amazon goes even further than Lululemon and Deutsche Telekom, having already designed its physical retail locations with the customers in mind. This includes decisions about store locations, the offered portfolio, and the design of the store. Based on data analysis, the company can "answer the most obvious questions that customers want to know through [their] signage" (Leinbach-Reyhle, 2018). Furthermore, the company designed the stores in a way that employees always have "a clear line of vision throughout any point of [the] store" (Leinbach-Reyhle, 2018) to assist the customer when necessary. Ultimately, a combination of anticipating customers' potential issues and proactively solving them before they are voiced, which leads to specific store designs and the behavior of retail employees, shapes the customer's disposition toward Amazon. As Amazon's vice president of physical stores summarizes, "In each of our Amazon 4-star stores, customers will find easy-to-navigate floor plans that also allow for our employees to see throughout the store and more easily identify where customers are and how they can best support them" (Leinbach-Reyhle, 2018). The intensity of the Amazon customer orientation can be deduced from Amazon's statement about what is expected of retail store employees and how they are trained. "Our employees are trained to put customers first... always. It really is that simple" (Leinbach-Reyhle, 2018). 


\subsubsection{Forging new linkages}

The analysis of how Lululemon, Amazon, and Deutsche Telekom forge new linkages among customers, as well as between employees and customers revealed that all three companies try to take advantage of local communities by utilizing the reputation of third parties.

\subsubsection{Third parties}

Lululemon is an ideal example of a company that has mastered the art of nurturing and tapping into local communities by proxy. To this end, the company established a local store ambassador program to identify and "recruit" store ambassadors from within the store's customer base. According to the company's website, suitable candidates have to "embody the three pillars of [the so-called] sweatlife" (Lululemon, 2020c). These are, sweat - that is, being a "leader in [a] community who loves to sweat and make a positive impact" (Lululemon, 2020c), grow-specifically, an ambition to growing "personally, professionally and in [the] community" (Lululemon, 2020c) and connect-that is, a focus on "building relationships in [the] community" (Lululemon, 2020c). As of February 2021, the company lists 1,554 different store ambassador profiles for Canadian and American stores on its website. Store ambassadors forge new linkages by teaching classes, hosting events, and facilitating dialog within the local community (Lululemon, 2020d). In contrast to hired professional ambassadors, store ambassadors are not paid for their services. Hence, individuals interested in being selected as store ambassadors by the company must be highly (intrinsically) motivated.

Deutsche Telekom also heavily relies on harnessing the power of local communities to generate new relationships with and between potential customers of their stores. Like Lululemon, Deutsche Telekom uses external personnel and their standing in the community. However, in contrast to Lululemon, Deutsche Telekom leverages strategic business partnerships to tap into local communities, instead of identifying store ambassadors among their customers. For instance, in late 2019, Deutsche Telekom acquired $25 \%$ of eSports company SK Gaming (Bresgen, 2019b). Two months later, the company hosted a complimentary "Beat the Pro" event in one of their stores in Munich. The local esport community was targeted and invited to meet like-minded people and compete against their stars (Schwartz Public Relations, 2020). The company later announced that the event exceeded the expectations and that more were being planned (Telekom Deutschland $\mathrm{GmbH}, 2020 b)$. Another relevant example of tapping into local communities by proxy is the "Business Xperience" format, where local startup founders were invited to meet up in Telekom stores and listen to successful entrepreneurs talking about their experiences in founding businesses (Telekom Deutschland GmbH, 2019c).

Similar to Lululemon and Deutsche Telekom, Amazon tries to benefit from the credibility of community-relevant testimonials to forge new linkages. However, in contrast to Lululemon, 
which prominently glorifies and presents its store ambassadors, Amazon testimonials remain "faceless." Once again, Amazon profits from its data analytics capabilities. In Amazon's 4-star stores, products are accompanied not only by digital price tags, featuring the "average star rating and the total number of reviews" (Amazon Staff, 2018), but also by customer review cards. These review card printouts display an actual quote from a customer, that has been deemed very helpful by other customers (Amazon Staff, 2018). Another example of how Amazon forges new linkages within their stores through a combination of testimonial credibility and community focus is the special thematic sections in the store. For instance, all 4-star stores feature a "trending around your city" selection. Based on data analytics, Amazon informs customers what their geographical peers (i.e., individuals from the same city) have recently bought or are interested in.

\subsubsection{Shape and generate value propositions}

The investigation into how Lululemon, Amazon, and Deutsche Telekom shape and generate value propositions (i.e., how to make customers less dependent on sales and service personnel) revealed that this is primarily achieved either by developing subject matter experts for their stores' customer base or through an "enabling customers to help themselves" approach.

\subsubsection{Subject matter experts}

Lululemon actively recruits influencers, even those with a very limited digital reach (< 5000 followers), current or legacy ambassadors with a preexisting relationship with Lululemon, and strategic sales partners (e.g., wholesale partners of Lululemon) for the so-called "Lululemon collective" (Lululemon, 2021b). The goal is that these subject matter experts serve as intermediaries between customers and the company and promote Lululemon's products, services, and events (Lululemon, 2021b). In return, these subject matter experts receive early access to new products and events, dedicated support by Lululemon if necessary, and commissions for items purchased based on their referrals. Lululemon profits from this approach in several ways. First and foremost, the Lululemon collective generates an additional revenue stream for Lululemon in general as well as additional revenue and customer frequency for the stores specifically. Furthermore, as evidenced by the countless semiprofessional Lululemon YouTube videos uploaded every day, influencers voluntarily invest a considerable amount of time and effort into product presentation and answering customer requests. This results in a decrease in customer service requests to the company.

Deutsche Telekom pursues a different approach. In their stores, Deutsche Telekom establishes dedicated self-service areas in which customers receive a demonstration (by a so-called customer experience manager) and learn how to use the "MeinMagenta App," a digital self-service center. Deutsche Telekom has realized that certain-rather simplecustomer requests and business transactions can be resolved by customers themselves as 
long as they receive the means to do so and are comfortable. Customers are enabled to check usage status, costs, and bills and to top up funds as well as request customer service from Deutsche Telekom's voice assistant “Magenta” (Telekom Deutschland GmbH, 2019b). As evidenced by the various tools, tutorials, and FAQs, the app is designed to help customers help themselves. Almost 80,000 customer reviews in the Apple app store, an average rating of 4.3 (out of 5), and voiced comments indicate that customers are quite satisfied with the app. By enabling customers to help themselves, Deutsche Telekom decreases the number of customer requests that are not profitable (i.e., requests that are time consuming and typically do not result in additional revenue), which gives employees the ability to dedicate more time to potentially profitable customers.

\subsubsection{Enabling customers to help themselves}

Like Deutsche Telekom, Amazon utilizes modern technology to enable customers to help themselves and thereby shape and generate value propositions in their stores. The prime example from the Amazon store cosmos is the shopping experience at Amazon Fresh stores. For example, the newly launched "Amazon Dash Carts" are equipped with "a ring of cameras, a scale, and computer-vision and weight sensors" (Statt, 2020) to identify products as well as their quantity and weight (Statt, 2020). The cart enables customers to keep track of what they already put into the cart, the total number of items, and the total amount of all items. Furthermore, the cart can display a customer's Alexa shopping list. Throughout the store, Amazon places "Amazon Echo Show" devices that help customers find the items they are looking for (Bernabe \& Messer, 2020). Finally, customers can just walk out of the store with their products, without having to wait in line to check out. The bill is directly charged to the Amazon account that logged into the cart as it was picked up. Hence, in most cases, customers can complete their shopping without having to interact with an employee but at the same time still receive all the support necessary from technology.

\subsubsection{Enhance resource density}

Lululemon, Deutsche Telekom, and Amazon provide inspiring examples of how to enhance resource density through facilitating and encouraging co-ideation and brainstorming activities in their stores, both among customers and between employees and customers.

\subsubsection{Co-ideation and brainstorming}

Lululemon's store ambassadors are at the core of the company's activities toward enhancing resource density. Within the company's approach, store ambassadors have a dual function. At the customer level, ambassadors directly enhance resource density through connecting various actors (e.g., customers, potential customers) and their resources (i.e., knowledge, experiences) with each other. Customers benefit from this network because they not only learn about new ways of resource application from the (experienced) ambassador(s) but also directly from their peers. Then, at the company-level, Lululemon 
uses its local ambassadors to absorb condensed firsthand knowledge (insights) from within the local communities, receive "critical feedback, and collaborate on product collections" (Lululemon, 2020d) to improve their products, store design, and how the company acts within communities. The company describes this as follows: "Our ambassadors connect us to communities around the world and provide us with insightful feedback so we can innovate and grow" (Lululemon, 2020c). As a result of Lululemon's efforts toward enhancing resource density, customers benefit both immediately and in the long run.

While the intent of Lululemon's approach is - to a certain extent-"invisible" to customers because the company utilizes external personnel (i.e., store ambassadors) as intermediaries, Deutsche Telekom makes no secret of the fact that they are interested in co-ideation with the customer to enhance resource density. In 2018, the company launched its online customer think tank, "Ideas Forge." A company executive explained, "We want to offer our customers perfect service, and the best way to do so is in close, direct dialog with our customers. In the Ideas Forge, we have created a platform to facilitate this dialog" (Halle, 2019). As of March 2021, 14,058 members have worked on 186 projects, generated 4,151 ideas, and left 9,482 comments (Deutsche Telekom Service GmbH, 2021). However, the company has realized that some topics require direct and personal interaction with customers. Therefore, Deutsche Telekom "holds personal meetings [in their stores] with community members, to discuss needs and requests for shaping products and services. Community members contribute their ideas, rate suggestions from other members, or provide their opinions on suggestions and questions from Deutsche Telekom. On-site workshops held in Deutsche Telekom's own 'Werkstatt' reinforce the direct interchange with customers" (Halle, 2019).

Amazon has built entire store formats, such as Amazon 4-star, based on the highly condensed knowledge approach. Hence, customers already profit from the high degree of resource density. However, our investigation of Amazon's practices in their retail stores, especially in the Amazon 4-star stores, revealed that there is an area in which Amazon is still actively and visibly trying to enhance resource density. In contrast to Lululemon and Deutsche Telekom, which primarily sell their own products in their stores, Amazon primarily sells items from third parties. One notable exception is Amazon's growing business connected to its virtual assistant Alexa. Similar to what has been reported in various blogs (e.g., Scott, 2020), we have noticed that, especially in Amazon Books and Amazon 4-star stores, there is an increased focus on co-ideation with customers regarding possible use cases and resource applications centered around Amazon's own hardware as well as through Alexa built-in devices from other manufacturers. Customers can test devices (e.g., Echos, Shows, Kindles, tablets, etc.) and, together with an employee, figure out how Amazon's virtual assistant can support them in everyday life. 


\subsubsection{Impacting resource access and combination}

Lululemon, Deutsche Telekom, and Amazon have realized the importance of enabling their customers to gain access to potentially beneficial and sometimes even internal knowledge. Within their stores, the companies actively try to build knowledge bridges (i.e., key links between customers and the company's knowledge resources) for their customers.

\subsubsection{Knowledge bridges}

In the case of Lululemon, dedicated store ambassadors are used as knowledge bridges. Each of the 1,554 ambassadors shares his or her personal goals and stories directly within their local communities and also prominently on the company's website. Lululemon specifically highlights where (i.e., at which physical retail store) customers can meet ambassadors they are interested in. The ambassadors are a diverse group (e.g., yoga teachers, philanthropists, nutritionists, personal trainers, musicians, etc.) and therefore cover a very broad interest spectrum. These individuals are a type of external employee of Lululemon. They are included in company-internal processes (e.g., product improvement/development) and therefore are closer to the company than regular customers. Customers benefit from this approach by accessing knowledge through selected ambassadors who align with their interests and who can not only supply purified and condensed information but also share potentially beneficial and sometimes even internal knowledge. For instance, someone interested in buying new training equipment from Lululemon could meet up with an ambassador (e.g., a personal trainer) in the store and discuss which products are best suited for the intended usage scenario. The ambassador can provide advice based on a combination of personal experience and insider knowledge (e.g., upcoming products, current promotions).

Deutsche Telekom has a different approach toward ensuring that customers have access to necessary resources and are aware of beneficial resource combinations. Store visits (to shops with their latest store concept) revealed that Deutsche Telekom addresses this issue with a two-step sales and service process. In the first step, (interested) customers receive comprehensive product consultations and demonstrations by experienced salespeople with the goal of closing a sale. This consultation can include the entire product range of fixednetwork or broadband, mobile communications, Internet, and Internet Protocol Television products. Once customers have chosen and bought a product (signed a contract), they are led to the so-called "service bar." This service bar represents Deutsche Telekom's knowledge bridge. In this second step, customers receive in-depth consultation, advice, and service with regard to their purchased products. Customers can even ask highly specific questions because the service bar is additionally staffed with service professionals and technicians. Customers have direct access to the know-how of experts, receive valuable tips, and benefit from the company's internal knowledge.

Amazon, in contrast, simply transferred its online approach into its stores. Amazon's 4-star and book stores are prime examples of this approach. Online, Amazon primarily ensures that customers have access to the necessary resources and are aware of beneficial 
resource combinations through its recommendation algorithms (e.g., also bought, frequently bought together). Within their 4-star and book retail stores, Amazon makes this information transparent to customers as well. Furthermore, the company shares insights such as "most wished for" or "most-registered" on Amazon.com. These categories directly connect customers to the company's knowledge and make resource combinations of other customers directly visible. This makes shopping at Amazon's physical retail locations at least as efficient as the online customer journey.

\subsubsection{Generating shared value systems}

Lululemon, Deutsche Telekom and Amazon design coherent in-store experiences (i.e., physical manifestation of their company vision) to reinforce and generate shared value systems represented through shared norms, languages, and/or symbols.

\subsubsection{Coherent experiences}

According to Lululemon's CEO, the company strives to be "the experiential brand that ignites a community of people living the sweatlife through sweat, grow and connect" (Lululemon, 2020b). Hence, Lululemon's stores are designed as "community hub[s] where people [can] learn and discuss the physical aspects of healthy living, mindfulness and living a life of possibility" (Lululemon, 2016). The effectiveness of their approach is evidenced by the established shared language between FLEs and customers, which is frequently spoken and understood in both the offline and online worlds. This language mainly consists of different abbreviations for famous products (e.g., TaTaTanner, WunderUnder, CoolRacerBack), for discounted excess inventory (WeMadeTooMuch), and for certain fits (e.g., WearWithAll, TrueToSize) but also describes company personnel (e.g., Lulu Angels) or specific Lululemon locations (e.g., Lulu Lab) (Maheshwari, 2013). The activities, offerings, and the way Lululemon's physical stores are used lead to a high degree of affiliation by the customer, thereby shielding Lululemon's customers from the competition.

Deutsche Telekom's vision is no less ambitious. The company has the aspiration to become the leading European telecommunications company by "[I]eading in customer experience, leading in technology, and leading in business productivity" (Deutsche Telekom AG, 2021). The new store concept Magenta Shop 2020, which has currently been rolled out throughout Germany, expands the role of Telekom Shops from a point of sale to a point of experience, where B2B and BC2 customers are inspired by the showcased possibilities of digitalization, futuristic use cases, and live demonstrations and events (Invidis Redaktion, 2021). Furthermore, within the new store format, the floors and the ceilings are mainly gray colored, which further highlights the prominent use of the company color magenta (Invidis Redaktion, 2021), which has become synonymous with the company internationally (Bresgen, 2019a). As evidenced by the successful rebranding and redesign of the "T-Mobile" shops in Austria into "Magenta" stores, which led to skyrocketing brand preference, favorable consumer assessment of the network (speed) as well as the price-performance 
ratio (Deutsche Telekom, 2020), magenta has become an embodiment of the company's vision and a shared symbol recognized worldwide for customer experience and technology leadership.

Each of Amazon's store formats is a direct reflection of Amazon's ultimate goal "to be Earth's most customer centric company" (About Amazon Staff, 2018). Amazon is famous for its working backward approach (i.e., start with the customer and work backward from the ideal customer end state). This method is also applied to Amazon's brick-and-mortar stores (Kromer, 2020). Basically, everything Amazon invents (e.g., cashierless stores, dash carts, Amazon One, etc.) is designed to satisfy customers and make their lives easier. While Amazon obsesses over its customers, Amazon customers are used to being obsessed about. This shared mental model is amplified by the customer experience in Amazon's physical retail stores. For instance, customers at Amazon books or Amazon 4-star can return products purchased on Amazon.com (Green, 2019). Customers purchasing additional Amazon smart devices (e.g., Echo, Show etc.) at an Amazon 4-star store do not have to worry about how to include new devices into their existing ecosystems because Amazon employees can advise them on such matters at the checkout counter (Scott, 2020). Amazon customers can simply walk into Amazon Go stores, select what they want, and walk out while the purchase is conveniently charged to the customer's Amazon account. These experiences strengthen the relationship between Amazon and its customers such that it is robust against competitors' offerings.

\subsubsection{Shaping, reshaping, and encouraging or constraining the ecosystem's structure}

Lululemon, Deutsche Telekom and Amazon use coordinated personnel planning to ensure customers' accessibility to subject matter experts at all times, in turn to shape and encourage the ecosystem's structure in a desirable way.

\subsubsection{Accessibility}

Even before the temporary shutdown, Lululemon offered personal and gift-shopping experiences for those customers interested in "a more in-depth shopping experience" (Lululemon, 2020a). During the pandemic, this offering was temporarily altered to video chat (e.g., Facetime, Zoom) appointments. Additionally, customers always have "direct" access to store ambassadors. Ambassadors' profiles on the individual store websites feature their contact info (e.g., Instagram and personal websites). These offerings allow Lululemon to preplan (coordinate) some of the customer requests and consequently reduce challenges for "regular" in-store personnel. In this way, Lululemon ensures customers' accessibility to subject matter experts at all times.

Similar to Lululemon, Deutsche Telekom has offered scheduled personal appointments in their stores for some time. The company primarily offers two services: customers in need of technical support can book "technical service" appointments with specially trained employees, and customers with an interest in general assistance and have questions 
about products and/or accessories can book a "consulting/sales" appointment (Telekom Deutschland $\mathrm{GmbH}, 2019$ a). Furthermore, through the integration of a service bar with specially trained employees into the new store format, Deutsche Telekom ensures that experts are always at the customers' disposal.

In contrast to Lululemon and Deutsch Telekom, Amazon does not offer appointments for any of its store formats. Nevertheless, based on descriptions in different blogs and vlogs, as well as our own store visits, there seems to be no problem in customers having immediate access to subject matter experts. From our point of view, there are three reasons for this: First, Amazon stores in general, and most of the products sold, are self-explanatory, which itself reduces the total number of requests. Second, Amazon seems to have identified those parts of the customer journey where their physical retail store customers need the most assistance (i.e., at the beginning of the shopping experience) and strategically position extra personnel to help customers get started (e.g., scan the app, scan the palm, use a dash cart). Third, we have noted that Amazon 4-star and Amazon bookstores, in particular, are extremely well staffed. This assessment is in line with what customers have reported: "I never got a final count on how many employees were running the store [...], it reminded me of Apple stores, where you feel like you're running into an employee every 10 seconds or so" (Scott, 2020).

\subsection{DISCUSSION AND IMPLICATIONS}

Against the background of the ongoing retail apocalypse, this study investigated the question of how Lululemon, Deutsche Telekom, and Amazon are achieving retail sales ecosystem well-being and whether their approach can be transferred to other businesses. By studying a native brick-and-mortar retailer that expands its physical retail spaces but also explores opportunities in the online world, a service provider invested in multiple sales channels and a native online retailer expanding offline, this study aimed to present a collection of best practices from different industries and to provide actionable insights to broaden the minds of managers from all industries and enable both intra-industry and inter-industry learning.

Our analysis revealed that within their retail stores, these companies rely on three different levers to achieve sales ecosystem well-being by successfully addressing the needs and wants of the modern customer. Those levers are employee mindset (i.e., self-conception, customer-centricity), resource delivery (i.e., customization, third parties, knowledge bridges, subject matter experts, coherent experience, accessibility), and customer empowerment (i.e., help customers help themselves, co-ideation/brainstorming).

Employee mindset: Frontline employees' role in the retail environment is considerable. In a modern world in which customers are more educated, better informed, and have more bargaining power than ever due to highly comparable products, the FLE makes the difference. However, to be successful, FLE's self-conception must evolve with changing customer requirements. FLEs need to focus on connecting, interacting with, and educating 
customers instead of closing sales at any cost. Companies can actively support this mindset by changing job descriptions and titles and abandoning sales-based compensation models. It is of the utmost importance that FLEs prioritize the needs and wants of their customers (customer-centricity) over their own. FLEs must build mutually beneficial (i.e., personal, authentic, and meaningful) relationships with their customers, which includes anticipating customers' potential issues and proactively solving them before they are voiced. The balance of power has shifted toward customers, and they are aware of it; hence, it is in every company's interest to determine how they can best support their customers in the joint value cocreation process.

Resource delivery: The analysis revealed the importance of customized knowledge transfer. Customers want to be treated as individuals and, as such, they require customization based on their individual information needs in terms of both content and the presentation of that content. The companies provided examples of successful in-person CKT (e.g., events, workshops, seminars) and technology-based CKT (e.g., recommendation algorithm). Companies should engage in carefully coordinated personnel planning (e.g., offer scheduled personal appointments, display personal contact information) to ensure customers' immediate access to both internal and external subject matter experts at all times. Furthermore, companies are advised to create knowledge bridges in the form of dedicated internal and external personnel and/or in-store processes to enable their customers to gain access to potentially beneficial, sometimes even internal, knowledge. The analysis has provided evidence that the conveyer of the message is more important than the message itself. Therefore, companies can utilize the credibility of company-external personnel (e.g., ambassadors, influencers) to harness the power of target communities and generate new relationships with and between both existing and potential customers of their stores. Furthermore, the analysis revealed that companies can build deeper relationships with customers (i.e., shared norms, languages, and/or symbols) that increase the resistance against competitive threats by designing in-store experiences as physical manifestations of their vision.

Customer empowerment: At first glance, helping customers help themselves further shifts power toward the customer, which might be considered counterproductive. However, as evidenced by the examples presented, there are certain upsides to this approach. Companies can use this tool to decrease their costs by "outsourcing" requests that are time consuming and/or do not result in additional revenue from the customer, which in turn gives employees the ability to dedicate more time to potentially profitable customers. The three retailers provided inspiring examples on how to utilize and profit from the firsthand knowledge of their customers. Retailers should always keep in mind that the more customers are integrated into shaping the value proposition, the more likely it is that the product or service fits the customers' needs. 


\subsection{CONCLUSION}

The purpose of this study was to identify how Lululemon, Deutsche Telekom, and Amazon achieve retail sales ecosystem well-being and to determine whether their approaches can be transferred to other businesses. After analyzing their best practices, we have identified three levers that, in our opinion, can effectively be transferred to other industries: employee mindset, resource delivery, and customer empowerment. Admittedly, replicating the success of the three companies by implementing new practices takes time, money, and dedicated management. Therefore, it is probably not feasible to implement all practices at once. However, because the practices are interdependent, companies could profit from implementing one practice, in several areas.

\subsection{LIMITATIONS AND FUTURE RESEARCH OPPORTUNITIES}

This study used a case study approach to investigate the practices of Lululemon, Deutsche Telekom and Amazon. This first qualitative approach toward the subject led to the identification of three levers used (by the companies) to achieve sales ecosystem well-being. However, we want to point out two opportunities for future research.

First, while we used many different data sources as possible, in order to triangulate the data to the best of our ability, there still is a significant influence of information released and published by the companies themselves on the presented findings. This information is not necessarily biased, but there is a possibility that such self-presentation is less objective than third-party reports, especially in cases of publicly traded companies. Therefore, future research is invited to validate that the information released by the companies is actually accurate and not overstated. Adding an additional layer of "internal" information, for example, interviewing company representatives may prove insightful. In hindsight, the application of consortium benchmarking, as suggested by Schiele and Krummaker (2011), could have resulted in a broader academic foundation of the research question, as well as increased exactness and robustness of the findings.

Second, while this study investigated three companies from different industries and with different business models, the generalizability of the findings can only be suspected. Future research is necessary to validate the findings for other retailers. 
Chapter 6

SYNOPSIS 


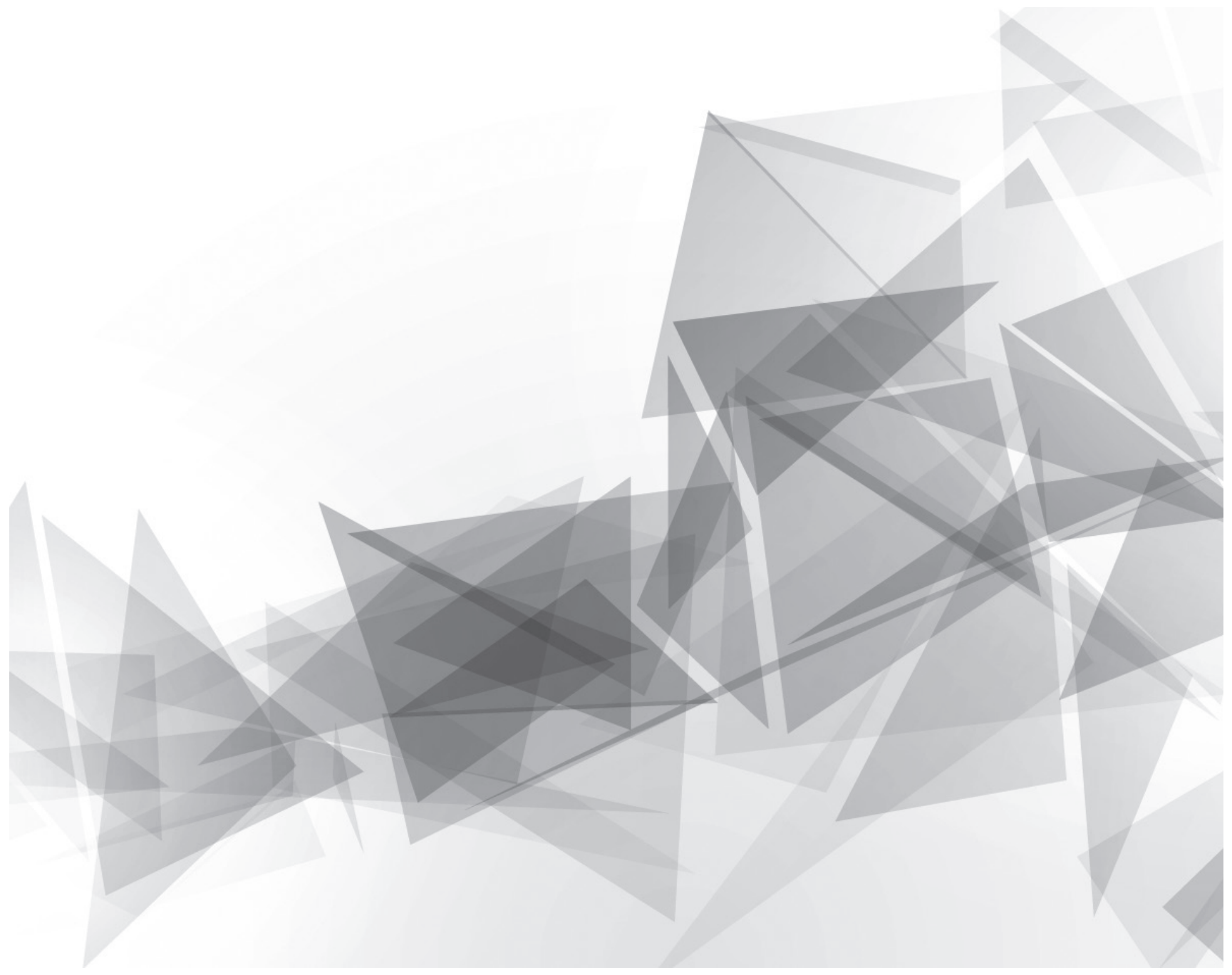




\subsection{INTRODUCTION}

This research project investigated value co-creation in multi-actor ecosystems. Against the background of the formation of the service ecosystem perspective, which "increases the range of activities and the number of actors considered to be involved in selling [and at the same time] expands the view from dyadic exchange to broader value creation practices influenced by institutional arrangements and institutionalization processes" (Hartmann et al., 2018, p. 2), the main goal of this dissertation was to answer two main research questions:

$\mathrm{RQ}_{1}$ : What characterizes selling actors and their behavior in multi-actor ecosystems?

$\mathrm{RQ}_{2}: \quad$ How can these actors and their behavior be influenced?

This dissertation approached this task by breaking down the central research questions into sub-questions, directing four research projects. Each research project focused on partial aspects necessary to answer the two questions. The following Section 6.2 merges the individual findings and thereby addresses the two main research questions.

\subsection{DISCUSSION}

Finding answers to the question(s) of what characterizes selling actors and their behavior in multi-actor ecosystems and how these actors and their behavior can be influenced was the primary goal of this PhD thesis, giving rise to the conducted research. The following sections present the findings of the individual chapters which, when viewed in isolation, answer the four sub-questions presented in Section 1.2. However, considering these puzzle parts together answers the two primary research questions.

\subsubsection{CHAPTER 2: SELLING ACTORS IN MULTI-ACTOR SALES ECOSYSTEMS}

In the context of this dissertation, the main goal of Chapter 2 was to investigate who salespeople's ecosystem partners are, what their characteristics and expectations are, and what tasks they perform and how they perform them.

Based on a World Café with 32 participants, selling actors' identities and participation behavior in a multi-actor sales ecosystem were investigated from the salesperson's perspective. This exploratory research revealed that the perceived participation behavior in fact differs depending on the actor's selling type and identity with whom the salespeople interacted. The findings show that salespeople assign different meanings and characteristics to eight selling actor identities, based on the perceived participation behavior of these actors. The "avoider" is suspected to be a former customer who is currently lost to the competition and therefore is neither interested in a relationship with the salespeople or company nor in the offered products and services. The "observer" is also a former customer who has had a prior relationship with the company. This actor is afraid of being talked to but also curious and interested in the offerings and displays signs of information-seeking behavior. The "receptive" actor is both unsatisfied with his current representation and open to a new 
service provider. This actor is actively searching for personal interaction and approaches salespeople proactively. The "prepper" has had no personal experience with the company but is currently an unsatisfied (former) customer of the competition. The prepper engages in personal interaction with salespeople proactively, is highly prepared, trusts salespeople, and reveals any information necessary. The "expecter" has had first experiences with the company, and the salespersons exceeded his or her expectations, which makes him or her receptive to offerings. However, he or she is cautious and insecure and expects to be approached proactively by a salesperson. The "savvy" actor is already a short-term customer of the company and has expert-level knowledge and high expectations of salespeople, which makes him or her a demanding and challenging interlocutor. The "challenger" has a long relationship with the company and understands his strong negotiation position. The challenger is willing to pressure salespeople in order to obtain what he or she wants. The "coworker" is also a long-term customer. However, in contrast to the challenger, he or she shares a certain intimacy and casual conversations with the salespeople and even acts as an advocate for the company. Subsequently, these findings (for a multi-actor sales ecosystem) were related to the findings (for dyadic interactions) of Swan et al. (2001) and converted in a salesperson-selling actor relationship/behavior typology. While the research was able to validate the authors' identification of the coworker and the expecter (also known as "business acquaintance") identities, it was unable to identify the identity referred to as "commercial friends." The fact that six additional identities were identified confirms the decision to investigate the identities of actors beyond the traditional customer-salesperson dyad. The developed salesperson-selling actor relationship/behavior typology addresses the first primary research question.

\subsubsection{CHAPTER 3: EXPERIENTIAL VALUE IN MULTI-ACTOR SERVICE ECOSYSTEMS}

The research presented in Chapter 3 contributes to the "value co-creation in multiactor ecosystem" puzzle by answering the question of which elements of multi-actor service ecosystems contribute to a customer's experiential value and whether and how they can be used to encourage customers' citizenship behavior, specifically, inter-customer helping behavior.

A quantitative study was conducted and scale development (i.e., exploratory, and confirmatory factor analysis) was followed by structural equation modeling. Based on the results of the confirmatory factor analysis $(n=468)$, experiential value in multi-actor ecosystems comprises five dimensions: The functional value of personnel (professionalism), the perception of other customers' appearance (similarity), the perception of other customers' behavior (suitable behavior), multisensory stimuli (sensory appeal), and a customer's enjoyment (playfulness). Hence, the personal interaction between customers and employees and interactions among customers in multi-actor service ecosystems account for three out of five relevant experiential value dimensions. Furthermore, the analysis confirmed that multi-actor ecosystems are in fact multisensory and that the sensory appeal 
is formed by olfactory, acoustic, haptic, and visual stimuli. The developed experiential value scale for multi-actor service ecosystem (EX-MAS) represents the first holistic approach that simultaneously accounts for a customer's interactions with the multisensory physical environment, personal interactions with employees, and interactions between customers in a multi-actor service ecosystem. The subsequent structural equation modeling revealed that experiential value positively and directly relates to a customer's interaction attitude and inter-customer helping behavior. Furthermore, experiential value indirectly relates to intercustomer helping behavior, mediated by interaction attitude. These findings strengthen the importance of correctly identifying and influencing experiential value in multi-actor ecosystems. As this represents a viable approach toward influencing selling actors' intercustomer helping behavior, it is also one possible answer to the second primary research question.

\subsubsection{CHAPTER 4: INFORMATION MANAGEMENT CAN'T BE ALL FUN AND GAMES}

Within the context of this thesis, the paper presented in Chapter 4 answers the question of whether and how gamified experiences can be used to encourage customers' participation behavior, or rather, their information exchange behavior, in a multi-actor service ecosystem.

A quantitative research approach, structural equation modeling, was used to assess the dynamic relationships and provide a scalable measurement instrument that can be applied to gamified experiences ranging from simple customer-interface interactions, all the way up to multi-actor service ecosystems. The presented study was the first to investigate attitude as a predecessor of the effects of gamification. The findings support the notion that gamification can be used to foster information exchange and thereby value co-creation between customers and employees directly, without necessarily having to change customers' attitudes first. Hence, it also represents a possible answer to the second primary research question. The findings also suggest that gamification can be applied successfully in cases of large groups of people with widely varying characteristics, backgrounds, and motivations, which is particularly useful in the context of multi-actor ecosystems. Furthermore, the research indicates that experiential value (and the EX-MAS) is a suitable candidate for a consistent measurement instrument for gamification.

\subsubsection{CHAPTER 5: PUTTING THE RETAIL APOCALYPSE OUT OF BUSINESS}

The research presented in Chapter 5 delivers the last piece of the "value co-creation in multi-actor ecosystem" puzzle by investigating how exactly companies achieve ecosystem well-being and whether and how it can be transferred to other businesses.

Based on the (qualitative) case study research of a native brick-and-mortar retailer (Lululemon), a service provider (Deutsche Telekom), and a native online retailer expanding offline (Amazon), their best practices and the three key levers used to achieve sales ecosystem well-being-by successfully addressing the needs and desires of modern customers-were identified. The levers are employees' mindset (i.e., self-conception 
and customer-centricity), resource delivery (i.e., customization, third parties, knowledge bridges, subject matter experts, coherent experience, and accessibility), and customer empowerment (i.e., helping customers help themselves and co-ideation/brainstorming). The analysis of the best practices indicates that it is certainly possible to transfer them to other industries; however, replicating the success of the three companies by implementing new practices takes time, money, and dedicated management. In the context of the second primary research question, the three levers can be interpreted as a (pragmatic) practitioners' approach toward influencing selling actors' behavior.

\subsection{IMPLICATIONS}

This thesis was concerned with value co-creation in multi-actor ecosystems. The following two sections contain a condensed overview of the implications for researchers and practitioners, based on the key-findings of the individual research projects, as presented in Chapters 2 to 5.

\subsubsection{IMPLICATIONS FOR RESEARCHERS}

In Section 1.2, it was acknowledged that the formation of the service ecosystem perspective "increases the range of activities and the number of actors considered to be involved in selling" (Hartmann et al., 2018, p. 2). Based on the thorough analysis of the World Café discussions (Chapter 2), this statement can be confirmed. The fact that the study uncovered six additional identities in multi-actor ecosystems, beyond those of Swan et al. (2001) for dyadic interactions highlights the importance of looking beyond the dyad and taking a more holistic perspective. The participants in the study revealed how they perceive and define the identity of a selling actor and how the identity determines how they interact with and adapt to these selling actors. Consequently, it is of utmost importance for research on selling actor-salesperson topics (e.g., behavior, performance, relationship) to be as precise as possible in the description of the types of selling actors and their identities. When sales literature fails to specify these, then the results and findings of a study are neither verifiable nor comparable. For example, two studies on salesperson performance in an identical scenario can show fundamentally different results if, in one case, the salespeople mainly deal with the avoider, observer or receptive actor identities and in the other case, there are primarily prepper, expecter and/or coworker identities; meanwhile the study only refers to customers/selling actors.

Furthermore, the investigation into whether and how these actors and their behavior can be influenced led to the development of the proposed EX-MAS scale, which demonstrates that experiential value in multi-actor ecosystems is based on the functional value of personnel (professionalism), perception of other customers' appearance (similarity), perception of other customers' behavior (suitable behavior), multisensory stimuli (sensory appeal), and visitors' enjoyment (playfulness). While these findings provide empirical validation for some of the findings of other researchers (e.g., Mathwick et al., 2001; Sánchez et al., 2006; 
Varshneya \& Das, 2017; Wiedmann et al., 2018), they also underline the importance of considering customers' interaction with the multisensory physical environment-as well as personal interaction with employees and between customers (simultaneously)-as sources of experiential value, in cases of multi-actor ecosystems. Considering that the concept of experiential value is (frequently) used (e.g., as an antecedent), without recognition that depending on the context (e.g., in a multi-actor ecosystem), additional influences on the experiential value might also exist, researchers can greatly benefit from a holistic scale.

The identified relationships between experiential value, interaction attitude and intercustomer helping behavior (Chapter 3 ) and between experiential value, knowledge sharing attitude, and information exchange behavior (Chapter 4 ) provide evidence that the VAB model also applies to multi-actor ecosystems. This finding can be useful to researchers trying to understand and explain selling actors' behaviors in multi-actor ecosystems but also to gamification researchers, as it provides a possible approach toward unlocking more of the mechanics of successful gamification applications.

Last but not least, the finding that practitioners (independently from research) have identified three key levers to achieve ecosystem well-being (Chapter 5) should inspire researchers to think outside the box and be open to ideas that are not scientifically explored (yet) but simply work. This speaks to the importance of accepting the fact that (scientific) research can be weak where applied-that is, designed-practice is strong and vice versa, but both disciplines should not be regarded as competing against, as opposed to being complementary to, each other (Henseler \& Guerreiro, 2020).

\subsubsection{IMPLICATIONS FOR PRACTITIONERS}

Likewise, the findings of the conducted research have several implications for managers; for example, the CEOs introduced in Section 1.1 and/or others with a similar mindset and a focus on creating value for their customers. The results of the first exploratory study (Chapter 2) reveal that the displayed participation behavior by the selling actors varies widely depending on identity. The salesperson-selling actor relationship/behavior typology and the firsthand experiences reported by participants of the World Café will be useful to companies for two reasons. First, the examples of cues to look for when interacting with selling actors enable salespeople to identify them faster. Second, salespeople can use the knowledge about selling actors' expectations and behaviors regarding the sales process in order to prepare fitting approaches for all selling actor identities. Accordingly, management must invest in training and coaching activities. Furthermore, managers must recognize that there are considerable differences between selling actors and that salesperson performance management must take that into account.

Chapter 3 presented evidence that the personal interaction between customers and employees and interactions among customers in multi-actor service ecosystems account for three out of five relevant experiential value dimensions. Managers may use this finding and invest in proper coaching and training activities for employees with direct customer 
contact, who might not have the necessary skills and knowledge required nor be aware of their importance. Furthermore, the findings suggest that perceptions of other customers' appearance and behavior impact customers' experiential value. Managers need to be aware of and accept the fact that there are drivers of experiential value outside of their direct sphere of influence. Considering that multi-actor service ecosystems are multisensory (i.e., sensory appeal is formed by olfactory, acoustic, haptic, and visual stimuli) managers must consciously weigh increased experiential value-through optimized multisensory appealagainst high investments with an uncertain return on investment. Furthermore, the analysis points to the importance of playfulness for the EX-MAS. Managers must weigh providing a fun and exciting experience against their own goals with regard to the messages they want to convey. Second, depending on the product or service, customers might expect different levels of playfulness. This is challenging because in most cases, multiple products or services are displayed simultaneously. Because the possibility of presenting products or services in a certain way is limited, due to limited budgets or availability of physical space, managers are likely to have to prioritize some products or services over others. Furthermore, the analysis supported the hypotheses that experiential value relates to customers' interaction attitude and inter-customer helping behavior. The direct relation on interaction attitude is relevant for several reasons. Managers can use this information to increase the number of interactions between customers and employees. This adds potential for customer acquisition but also the potential to increase revenue from existing customers (e.g., cross-selling, up-selling). Furthermore, companies can utilize customers' direct feedback for product improvement and new product development. Knowledge about the positive influence of experiential value on inter-customer helping behavior is also highly relevant to companies. Managers considering a reduction of service personnel can attempt to utilize customers as "pseudo employees" to compensate for such downsizing.

Chapter 4 presented evidence that the experiential value of a gamified experience positively influences both the customers' information-sharing and information-seeking behaviors. This direct influence on customers' information exchange behavior will be particularly interesting to managers, as the findings support the notion that gamification may be used to foster information exchange and value co-creation between customers and employees directly, without necessarily having to change customers' attitudes first. This probably will result in gamification becoming even more attractive to managers as it presents itself as an easy way to influence such an important customer behavior. However, such expectations need to be tempered somewhat as the investigation also revealed that customers' knowledge sharing attitudes precede information-sharing behavior. Additionally, knowledge sharing attitude mediates the relationship between experiential value and information-sharing behavior. Hence, managers must be aware that there also is a significant indirect effect on information-sharing behavior to be considered.

Furthermore, the findings suggest that gamification can be applied in cases of large groups of people with widely varying characteristics, backgrounds, and motivations. 
Applying the experiential value scale for multi-actor service ecosystems revealed that in such a case, a customer's perception of the other actors of the ecosystem (employees and other customers) has a significant influence on the overall experiential value of the gamified experience. This is of high importance to management. In cases of gamification deployed in the virtual world (e.g., websites or apps), other actors largely stay anonymous. However, in real-world multi-actor service ecosystems, all participants, their behaviors, and their characteristics are directly visible to other participating actors. Therefore, actors within this environment will influence one another's perceptions and impact the potential customer experiential value. Managers need to be made aware of this important difference between gamification in the virtual world and in multi-actor service ecosystems before executing any gamification strategies.

Chapter 5 analyzed the best practices of three successful retailers and identified three levers-namely, employee mindset, resource delivery, and customer empowerment-that can effectively be transferred to other businesses and industries. Admittedly, replicating the success of the three companies by implementing new practices takes time, money, and dedicated management. Therefore, it is probably not feasible to implement all practices at once. However, because the practices are interdependent, companies could profit from implementing one practice in several areas.

\subsection{LIMITATIONS AND FUTURE RESEARCH OPPORTUNITIES}

The findings presented in this thesis add to the (very) limited understanding of value cocreation in multi-actor ecosystems. Two primary research questions and, four sub-questions were addressed, and subsequently answered. The sub-questions can also be interpreted as statements of what is within the scope of the research, specifically, where the boundaries lie. While Chapters 2 to 5 also contain the specific limitations of the individual research (papers) they present, this section is concerned with some limitations of this thesis as a whole. In particular, future research is invited to take the following three opportunities:

First, the exploration of selling actor identities and their behavior (Chapter 2), the investigation into which elements of multi-actor service ecosystems contribute to a customer's experiential value (Chapter 3), and whether and how they can be used to encourage customers' behavior (Chapters 3 and 4) were based on data gathered at the IFA 2017 and IFA 2018, respectively. Therefore, the findings presented in this thesis are (to a large extent) based on the investigation of multi-actor ecosystems in the information and communications technology (ICT) industry. Consequently, it would be valuable to validate the findings (e.g., selling actor types, EX-MAS scale) in other settings and industries.

Second, the investigation into the relationship between experiential value and intercustomer helping behavior (Chapter 3) and customers' information exchange behavior (Chapter 4), laid the foundation for the applicability of the VAB model in the context of customers' value co-creation behavior in multi-actor ecosystems. However, the research presented in Chapter 3 only focused on one out of the four components of customer 
citizenship behavior and Chapter 4 focused on two out of the four components of customer participation behavior. In a future step, research could include both dimensions (with all their components) into their research.

Finally, it must be said that it was a conscious decision to use a multitude of different qualitative (Chapter 5), quantitative (Chapters 3 and 4), and mixed methods (Chapter 2) to obtain the data that led to the presented findings. However, the decision to benefit from the strengths of a certain method always comes with the acceptance of its respective weaknesses. Future research is invited to challenge the presented findings with the help of other research approaches than the ones used in the respective papers in order to ensure that the findings remain the same, no matter the method.

\subsection{FINAL THOUGHTS}

This thesis strived to bring a little light into the darkness - that is, value co-creation in multi-actor ecosystems-by asking and addressing two important questions. Interestingly, the research process not only revealed answers but also uncovered (additional) questions worth asking. While this was unsettling at first, upon reflection I realized that while this thesis has come to an end, the (necessary) research on the topic has only just begun.

One goal of this thesis was to inspire academics and practitioners alike to interpret, transfer, and make use of the presented findings in their individual contexts. If, in doing so, you yourself now have uncovered the questions relevant to your research or management practice, the thesis successfully stimulated your mind into doing its own thinking, that is all I hoped for in the first place. 
A

APPENDIX 


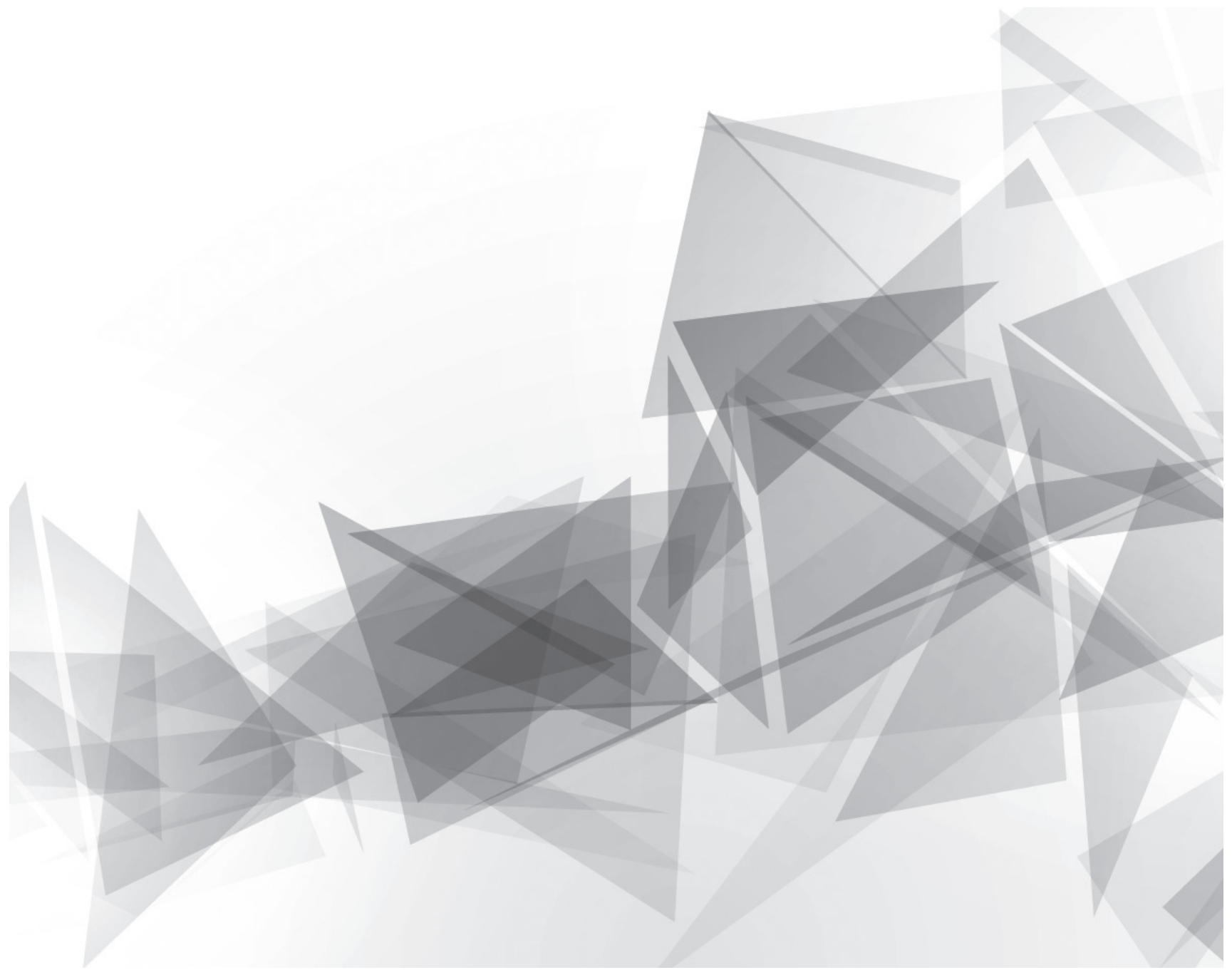




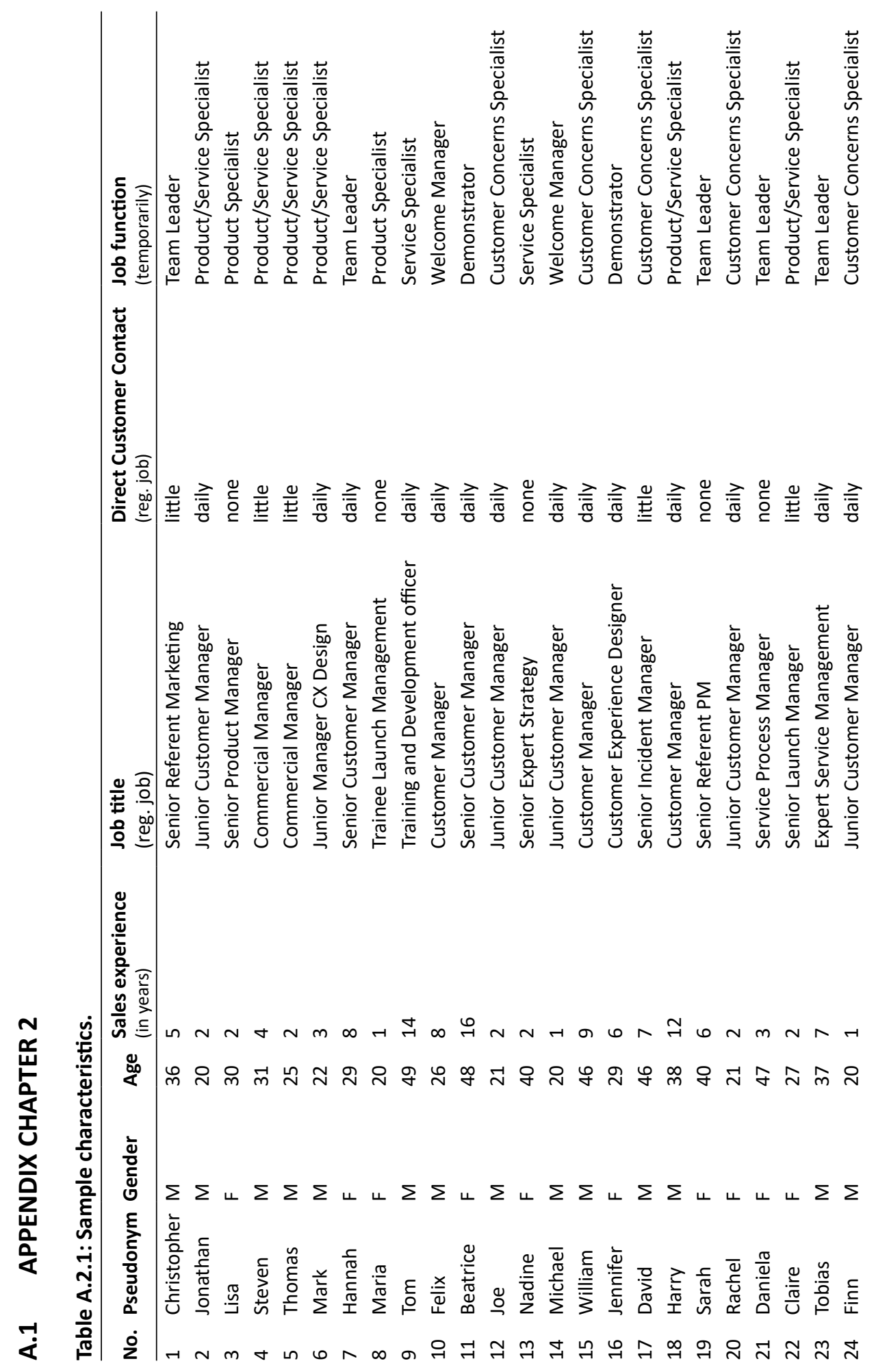




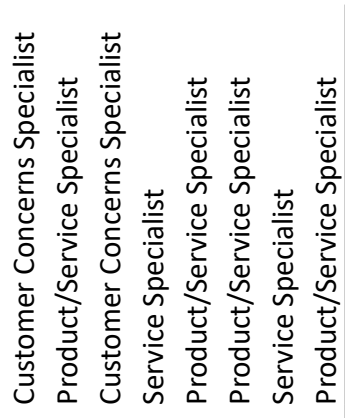

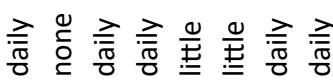

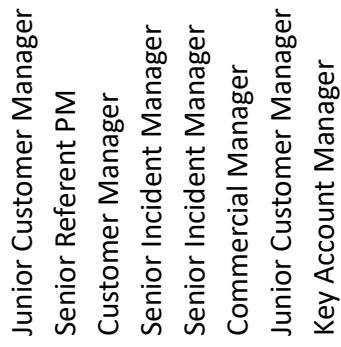

$m \rightarrow \underset{4}{a}$ 우 $n$

$\vec{\sim} \stackrel{\sim}{m}$ 웜

$\sum \sqcup \sqcup \Sigma \sqcup \Sigma \sqcup \Sigma$

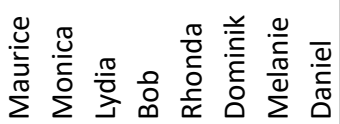

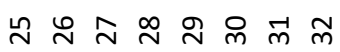




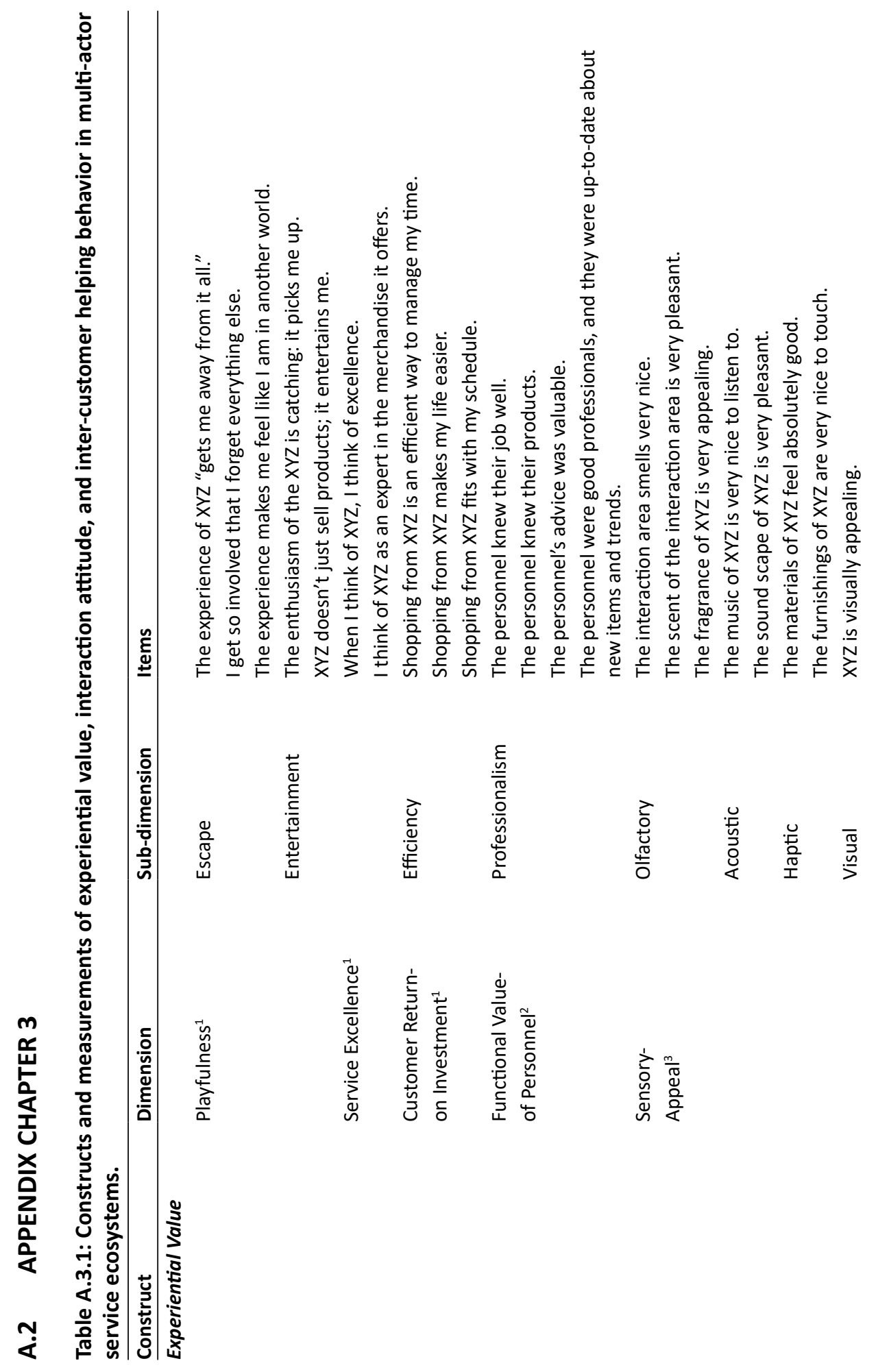




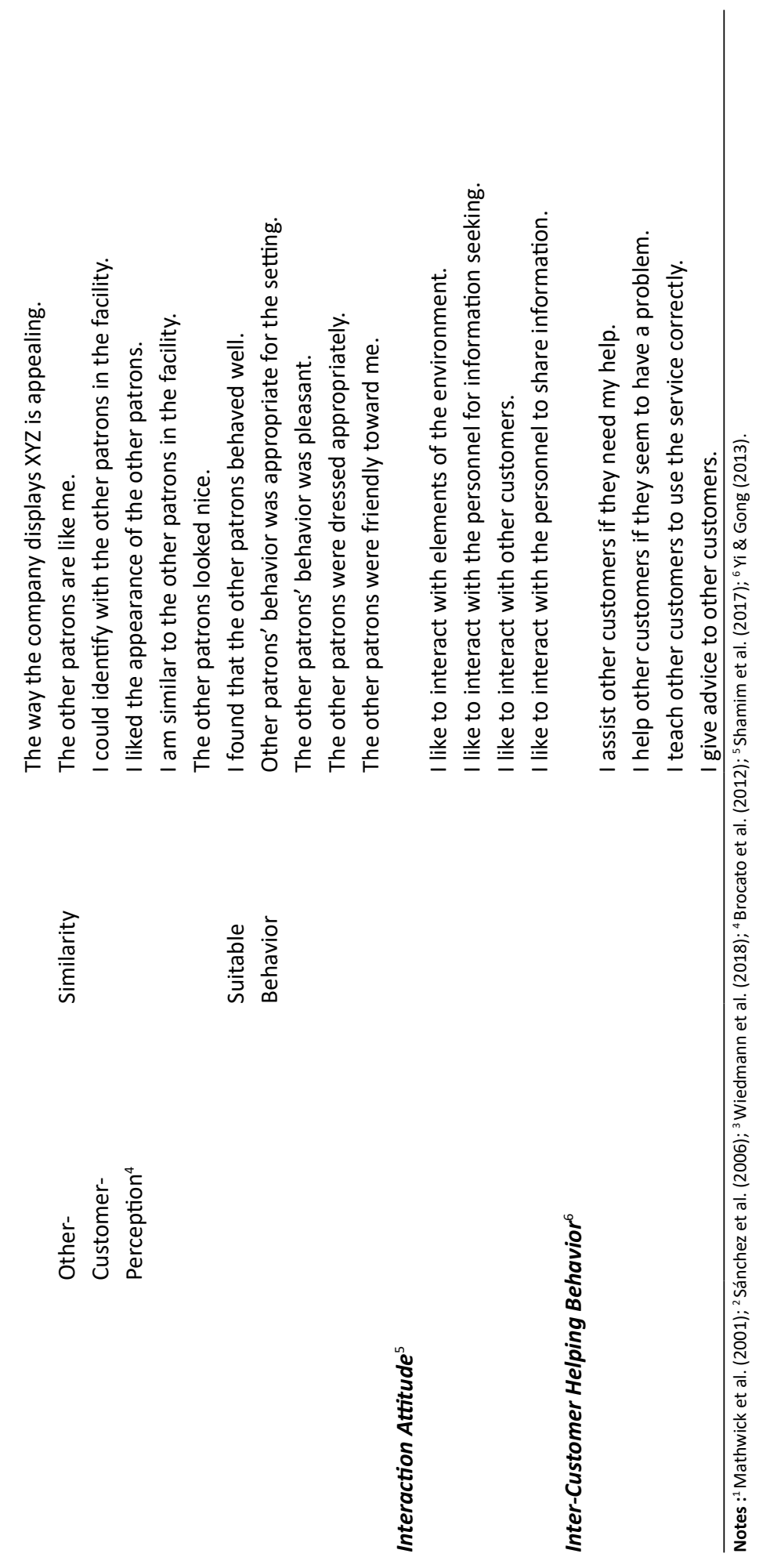




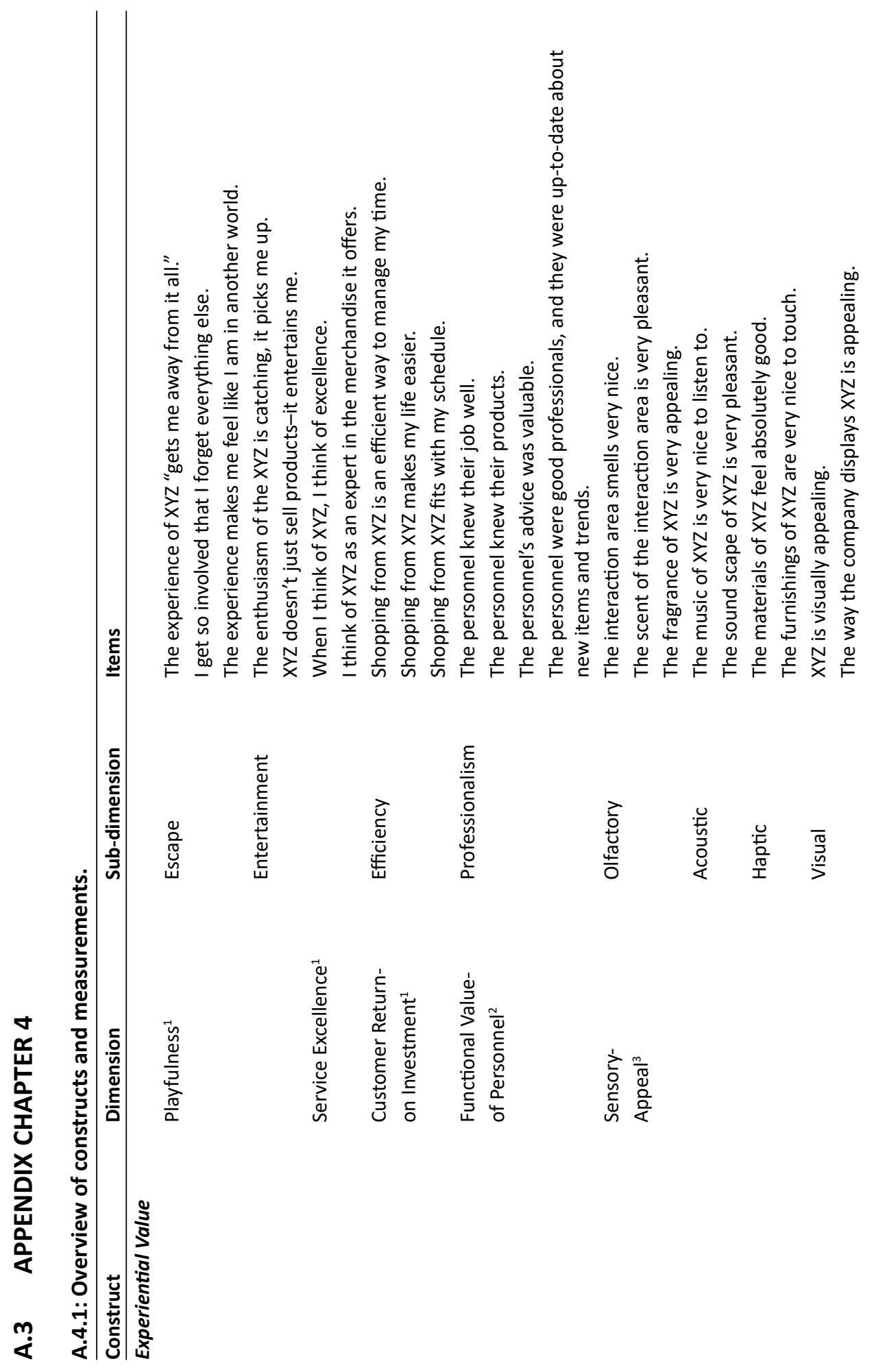



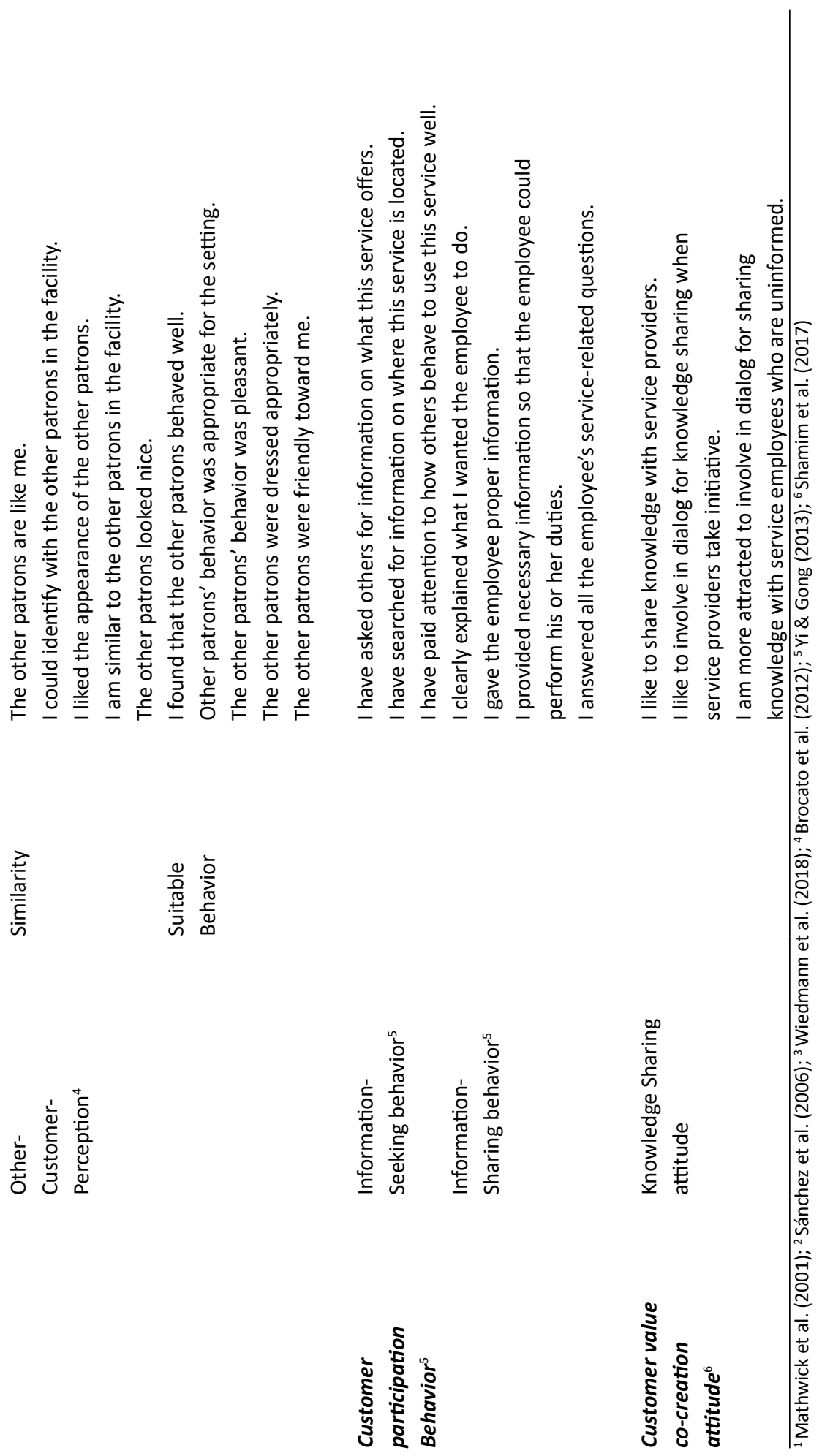
Bibliography 


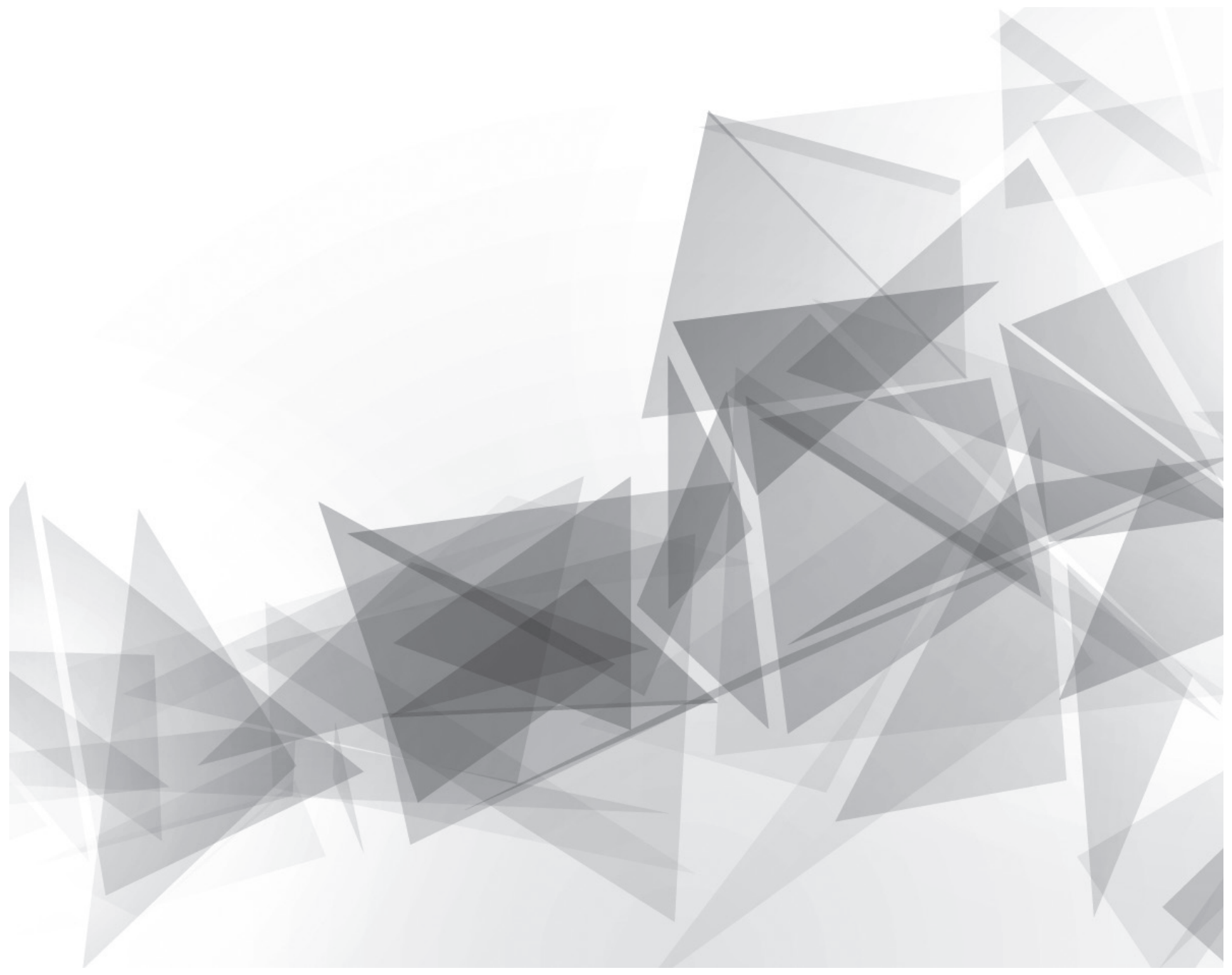


About Amazon Staff. (2018, April 18). Our mission. UK About Amazon. https://www.aboutamazon. co.uk/uk-investment/our-mission

Ajzen, I. (1991). The theory of planned behavior. Organizational Behavior and Human Decision Processes, 50(2), 179-211. https://doi.org/10.1016/0749-5978(91)90020-T

Alexander, M. J., Jaakkola, E., \& Hollebeek, L. D. (2018). Zooming out: actor engagement beyond the dyadic. Journal of Service Management, 29(3), 333-351. https://doi.org/10.1108/JOSM-08-20160237

Amazon. (2020, November 30). Physical Retail. About Amazon. https://www.aboutamazon.com/whatwe-do/physical-retail

Amazon. (2021a, May 14). amazon 4-star. Amazon. https://www.amazon.com/amazon-4-star/ b/?node $=17988552011$

Amazon. (2021b, May 14). amazon books. Amazon. https://www.amazon.com/amazon-books/ b?ie=UTF8\&node $=13270229011$

Amazon Autor. (2018, August 23). Unsere Geschichte: Was aus einer Garagen-Idee werden kann? About Amazon. https://www.aboutamazon.de/über-amazon/unsere-geschichte-was-aus-einergaragen-idee-werden-kann

Amazon Staff. (2018, September 26). Introducing Amazon 4-star. US About Amazon. https://www. aboutamazon.com/news/retail/introducing-amazon-4-star

Anderson, G. (2021, January 22). NRF 2021: Will Lululemon ever get tired of winning? RetailWire. https://www.retailwire.com/discussion/nrf-2021-will-lululemon-ever-get-tired-of-winning/

Anderson, J. C., \& Gerbing, D. W. (1988). Structural equation modeling in practice: A review and recommended two-step approach. Psychological Bulletin, 103(3), 411-423. https://doi. org/10.1037/0033-2909.103.3.411

Bagheri, S., Kusters, R. J., \& Trienekens, J. J. M. (2019). Customer knowledge transfer challenges in a co-creation value network: Toward a reference model. International Journal of Information Management, 47(December 2018), 198-214. https://doi.org/10.1016/j.ijinfomgt.2018.12.019

Barata, G., Gama, S., Jorge, J., \& Gonçalves, D. (2013). Improving participation and learning with gamification. Proceedings of the First International Conference on Gameful Design, Research, and Applications, 10-17. https://doi.org/10.1145/2583008.2583010

Bardi, A., \& Schwartz, S. H. (2003). Values and Behavior: Strength and Structure of Relations. Personality and Social Psychology Bulletin, 29(10), 1207-1220. https://doi.org/10.1177/0146167203254602

Barton, A. H. (1955). The Concept of Property-Space in Social Research. In P. F. Lazarsfeld \& M. Rosenberg (Eds.), The Language of Social Research: A Reader in the Methodology of Social Research (pp. 40-53). Free Press.

Bergel, M., Frank, P., \& Brock, C. (2019). The role of customer engagement facets on the formation of attitude, loyalty and price perception. Journal of Services Marketing, 33(7), 890-903. https://doi. org/10.1108/JSM-01-2019-0024

Berger, A., Schlager, T., Sprott, D. E., \& Herrmann, A. (2018). Gamified interactions: whether, when, and how games facilitate self-brand connections. Journal of the Academy of Marketing Science, 46(4), 652-673. https://doi.org/10.1007/s11747-017-0530-0 
Bernabe, A. J., \& Messer, S. (2020, August 27). Amazon launches new grocery shopping experience. Good Morning America. https://www.goodmorningamerica.com/food/story/amazon-freshincorporates-echo-show-devices-alexa-grocery-72642473

Bettencourt, L. (1997). Customer voluntary performance: Customers as partners in service delivery. Journal of Retailing, 73(3), 383-406. https://doi.org/10.1016/\$0022-4359(97)90024-5

Bezos, J. P. (2021, April 15). 2020 Letter to Shareholders. US About Amazon. https://www.aboutamazon. com/news/company-news/2020-letter-to-shareholders

Bitner, M. J. (1992). Servicescapes: The Impact of Physical Surroundings on Customers and Employees. Journal of Marketing, 56(2), 57. https://doi.org/10.2307/1252042

Bittner, J. V., \& Schipper, J. (2014). Motivational effects and age differences of gamification in product advertising. Journal of Consumer Marketing, 31(5), 391-400. https://doi.org/10.1108/JCM-042014-0945

Blau, P. M. (1964). Exchange and power in social life. Wiley.

Blumer, H. (1969). Symbolic Interactionism: Perspective and Method. Prentice-Hall.

Bock, G.-W., Zmud, R. W., Kim, Y.-G., \& Lee, J.-N. (2005). Behavioral Intention Formation in Knowledge Sharing: Examining the Roles of Extrinsic Motivators, Social-Psychological Forces, and Organizational Climate. MIS Quarterly, 29(1), 87. https://doi.org/10.2307/25148669

Bolton, R. N., McColl-Kennedy, J. R., Cheung, L., Gallan, A., Orsingher, C., Witell, L., \& Zaki, M. (2018). Customer experience challenges: bringing together digital, physical and social realms. Journal of Service Management, 29(5), 776-808. https://doi.org/10.1108/JOSM-04-2018-0113

Bresgen, R. (2019a, May 7). „T steht für Magenta und Magenta für das T“. Deutsche Telekom. https:// www.telekom.com/de/konzern/details/t-steht-fuer-magenta-und-magenta-fuer-das-t-571420

Bresgen, R. (2019b, December 17). Telekom invests in eSports / Deutsche Telekom. Deutsche Telekom. https://www.telekom.com/en/media/media-information/archive/telekom-invests-inesports-588332

Brocato, E. D., Voorhees, C. M., \& Baker, J. (2012). Understanding the Influence of Cues from Other Customers in the Service Experience: A Scale Development and Validation. Journal of Retailing, 88(3), 384-398. https://doi.org/10.1016/j.jretai.2012.01.006

Brown, J., \& Isaacs, D. (2005). The World Café: Shaping our futures through conversations that matter (p. 242). Berrett-Koehler Publishers.

Busch, U. (2013, June 7). Swisscom-Aktion: Wie aus einer simplen Idee ein Viralhit wird. Werbung \& Vertrieb. https://www.wuv.de/tech/swisscom_aktion_wie_aus_einer_simplen_idee_ein_ viralhit_wird

Business Roundtable. (2021, February 14). Our Commitment. Business Roundtable - Opportunity Agenda. https://opportunity.businessroundtable.org/ourcommitment/

Butler, C. (2014). A Framework for Evaluating the Effectiveness of Gamification Techniques by Personality Type. In Lecture Notes in Computer Science: Vol. 8527 LNCS (pp. 381-389). Springer. https://doi.org/10.1007/978-3-319-07293-7_37 
Cabrera, E. F., \& Cabrera, A. (2005). Fostering knowledge sharing through people management practices. The International Journal of Human Resource Management, 16(5), 720-735. https:// doi.org/10.1080/09585190500083020

Cai, Y., \& Shannon, R. (2012). Personal Values and Mall Shopping Behavior: The Mediating Role of Attitude and Intention among Chinese and Thai Consumers. Australasian Marketing Journal, 20(1), 37-47. https://doi.org/10.1016/j.ausmj.2011.10.013

Camelis, C., Dano, F., Hamon, V., \& Llosa, S. (2017). How Other Customers Influence Customer Satisfaction During the Service Delivery. In C.L. Campbell (Eds), The Customer is NOT Always Right? Marketing Orientationsin a Dynamic Business World. Developments in Marketing Science: Proceedings of the Academy of Marketing Science (pp. 377-380). Springer, Cham. https://doi. org/10.1007/978-3-319-50008-9_103

Carpenter, S. (2018). Ten Steps in Scale Development and Reporting: A Guide for Researchers. Communication Methods and Measures, 12(1), 25-44. https://doi.org/10.1080/19312458.2017 .1396583

Chang, W.-L., \& Chen, S.-T. (2015). The impact of World Café on entrepreneurial strategic planning capability. Journal of Business Research, 68(6), 1283-1290. https://doi.org/10.1016/j. jbusres.2014.11.020

Chen, K., Chen, J., Zhan, W., \& Sharma, P. (2020). When in Rome! Complaint contagion effect in multiactor service ecosystems. Journal of Business Research, 121(January), 628-641. https://doi. org/10.1016/j.jbusres.2020.01.051

Cheung, M. F. Y., \& To, W. M. (2019). An extended model of value-attitude-behavior to explain Chinese consumers' green purchase behavior. Journal of Retailing and Consumer Services, 50(December 2018), 145-153. https://doi.org/10.1016/j.jretconser.2019.04.006

Choi, J., Choi, H., So, W., Lee, J., \& You, J. (2014). A Study about Designing Reward for Gamified Crowdsourcing System (pp. 678-687). https://doi.org/10.1007/978-3-319-07626-3_64

Conde, R., Prybutok, V., \& Sumlin, C. (2020). The utilization of online sales forums by salespeople as a mesosystem for enhancing sales-activity knowledge. Journal of Business and Industrial Marketing, 36(4), 630-640. https://doi.org/10.1108/JBIM-03-2020-0129

Datta, P. P. (2020). Hidden costs in different stages of advanced services - A multi-actor perspective of performance based contracts. Journal of Business Research, 121(March), 667-685. https://doi. org/10.1016/j.jbusres.2020.03.036

Davis, L., Hautamaki, P., \& Deeter-Schmelz, D. R. (2021). Guest editorial. Journal of Business \& Industrial Marketing, 36(4), 569-570. https://doi.org/10.1108/JBIM-04-2021-556

Delpechitre, D., Beeler-Connelly, L. L., \& Chaker, N. N. (2018). Customer value co-creation behavior: A dyadic exploration of the influence of salesperson emotional intelligence on customer participation and citizenship behavior. Journal of Business Research, 92(July 2017), 9-24. https:// doi.org/10.1016/j.jbusres.2018.05.007

Delpechitre, D., Gupta, A., Zadeh, A. H., Lim, J. H., \& Taylor, S. A. (2020). Toward a new perspective on salesperson success and motivation: a trifocal framework. Journal of Personal Selling and Sales Management, 40(4), 267-288. https://doi.org/10.1080/08853134.2020.1805748 
Demodern. (2018, October 2). Telekom - Interactive Games at IFA. Demodern. https://demodern.com/ projects/telekom-ifa-gamingstations

Deterding, S., Dixon, D., Khaled, R., \& Nacke, L. (2011). From game design elements to gamefulness. Proceedings of the 15th International Academic MindTrek Conference on Envisioning Future Media Environments - MindTrek '11, September, 9. https://doi.org/10.1145/2181037.2181040

Deutsche Telekom. (2020, February 10). Brand is right in tune with times. Deutsche Telekom. https:// www.telekom.com/en/company/details/brand-is-right-in-tune-with-times-593062

Deutsche Telekom AG. (2021, May 4). Leading European Telco. Deutsche Telekom AG. https://www. telekom.com/en/company/companyprofile/company-profile-625808

Deutsche Telekom Service GmbH. (2021, February 3). Ideenschmiede - Die Telekom mitgestalten. https://ideenschmiede.telekom-dienste.de/

DeVellis, R. F. (2016). Scale Development: Theory and Applications (Vol. 26). Sage Publications, Inc.

Dixon, A. L., \& Tanner, J. F. (2012). Transforming Selling: Why It Is Time to Think Differently About Sales Research. Journal of Personal Selling \& Sales Management, 32(1), 9-13. https://doi.org/10.2753/ PSS0885-3134320102

Drumwright, M. E. (1994). Socially Responsible Organizational Buying: Environmental Concern as a Noneconomic Buying Criterion. Journal of Marketing, 58(3), 1. https://doi.org/10.2307/1252307

Dunfield, K. A. (2014). A construct divided: prosocial behavior as helping, sharing, and comforting subtypes. Frontiers in Psychology, 5(AUG), 1-13. https://doi.org/10.3389/fpsyg.2014.00958

Dwyer, F. R., Schurr, P. H., \& Oh, S. (1987). Developing Buyer-Seller Relationships. Journal of Marketing, 51(2), 11. https://doi.org/10.2307/1251126

Echeverri, P., \& Skålén, P. (2011). Co-creation and co-destruction: A practice-theory based study of interactive value formation. Marketing Theory, 11(3), 351-373. https://doi. org/10.1177/1470593111408181

Eggert, A., Henseler, J., \& Hollmann, S. (2012). Who Owns the Customer? Disentangling Customer Loyalty in Indirect Distribution Channels. Journal of Supply Chain Management, 48(2), 75-92. https://doi.org/10.1111/j.1745-493X.2011.03260.x

Eggert, A., Ulaga, W., Frow, P., \& Payne, A. (2018). Conceptualizing and communicating value in business markets: From value in exchange to value in use. Industrial Marketing Management, 69, 80-90. https://doi.org/10.1016/j.indmarman.2018.01.018

Eisenhardt, K. M. (1989). Building Theories from Case Study Research. The Academy of Management Review, 14(4), 532. https://doi.org/10.2307/258557

Ennew, C. T., \& Binks, M. R. (1999). Impact of Participative Service Relationships on Quality, Satisfaction and Retention. Journal of Business Research, 46(2), 121-132. https://doi.org/10.1016/S01482963(98)00016-2

Eppmann, R., Bekk, M., \& Klein, K. (2018). Gameful Experience in Gamification: Construction and Validation of a Gameful Experience Scale [GAMEX]. Journal of Interactive Marketing, 43(2018), 98-115. https://doi.org/10.1016/j.intmar.2018.03.002 
Fazio, R. H., \& Zanna, M. P. (1981). Direct Experience And Attitude-Behavior Consistency. In Advances in experimental social psychology (pp. 161-202). Academic Press. https://doi.org/10.1016/ S0065-2601(08)60372-X

Fehrer, J. A., Woratschek, H., Germelmann, C. C., \& Brodie, R. J. (2018). Dynamics and drivers of customer engagement: within the dyad and beyond. Journal of Service Management, 29(3), 443467. https://doi.org/10.1108/JOSM-08-2016-0236

Fischer, G. (2012). Context-aware systems. Proceedings of the International Working Conference on Advanced Visual Interfaces - AVI '12, 2006, 287. https://doi.org/10.1145/2254556.2254611

Fishbein, M., Ajzen, I., \& Fishbein. (1975). Belief, Attitude, Intention and Behavior: An Introduction to Theory and Research. Addison-Wesley.

Fisher, S. (2020, April 20). Free Yoga Classes You'll Love at Your Local Lululemon. Verywellfit. https:// www.verywellfit.com/free-yoga-classes-at-lululemon-1356516

Fornell, C., \& Larcker, D. F. (1981). Evaluating Structural Equation Models with Unobservable Variables and Measurement Error. Journal of Marketing Research, 18(1), 39-50. https://doi. org/10.1177/002224378101800104

Friend, S. B., \& Malshe, A. (2016). Key Skills for Crafting Customer Solutions Within an Ecosystem. Journal of Service Research, 19(2), 174-191. https://doi.org/10.1177/1094670515617154

Frow, P., Mccoll-Kennedy, J. R., \& Payne, A. (2016). Industrial Marketing Management Co-creation practices : Their role in shaping a health care ecosystem. Industrial Marketing Management, 56, 24-39. https://doi.org/10.1016/j.indmarman.2016.03.007

Gajsek, D. (2020, April 5). [Growth Study] Lululemon Athletica - How to Beat Nike by Creating a New Category. Dgajsek. https://dgajsek.com/growth-study-lululemon/

Garcia, T. (2020, December 28). Retail bankruptcies in 2020 hit the highest levels in more than a decade, and experts say there are more to come. MarketWatch. https://www.marketwatch.com/ story/retail-bankruptcies-in-2020-hit-the-highest-levels-in-more-than-a-decade-and-expertssay-there-are-more-to-come-11608151350

Gillison, S., Givan, A. M., Beatty, S. E., Kim, K., Reynolds, K., \& Baker, J. (2015). Mother-adolescent daughter identity interplay processes. Journal of Consumer Marketing, 32(4), 234-244. https:// doi.org/10.1108/JCM-12-2014-1244

Godes, D., \& Mayzlin, D. (2009). Firm-Created Word-of-Mouth Communication: Evidence from a Field Test. Marketing Science, 28(4), 721-739. https://doi.org/10.1287/mksc.1080.0444

Goel, T. (2021, January 6). Educator / Cologne Showroom. Linkedln. https://de.linkedin.com/jobs/ view/educator-cologne-showroom-at-lululemon-2343394510

Gong, T., Choi, J. N., \& Murdy, S. (2016). Does Customer Value Creation Behavior Drive Customer Well-being? Social Behavior and Personality: An International Journal, 44(1), 59-75. https://doi. org/10.2224/sbp.2016.44.1.59

Gonos, G. (1977). "Situation" versus "Frame": The "Interactionist" and the "Structuralist" Analyses of Everyday Life. American Sociological Review, 42(6), 854. https://doi.org/10.2307/2094572

Gray, A. (2020). Lululemon plans overseas expansion as yogawear booms. Financial Times. https:// www.ft.com/content/c3ae04c5-ea00-452b-a33f-6a02adb5ca34 
Gray, L. (2020, December 12). This Legendary Chain Is Closing Over 1,000 Stores by March. Yahoo! https://www.yahoo.com/now/legendary-chain-closing-over-1-121358189.html

Green, D. (2019, June 4). Amazon online orders can be returned to its stores. Here's how. Business Insider. https://www.businessinsider.com/amazon-online-orders-cant-be-returned-to-stores-2019-5

Grönroos, C. (2011). Value co-creation in service logic: A critical analysis. Marketing Theory, 11(3), 279-301. https://doi.org/10.1177/1470593111408177

Gross, R. (2019, June 7). How the Amazon Go Store's Al Works. Towards Data Science. https:// towardsdatascience.com/how-the-amazon-go-store-works-a-deep-dive-3fde9d9939e9

Groth, M. (2005). Customers as Good Soldiers: Examining Citizenship Behaviors in Internet Service Deliveries. Journal of Management, 31(1), 7-27. https://doi.org/10.1177/0149206304271375

Grove, S. J., \& Fisk, R. P. (1997). The impact of other customers on service experiences: A critical incident examination of "getting along." Journal of Retailing, 73(1), 63-85. https://doi.org/10.1016/S00224359(97)90015-4

Gruen, T. W., Osmonbekov, T., \& Czaplewski, A. J. (2007). Customer-to-customer exchange: Its MOA antecedents and its impact on value creation and loyalty. Journal of the Academy of Marketing Science, 35(4), 537-549. https://doi.org/10.1007/s11747-006-0012-2

Guo, B. (2011). The scope of external information-seeking under uncertainty: An individual-level study. International Journal of Information Management, 31(2), 137-148. https://doi.org/10.1016/j. ijinfomgt.2010.08.005

Gurel-Atay, E., Xie, G. X., Chen, J., \& Kahle, L. R. (2010). Changes in Social Values in the United States: 1976-2007. Journal of Advertising Research, 50(1), 57-67. https://doi.org/10.2501/ S002184991009118X

Guyer, J. J., \& Fabrigar, L. R. (2015). Attitudes and Behavior. In International Encyclopedia of the Social \& Behavioral Sciences (2 ${ }^{\text {nd }}$ ed., Vol. 2, pp. 183-189). Elsevier. https://doi.org/10.1016/B978-0-08097086-8.24007-5

Hair, J. F., Black, W. C., Babin, B. J., \& Anderson, R. E. (2018). Multivariate Data Analysis (8 ${ }^{\text {th }}$ ed.). Cengage Learning EMEA.

Halle, S. (2019, January 28). Deutsche Telekom's Ideenschmiede: one year on. Deutsche Telekom AG. https://www.telekom.com/en/media/media-information/archive/telekomideenschmiede-559774

Hamari, J., \& Koivisto, J. (2014). Measuring flow in gamification: Dispositional Flow Scale-2. Computers in Human Behavior, 40, 133-143. https://doi.org/10.1016/j.chb.2014.07.048

Hammedi, W., Leclerq, T., \& Van Riel, A. C. R. (2017). The use of gamification mechanics to increase employee and user engagement in participative healthcare services. Journal of Service Management, 28(4), 640-661. https://doi.org/10.1108/JOSM-04-2016-0116

Hanks, L., Zhang, L., \& Line, N. (2020). Perceived similarity in third places: Understanding the effect of place attachment. International Journal of Hospitality Management, 86(December 2019), 102455. https://doi.org/10.1016/j.ijhm.2020.102455 
Hansen, T. (2008). Consumer values, the theory of planned behaviour and online grocery shopping. International Journal of Consumer Studies, 32(2), 128-137. https://doi.org/10.1111/j.14706431.2007.00655.x

Harmeling, C. M., Moffett, J. W., Arnold, M. J., \& Carlson, B. D. (2017). Toward a theory of customer engagement marketing. Journal of the Academy of Marketing Science, 45(3), 312-335. https:// doi.org/10.1007/s11747-016-0509-2

Harmeling, C. M., Moffett, J. W., \& Palmatier, R. W. (2018). Conclusion: Informing Customer Engagement Marketing and Future Research. In R. W. Palmatier, V. Kumar, \& C. M. Harmeling, (Eds.), Customer Engagement Marketing (pp. 307-323). Springer International Publishing. https:// doi.org/10.1007/978-3-319-61985-9_14

Hart, P. M., \& Dale, R. (2014). With or without you: The positive and negative influence of retail companions. Journal of Retailing and Consumer Services, 21(5), 780-787. https://doi. org/10.1016/j.jretconser.2014.06.004

Hartmann, N. N., Wieland, H., \& Lussier, B. (2021). An exploration of sales activities from a service ecosystems perspective. In F. Jaramillo \& J. P. Mulki (Eds.), A Research Agenda for Sales (Vol. 31, Issue 1, pp. 1-19). Edward Elgar Publishing. https://doi.org/10.4337/9781788975315.00008

Hartmann, N. N., Wieland, H., \& Vargo, S. L. (2018). Converging on a New Theoretical Foundation for Selling. Journal of Marketing, 82(2), 1-18. https://doi.org/10.1509/jm.16.0268

Hartmann, N. N., Wieland, H., Vargo, S. L., \& Ahearne, M. (2020). Advancing sales theory through a holistic view: how social structures frame selling. Journal of Personal Selling \& Sales Management, 40(4), 221-226. https://doi.org/10.1080/08853134.2020.1838916

Harwood, T., \& Garry, T. (2015). An investigation into gamification as a customer engagement experience environment. Journal of Services Marketing, 29(6/7), 533-546. https://doi.org/10.1108/JSM-012015-0045

Heide, J. B., \& Wathne, K. H. (2006). Friends, Businesspeople, and Relationship Roles: A Conceptual Framework and a Research Agenda. Journal of Marketing, 70(3), 90-103. https://doi.org/10.1509/ jmkg.70.3.90

Henseler, J., \& Guerreiro, M. (2020). Design and marketing: Intersections and challenges. Creativity and Innovation Management, 29(S1), 3-10. https://doi.org/10.1111/caim.12412

Ho, M. H.-W., Chung, H. F. L., Kingshott, R., \& Chiu, C.-C. (2020). Customer engagement, consumption and firm performance in a multi-actor service eco-system: The moderating role of resource integration. Journal of Business Research, 121(April 2019), 557-566. https://doi.org/10.1016/j. jbusres.2020.02.008

Hofacker, C. F., de Ruyter, K., Lurie, N. H., Manchanda, P., \& Donaldson, J. (2016). Gamification and Mobile Marketing Effectiveness. Journal of Interactive Marketing, 34(2016), 25-36. https://doi. org/10.1016/j.intmar.2016.03.001

Högberg, J., Hamari, J., \& Wästlund, E. (2019). Gameful Experience Questionnaire (GAMEFULQUEST): an instrument for measuring the perceived gamefulness of system use. User Modeling and UserAdapted Interaction, 29(3), 619-660. https://doi.org/10.1007/s11257-019-09223-w 
Högberg, J., Ramberg, M. O., Gustafsson, A., \& Wästlund, E. (2019). Creating brand engagement through in-store gamified customer experiences. Journal of Retailing and Consumer Services, 50(November 2018), 122-130. https://doi.org/10.1016/j.jretconser.2019.05.006

Holbrook, M. (1999). Consumer Value: A Framework for Analysis and Research. Routledge. https://doi. org/10.4324/9780203010679

Holmqvist, J., Visconti, L. M., Grönroos, C., Guais, B., \& Kessous, A. (2020). Understanding the value process: Value creation in a luxury service context. Journal of Business Research, 120(June 2019), 114-126. https://doi.org/10.1016/j.jbusres.2020.07.002

Holmqvist, J., Wirtz, J., \& Fritze, M. P. (2020). Luxury in the digital age: A multi-actor service encounter perspective. Journal of Business Research, 121(January), 747-756. https://doi.org/10.1016/j. jbusres.2020.05.038

Homer, P. M., \& Kahle, L. R. (1988). A structural equation test of the value-attitude-behavior hierarchy. Journal of Personality and Social Psychology, 54(4), 638-646. https://doi.org/10.1037/00223514.54.4.638

Howard, D. J., \& Gengler, C. (2001). Emotional Contagion Effects on Product Attitudes: Figure 1. Journal of Consumer Research, 28(2), 189-201. https://doi.org/10.1086/322897

Howard, J. A. (2000). Social Psychology of Identities. Annual Review of Sociology, 26(1), 367-393. https://doi.org/10.1146/annurev.soc.26.1.367

Huotari, K., \& Hamari, J. (2017). A definition for gamification: anchoring gamification in the service marketing literature. Electronic Markets, 27(1), 21-31. https://doi.org/10.1007/s12525-0150212-z

Iden, J., Eikebrokk, T. R., \& Marrone, M. (2020). Process reference frameworks as institutional arrangements for digital service innovation. International Journal of Information Management, 54(November 2019), 102150. https://doi.org/10.1016/j.ijinfomgt.2020.102150

Invidis Redaktion. (2021, February 15). Telekom: Erlebnisinseln statt Verkaufstresen. Invidis. https:// invidis.de/2021/02/telekom-erlebnisinseln-statt-verkaufstresen/

Jang, S., Kitchen, P. J., \& Kim, J. (2018). The effects of gamified customer benefits and characteristics on behavioral engagement and purchase: Evidence from mobile exercise application uses. Journal of Business Research, 92(January), 250-259. https://doi.org/10.1016/j.jbusres.2018.07.056

Jayawardhena, C. (2004). Personal values' influence on e-shopping attitude and behaviour. Internet Research, 14(2), 127-138. https://doi.org/10.1108/10662240410530844

Johnson, J. D., Donohue, W. A., Atkin, C. K., \& Johnson, S. (1995). A Comprehensive Model of Information Seeking.Science Communication,16(3),274-303.https://doi.org/10.1177/1075547095016003003

Johnson, J. S. (2015). Qualitative sales research: an exposition of grounded theory. Journal of Personal Selling \& Sales Management, 35(3), 262-273. https://doi.org/10.1080/08853134.2014.954581

Kaiser, H. F., \& Rice, J. (1974). Little Jiffy, Mark Iv. Educational and Psychological Measurement, 34(1), 111-117. https://doi.org/10.1177/001316447403400115

Kakai, M., Odongo, R. I., \& Bukenya, I. M. N. K. (2004). A study of the information seeking behavior of undergraduate students of Makerere University, Uganda. World Libraries, 14(1), 1-22. http:// www.worlib.org/vol14no1/print/kakai_print.htm 
Kang, J., Jun, J., \& Arendt, S. W. (2015). Understanding customers' healthy food choices at casual dining restaurants: Using the Value-Attitude-Behavior model. International Journal of Hospitality Management, 48, 12-21. https://doi.org/10.1016/j.ijhm.2015.04.005

Kaski, T. A., Hautamaki, P., Pullins, E. B., \& Kock, H. (2017). Buyer versus salesperson expectations for an initial B2B sales meeting. Journal of Business \& Industrial Marketing, 32(1), 46-56. https://doi. org/10.1108/JBIM-12-2015-0246

Kautish, P., \& Sharma, R. (2019). Value orientation, green attitude and green behavioral intentions: an empirical investigation among young consumers. Young Consumers, 20(4), 338-358. https://doi. org/10.1108/YC-11-2018-0881

Keng, C., Huang, T., Zheng, L., \& Hsu, M. K. (2007). Modeling service encounters and customer experiential value in retailing. International Journal of Service Industry Management, 18(4), 349367. https://doi.org/10.1108/09564230710778137

Keng, C., \& Ting, H. (2009). The acceptance of blogs: using a customer experiential value perspective. Internet Research, 19(5), 479-495. https://doi.org/10.1108/10662240910998850

Kespohl, P. (2020, January 2). 25 years of Deutsche Telekom AG - from state-owned enterprise to stock corporation. Deutsche Telekom AG. https://www.telekom.com/en/media/media-information/ archive/25-years-of-deutsche-telekom-ag-589922\#5ebdbebc263cd001718bdbf5

Khadraoui, M., \& Gharbi, J.-E. (2012). Second-Order Constructs in Structural Equations. International Journal of Online Marketing, 2(4), 15-41. https://doi.org/10.4018/ijom.2012100102

Kim, K. A., \& Byon, K. K. (2018). A mechanism of mutually beneficial relationships between employees and consumers: A dyadic analysis of employee-consumer interaction. Sport Management Review, 21(5), 582-595. https://doi.org/10.1016/j.smr.2018.01.003

Kim, S. Y. (2017). Inter-customer helping during service failures: The mediating role of disappointment. Journal of Service Science Research, 9(1), 61-71. https://doi.org/10.1007/s12927-017-0004-4

Koivisto, J., \& Hamari, J. (2014). Demographic differences in perceived benefits from gamification. Computers in Human Behavior, 35, 179-188. https://doi.org/10.1016/j.chb.2014.03.007

Koivisto, J., \& Hamari, J. (2019). The rise of motivational information systems: A review of gamification research. International Journal of Information Management, 45(December 2018), 191-210. https://doi.org/10.1016/j.ijinfomgt.2018.10.013

Kral, J. (2020, September 11). Neuer Flagship Store: Telekom Experience Store öffnet in Stuttgart. Invidis. https://invidis.de/2020/09/neuer-flagship-store-telekom-experience-store-oeffnet-instuttgart/

Kromer, E. (2020, December 8). Foster the Product: Working backwards from the customer. Foster Blog. https://blog.foster.uw.edu/foster-product-working-backward-customer/

Kropp, F., Lavack, A. M., \& Silvera, D. H. (2005). Values and collective self-esteem as predictors of consumer susceptibility to interpersonal influence among university students. International Marketing Review, 22(1), 7-33. https://doi.org/10.1108/02651330510581154

Kuo, M.-S., \& Chuang, T.-Y. (2016). How gamification motivates visits and engagement for online academic dissemination - An empirical study. Computers in Human Behavior, 55, 16-27. https:// doi.org/10.1016/j.chb.2015.08.025 
Lagrosen, Y. (2019). The Quality Café: developing the World Café method for organisational learning by including quality management tools. Total Quality Management \& Business Excellence, 30(1314), 1515-1527. https://doi.org/10.1080/14783363.2017.1377606

Landers, R. N., Tondello, G. F., Kappen, D. L., Collmus, A. B., Mekler, E. D., \& Nacke, L. E. (2019). Defining gameful experience as a psychological state caused by gameplay: Replacing the term 'Gamefulness' with three distinct constructs. International Journal of Human-Computer Studies, 127(May 2018), 81-94. https://doi.org/10.1016/j.ijhcs.2018.08.003

Lassk, F. G., Ingram, T. N., Kraus, F., \& Di Mascio, R. (2012). The Future of Sales Training: Challenges and Related Research Questions. Journal of Personal Selling \& Sales Management, 32(1), 141-154. https://doi.org/10.2753/PSS0885-3134320112

Leclercq, T., Hammedi, W., \& Poncin, I. (2018). The Boundaries of Gamification for Engaging Customers: Effects of Losing a Contest in Online Co-creation Communities. Journal of Interactive Marketing, 44, 82-101. https://doi.org/10.1016/j.intmar.2018.04.004

Leclercq, T., Poncin, I., \& Hammedi, W. (2020). Opening the black box of gameful experience: Implications for gamification process design. Journal of Retailing and Consumer Services, 52(July 2019), 101882. https://doi.org/10.1016/j.jretconser.2019.07.007

Lee, M. K. O., Cheung, C. M. K., Lim, K. H., \& Ling Sia, C. (2006). Understanding customer knowledge sharing in web-based discussion boards. Internet Research, 16(3), 289-303. https://doi. org/10.1108/10662240610673709

Leinbach-Reyhle, N. (2018, December 10). Q\&A With Amazon's VP of Physical Stores, Cameron Janes I ASD Market Week. https://asdonline.com/blog/online-selling/q-a-with-amazon-s-vp-of-physicalstores-cameron-janes/

Lengnick-Hall, C. A., Claycomb, V. (Cindy), \& Inks, L. W. (2000). From recipient to contributor: examining customer roles and experienced outcomes. European Journal of Marketing, 34(3/4), 359-383. https://doi.org/10.1108/03090560010311902

Li, L. P., Juric, B., \& Brodie, R. J. (2017). Dynamic multi-actor engagement in networks: the case of United Breaks Guitars. Journal of Service Theory and Practice, 27(4), 738-760. https://doi. org/10.1108/JSTP-04-2016-0066

Lin, H.-F. (2007). Effects of extrinsic and intrinsic motivation on employee knowledge sharing intentions. Journal of Information Science, 33(2), 135-149. https://doi.org/10.1177/0165551506068174

Liu, D., Santhanam, R., \& Webster, J. (2017). Toward Meaningful Engagement: A Framework for Design and Research of Gamified Information Systems. MIS Quarterly, 41(4), 1011-1034. https://doi. org/10.25300/MISQ/2017/41.4.01

Löhr, K., Weinhardt, M., \& Sieber, S. (2020). The "World Café" as a Participatory Method for Collecting Qualitative Data. International Journal of Qualitative Methods, 19, 1-15. https://doi. org/10.1177/1609406920916976

Lululemon. (2016, May 15). History. Lululemon. https://info.lululemon.com/about/our-story/history Lululemon. (2020a, May 3). Shop over video chat. Lululemon. https://www.lululemon-virtualshopping. com/ 
Lululemon. (2020b, June 29). Iululemon athletica inc. to Acquire Home Fitness Innovator MIRROR. Lululemon. https://investor.lululemon.com/index.php/news-releases/news-release-details/ lululemon-athletica-inc-acquire-home-fitness-innovator-mirror

Lululemon. (2020c, December 14). About the program. Lululemon. https://shop.lululemon.com/ ambassadors/about-the-program

Lululemon. (2020d, December 14). Meet Our Global \& Store Ambassadors. Lululemon. https://shop. Iululemon.com/ambassadors

Lululemon. (2021a). Contract Educator. https://info.lululemon.com/stores/us/san-francisco/ sanfranciscocentre/jobs/contract-educator-0095840?sType=FashionJob

Lululemon. (2021b, March 28). Iululemon collective. Lululemon. https://signup.partnerize.com/ signup/en/lululemon

Macdonald, E. K., Kleinaltenkamp, M., \& Wilson, H. N. (2016). How Business Customers Judge Solutions: Solution Quality and Value in Use. Journal of Marketing, 80(3), 96-120. https://doi. org/10.1509/jm.15.0109

Maghnati, F., Ling, K. C., \& Nasermoadeli, A. (2012). Exploring the Relationship between Experiential Marketing and Experiential Value in the Smartphone Industry. International Business Research, 5(11), 169-177. https://doi.org/10.5539/ibr.v5n11p169

Maheshwari, S. (2013, June 11). The Secret Language Of Lululemon. BuzzFeed News. https://www. buzzfeednews.com/article/sapna/the-secret-language-of-lululemon

Maheshwari, S. (2020, June 29). Lululemon to Buy Mirror, a Fitness Start-Up, for \$500 Million. The New York Times. https://www.nytimes.com/2020/06/29/business/lululemon-buys-mirror.html

Mathwick, C., Malhotra, N., \& Rigdon, E. (2001). Experiential value: conceptualization, measurement and application in the catalog and Internet shopping environment. Journal of Retailing, 77(1), 39-56. https://doi.org/10.1016/S0022-4359(00)00045-2

Mayring, P. (2015). Qualitative Content Analysis: Theoretical Background and Procedures. In A. Bikner-Ahsbahs, C. Knipping, \& N. Presmeg (Eds.), Approaches to qualitative research in Mathematics Education. Advances in Mathematics Education (pp. 365-380). Springer. https:// doi.org/10.1007/978-94-017-9181-6_13

McAlexander, J. H., \& Schouten, J. (1998). Brandfests: Servicescapes for the cultivation of brand equity. In J. F. Sherry, Servicescapes: The Concept of Place in Contemporary Markets (pp. 377-402). NTC Books.

McCarty, J. A., \& Shrum, L. J. (1994). The recycling of solid wastes: Personal values, value orientations, and attitudes about recycling as antecedents of recycling behavior. Journal of Business Research, 30(1), 53-62. https://doi.org/10.1016/0148-2963(94)90068-X

McColl-Kennedy, J. R., Cheung, L., \& Coote, L. V. (2020). Tensions and trade-offs in multi-actor service ecosystems. Journal of Business Research, 121(June), 655-666. https://doi.org/10.1016/j. jbusres.2020.06.055

Medberg, G., \& Grönroos, C. (2020). Value-in-use and service quality: do customers see a difference? Journal of Service Theory and Practice, 30(4/5), 507-529. https://doi.org/10.1108/JSTP-09-20190207 
Milfont, T. L., Duckitt, J., \& Wagner, C. (2010). A Cross-Cultural Test of the Value-Attitude-Behavior Hierarchy. Journal of Applied Social Psychology, 40(11), 2791-2813. https://doi.org/10.1111/ j.1559-1816.2010.00681.x

Moore, D. S., McCabe, G. P., \& Craig, B. A. (2012). Introduction to the practice of statistics ( $7^{\text {th }}$ ed.). W.H. Freeman.

Morschheuser, B., Hassan, L., Werder, K., \& Hamari, J. (2018). How to design gamification? A method for engineering gamified software. Information and Software Technology, 95(April 2017), 219237. https://doi.org/10.1016/j.infsof.2017.10.015

Müller-Stewens, J., Schlager, T., Häubl, G., \& Herrmann, A. (2017). Gamified Information Presentation and Consumer Adoption of Product Innovations. Journal of Marketing, 81(2), 8-24. https://doi. org/10.1509/jm.15.0396

Mustak, M., \& Plé, L. (2020). A critical analysis of service ecosystems research: rethinking its premises to move forward. Journal of Services Marketing, 34(3), 399-413. https://doi.org/10.1108/JSM02-2019-0084

Nguyen, T. D., Paswan, A., \& Dubinsky, A. J. (2018). Allocation of Salespeople's resources for generating new sales opportunities across four types of customers. Industrial Marketing Management, 68(October 2017), 114-131. https://doi.org/10.1016/j.indmarman.2017.10.006

Paesbrugghe, B., Rangarajan, D., Hochstein, B., \& Sharma, A. (2020). Evaluation of salespeople by the purchasing function: implications for the evolving role of salespeople. Journal of Personal Selling and Sales Management, 40(4), 289-305. https://doi.org/10.1080/08853134.2020.1813590

Parasuraman, A. (1997). Reflections on gaining competitive advantage through customer value. Journal of the Academy of Marketing Science, 25(2), 154-161. https://doi.org/10.1007/BF02894351

Pathak, B., Ashok, M., \& Tan, Y. L. (2020). Value co-destruction: Exploring the role of actors' opportunism in the B2B context. International Journal of Information Management, 52(June 2019), 102093. https://doi.org/10.1016/j.ijinfomgt.2020.102093

Patton, L., \& Rastello, S. (2019, July 11). You Can Now Sweat in Lululemon's Gear Before Buying It. Bloomberg. https://www.bloombergquint.com/onweb/lululemon-s-new-lincoln-park-store-has25-hiit-yoga-classes

Peeters, M., Megens, C., van den Hoven, E., Hummels, C., \& Brombacher, A. (2013). Social Stairs: Taking the Piano Staircase towards Long-Term Behavioral Change. In S. Berkovsky, \& J. Freyne (Eds.), Persuasive Technologoy, lecture notes in Computer Sciences (Vol. 7822, Issue April, pp. 174-179). Springer Berlin Heidelberg. https://doi.org/10.1007/978-3-642-37157-8_21

Petersen, J. A., Kumar, V., Polo, Y., \& Sese, F. J. (2018). Unlocking the power of marketing: understanding the links between customer mindset metrics, behavior, and profitability. Journal of the Academy of Marketing Science, 46(5), 813-836. https://doi.org/10.1007/s11747-017-0554-5

Pett, M. A., Lackey, N. R., \& Sullivan, J. J. (2003). Making Sense of Factor Analysis An Overview of Factor Analysis An Overview of Factor Analysis. SAGE Publications, Inc., 18(6), 1-13.

Phung, V. D., Hawryszkiewycz, I., Chandran, D., \& Ha, B. M. (2019). Promoting Knowledge Sharing Amongst Academics: A Case Study from Vietnam. Journal of Information \& Knowledge Management, 18(03), 1950032. https://doi.org/10.1142/S0219649219500321 
Pinna, R., De Simone, S., Cicotto, G., \& Malik, A. (2020). Beyond organisational support: Exploring the supportive role of co-workers and supervisors in a multi-actor service ecosystem. Journal of Business Research, 121(May 2019), 524-534. https://doi.org/10.1016/j.jbusres.2020.02.022

Poncin, I., Garnier, M., Ben Mimoun, M. S., \& Leclercq, T. (2017). Smart technologies and shopping experience: Are gamification interfaces effective? The case of the Smartstore. Technological Forecasting and Social Change, 124, 320-331. https://doi.org/10.1016/j.techfore.2017.01.025

Prahalad, C. K., \& Ramaswamy, V. (2004). Co-creating unique value with customers. Strategy \& Leadership, 32(3), 4-9. https://doi.org/10.1108/10878570410699249

Prewitt, V. (2011). Working in the café: lessons in group dialogue. The Learning Organization, 18(3), 189-202. https://doi.org/10.1108/09696471111123252

Pulles, N. J., Schiele, H., Veldman, J., \& Hüttinger, L. (2016). The impact of customer attractiveness and supplier satisfaction on becoming a preferred customer. Industrial Marketing Management, 54(July), 129-140. https://doi.org/10.1016/j.indmarman.2015.06.004

Quiroz, M. A. (2019, March 20). A Growth Strategy for Lululemon 2018. Medium. https://medium. com/@michaelangelo_q/a-growth-strategy-for-lululemon-68819680e511

Ramani, G., \& Kumar, V. (2008). Interaction orientation and firm performance. Journal of Marketing, 72(1), 27-45. https://doi.org/10.1509/jmkg.72.1.27

Randall Brandt, D. (1988). HOW SERVICE MARKETERS CAN IDENTIFY VALUE-ENHANCING SERVICE ELEMENTS. Journal of Services Marketing, 2(3), 35-41. https://doi.org/10.1108/eb024732

Ranjan, K. R., \& Friend, S. B. (2020). An integrative framework of sales ecosystem well-being. Journal of Personal Selling and Sales Management, 40(4), 234-250. https://doi.org/10.1080/08853134. 2020.1822176

Rapp, A., Gabler, C., \& Ogilvie, J. (2020). A holistic perspective of sales research: areas of consideration to develop more comprehensive conceptual and empirical frameworks. Journal of Personal Selling \& Sales Management, 40(4), 227-233. https://doi.org/10.1080/08853134.2020.1823229

Razali, N. N., Anuar, M. M., \& Ngah, A. H. (2021). Green value and sustainable transportation engagement: The mediating role of attitude. Management Science Letters, 11, 547-554. https:// doi.org/10.5267/j.msl.2020.9.012

Razmerita, L., Kirchner, K., \& Nielsen, P. (2016). What factors influence knowledge sharing in organizations? A social dilemma perspective of social media communication. Journal of Knowledge Management, 20(6), 1225-1246. https://doi.org/10.1108/JKM-03-2016-0112

Reiff, N. (2021, February 5). How Amazon Makes Money. Investopedia. https://www.investopedia. com/how-amazon-makes-money-4587523

Revilla-Camacho, M. Á., Vega-Vázquez, M., \& Cossío-Silva, F. J. (2015). Customer participation and citizenship behavior effects on turnover intention. Journal of Business Research, 68(7), 16071611. https://doi.org/10.1016/j.jbusres.2015.02.004

Rodrigues, L. F., Costa, C. J., \& Oliveira, A. (2016). Gamification: A framework for designing software in e-banking. Computers in Human Behavior, 62, 620-634. https://doi.org/10.1016/j. chb.2016.04.035 
Rosenbaum, M. S. (2009). Exploring commercial friendships from employees' perspectives. Journal of Services Marketing, 23(1), 57-66. https://doi.org/10.1108/08876040910933101

Rosenbaum, M. S., Russell-Bennett, R., \& Drennan, J. (2015). Commercial friendships between gay sales associates and straight female customers in luxury settings: A proposed theoretical framework. Journal of Retailing and Consumer Services, 27, 179-186. https://doi.org/10.1016/j. jretconser.2015.08.004

Rusthollkarhu, S., Hautamaki, P., \& Aarikka-Stenroos, L. (2020). Value (co-)creation in B2B sales ecosystems. Journal of Business and Industrial Marketing, 36(4), 590-598. https://doi. org/10.1108/JBIM-03-2020-0130

Ryan, R. M., \& Deci, E. L. (2020). Intrinsic and extrinsic motivation from a self-determination theory perspective: Definitions, theory, practices, and future directions. Contemporary Educational Psychology, 61(April), 101860. https://doi.org/10.1016/j.cedpsych.2020.101860

Sánchez, J., Callarisa, L., Rodríguez, R. M., \& Moliner, M. A. (2006). Perceived value of the purchase of a tourism product. Tourism Management, 27(3), 394-409. https://doi.org/10.1016/j. tourman.2004.11.007

Sandström, S., Edvardsson, B., Kristensson, P., \& Magnusson, P. (2008). Value in use through service experience. Managing Service Quality: An International Journal, 18(2), 112-126. https://doi. org/10.1108/09604520810859184

Savolainen, R. (2019). Modeling the interplay of information seeking and information sharing. Aslib Journal of Information Management, 71(4), 518-534. https://doi.org/10.1108/AJIM-10-20180266

Schiele, H. \& Krummaker, S. (2011). Consortium benchmarking: Collaborative academic-practitioner case study research. Journal of Business Research, 64(10), 1137-1145. https://doi.org/10.1016/j. jbusres.2010.11.007

Schouten, J. W., McAlexander, J. H., \& Koenig, H. F. (2007). Transcendent customer experience and brand community. Journal of the Academy of Marketing Science, 35(3), 357-368. https://doi. org/10.1007/s11747-007-0034-4

Schulze-Horn, I., Hueren, S., Scheffler, P., \& Schiele, H. (2020). Artificial Intelligence in Purchasing: Facilitating Mechanism Design-based Negotiations. Applied Artificial Intelligence, 34(8), 618-642. https://doi.org/10.1080/08839514.2020.1749337

Schwartz Public Relations. (2020, February 18). Beat the Pro: SK Gaming Stars fordern OnePlus Community in München heraus. Schwartz Public Relations. https://schwartzpr.de/newsroom/ oneplus/beat-the-pro-sk-gaming-stars-fordern-oneplus-community-in-muenchen-heraus/

Scott, K. (2020, October 16). Here's What an Amazon 4-Star Store Is Like. Cheapism. https://blog. cheapism.com/amazon-store-review/\#slide=4

SGB Executive. (2021, January 22). Lululemon Highlights Benefit Of Physical Stores Despite Online Shift. SGB Media Online. https://sgbonline.com/lululemon-highlights-benefit-of-physical-storesdespite-online-shift/ 
Shamim, A., Ghazali, Z., \& Albinsson, P. A. (2017). Construction and validation of customer value cocreation attitude scale. Journal of Consumer Marketing, 34(7), 591-602. https://doi.org/10.1108/ JCM-01-2016-1664

Shim, S., \& Eastlick, M. A. (1998). The hierarchical influence of personal values on mall shopping attitute and behavior. Journal of Retailing, 74(1), 139-160. https://doi.org/10.1016/S00224359(99)80091-8

Shin, Y. H., Moon, H., Jung, S. E., \& Severt, K. (2017). The effect of environmental values and attitudes on consumer willingness to pay more for organic menus: A value-attitude-behavior approach. Journal of Hospitality and Tourism Management, 33, 113-121. https://doi.org/10.1016/j. jhtm.2017.10.010

Shugan, S. M. (2017, March 15). Best Most cited marketing articles. Warrington College of Business. http://bear.warrington.ufl.edu/centers/mks/vol4no01.htm

Singh, J., Flaherty, K., Sohi, R. S., Deeter-Schmelz, D., Habel, J., Le Meunier-FitzHugh, K., Malshe, A., Mullins, R., \& Onyemah, V. (2019). Sales profession and professionals in the age of digitization and artificial intelligence technologies: concepts, priorities, and questions. Journal of Personal Selling \& Sales Management, 39(1), 2-22. https://doi.org/10.1080/08853134.2018.1557525

So, J. C. F., \& Bolloju, N. (2005). Explaining the intentions to share and reuse knowledge in the context of IT service operations. Journal of Knowledge Management, 9(6), 30-41. https://doi. org/10.1108/13673270510629945

Soars, B. (2009). Driving sales through shoppers' sense of sound, sight, smell and touch. International Journal of Retail \& Distribution Management, 37(3), 286-298. https://doi. org/10.1108/09590550910941535

Sonnenwald, D. H. (2006). Challenges in sharing information effectively: Examples from command and control. Information Research, 11(4).

Spence, C., Puccinelli, N. M., Grewal, D., \& Roggeveen, A. L. (2014). Store Atmospherics: A Multisensory Perspective. Psychology \& Marketing, 31(7), 472-488. https://doi.org/10.1002/mar.20709

Srinivasan, S. S., Anderson, R., \& Ponnavolu, K. (2002). Customer loyalty in e-commerce: an exploration of its antecedents and consequences. Journal of Retailing, 78(1), 41-50. https://doi.org/10.1016/ S0022-4359(01)00065-3

Statt, N. (2020, July 14). Amazon's new smart shopping cart lets you check out without a cashier. The Verge. https://www.theverge.com/2020/7/14/21323421/amazon-dash-cart-smart-groceryshopping-woodland-hills-store-cashierless

Swan, J. E., Goodwin, C., Mayo, M. A., \& Richardson, L. D. (2001). Customer identities: Customers as commercial friends, customer coworkers or business acquaintances. Journal of Personal Selling and Sales Management, 21(1-2), 29-37. https://doi.org/10.1080/08853134.2001.10754254

Telekom Deutschland GmbH. (2019a, May 13). Terminvereinbarung. Telekom Deutschland GmbH. https://www.telekom.de/start/telekom-shops/terminvereinbarung\#

Telekom Deutschland GmbH. (2019b, June 18). MeinMagenta App. Telekom Deutschland GmbH. https://www.telekom.de/hilfe/meinmagenta-app?samChecked=true\#e_334826 
Telekom Deutschland GmbH. (2019c, October 18). Event: Gründer MeetUp mit Felix Thönnessen im Telekom Flagshipstore in Düsseldorf. Telekom Deutschland GmbH. https://telekomhilft. telekom.de/t5/News-Events/Event-Gruender-MeetUp-mit-Felix-Thoennessen-im-Telekom/ba$\mathrm{p} / 4227065 /$ jump-to/first-unread-message

Telekom Deutschland GmbH. (2020a, January 24). Events im Telekom Shop. Telekom Deutschland GmbH. https://www.telekom.de/events

Telekom Deutschland GmbH. (2020b, August 8). Mehr Magenta: SK Gaming - "Schlag den Profi“. Telekom Deutschland GmbH. https://www.telekom.de/mehr-magenta/sk-gaming-schlag-denprofi

Telekom Deutschland GmbH. (2021). Vertriebspartner. Telekom Deutschland. https://www.telekom. de/vertriebspartner?wt_mc=alias_301_telekom-partner.de

Thomas, L. (2020, December 26). The 10 biggest retail bankruptcies of 2020. CNBC. https://www.cnbc. com/2020/12/26/the-10-biggest-retail-bankruptcies-of-2020.html

Tuan, L. T. (2017). Under entrepreneurial orientation, how does logistics performance activate customer value co-creation behavior? The International Journal of Logistics Management, 28(2), 600-633. https://doi.org/10.1108/IJLM-12-2015-0242

van den Hooff, B., \& de Ridder, J. A. (2004). Knowledge sharing in context: the influence of organizational commitment, communication climate and $\mathrm{CMC}$ use on knowledge sharing. Journal of Knowledge Management, 8(6), 117-130. https://doi.org/10.1108/13673270410567675

Vargo, S. L., Akaka, M. A., \& Vaughan, C. M. (2017). Conceptualizing Value: A Service-ecosystem View. Journal of Creating Value, 3(2), 117-124. https://doi.org/10.1177/2394964317732861

Vargo, S. L., \& Lusch, R. F. (2004). Evolving to a New Dominant Logic for Marketing. Journal of Marketing, 68(1), 1-17. https://doi.org/10.1509/jmkg.68.1.1.24036

Vargo, S. L., \& Lusch, R. F. (2008). Service-dominant logic: Continuing the evolution. Journal of the Academy of Marketing Science, 36(1), 1-10. https://doi.org/10.1007/s11747-007-0069-6

Vargo, S. L., \& Lusch, R. F. (2016). Institutions and axioms: an extension and update of service-dominant logic. Journal of the Academy of Marketing Science, 44(1), 5-23. https://doi.org/10.1007/s11747015-0456-3

Vargo, S. L., \& Lusch, R. F. (2017). Service-dominant logic 2025. International Journal of Research in Marketing, 34(1), 46-67. https://doi.org/10.1016/j.ijresmar.2016.11.001

Vargo, S. L., Maglio, P. P., \& Akaka, M. A. (2008). On value and value co-creation: A service systems and service logic perspective. European Management Journal, 26(3), 145-152. https://doi. org/10.1016/j.emj.2008.04.003

Varshneya, G., \& Das, G. (2017). Experiential value: Multi-item scale development and validation. Journal of Retailing and Consumer Services, 34(January 2017), 48-57. https://doi.org/10.1016/j. jretconser.2016.09.010

Varshneya, G., Das, G., \& Khare, A. (2017). Experiential value: a review and future research directions. Marketing Intelligence \& Planning, 35(3), 339-357. https://doi.org/10.1108/MIP-05-2016-0075 
Vaske, J. J., \& Maureen, P. D. (1999). A Value-Attitude-Behavior Model Predicting Wildland Preservation Voting Intentions. Society \& Natural Resources, 12(6), 523-537. https://doi. org/10.1080/089419299279425

Verhoef, P. C., Kannan, P. K., \& Inman, J. J. (2015). From Multi-Channel Retailing to Omni-Channel Retailing. Journal of Retailing, 91(2), 174-181. https://doi.org/10.1016/j.jretai.2015.02.005

Wang, H., Schrock, W. A., Kumar, A., \& Hughes, D. E. (2020). Effectual selling in service ecosystems. Journal of Personal Selling \& Sales Management, 40(4), 251-266. https://doi.org/10.1080/0885 3134.2020.1834865

Warmelink, H., Koivisto, J., Mayer, I., Vesa, M., \& Hamari, J. (2020). Gamification of production and logistics operations: Status quo and future directions. Journal of Business Research, 106(February 2018), 331-340. https://doi.org/10.1016/j.jbusres.2018.09.011

Whiteman, D. (2021, April 5). These Chains Are Permanently Closing the Most Stores in 2020. Moneywise. https://moneywise.com/a/chains-closing-the-most-stores-in-2020

Wicker, A. W. (1969). Attitudes versus Actions: The Relationship of Verbal and Overt Behavioral Responses to Attitude Objects. Journal of Social Issues, 25(4), 41-78. https://doi. org/10.1111/j.1540-4560.1969.tb00619.x

Wiedmann, K.-P., Labenz, F., Haase, J., \& Hennigs, N. (2018). The power of experiential marketing: exploring the causal relationships among multisensory marketing, brand experience, customer perceived value and brand strength. Journal of Brand Management, 25(2), 101-118. https://doi. org/10.1057/s41262-017-0061-5

Wieseke, J., Alavi, S., \& Habel, J. (2014). Willing to Pay More, Eager to Pay Less: The Role of Customer Loyalty in Price Negotiations. Journal of Marketing, 78(6), 17-37. https://doi.org/10.1509/ jm.13.0104

Wilson, S. (2020, August 5). Amazon Go: why the retail giant is launching 30 shops in the UK with no till system - and how they will work. The Scotsman. https://www.scotsman.com/lifestyle/ shopping/amazon-go-why-retail-giant-launching-30-shops-uk-no-till-system-and-how-they-willwork-2933821

Wilson, T. D. (1999). Models in information behaviour research. Journal of Documentation, 55(3), 249270. https://doi.org/10.1108/EUM0000000007145

Wolf, T., Weiger, W. H., \& Hammerschmidt, M. (2020). Experiences that matter? The motivational experiences and business outcomes of gamified services. Journal of Business Research, 106(December), 353-364. https://doi.org/10.1016/j.jbusres.2018.12.058

Wünderlich, N. V., Gustafsson, A., Hamari, J., Parvinen, P., \& Haff, A. (2020). The great game of business: Advancing knowledge on gamification in business contexts. Journal of Business Research, 106(xxxx), 273-276. https://doi.org/10.1016/j.jbusres.2019.10.062

Yang, J. (2008). Individual attitudes and organisational knowledge sharing. Tourism Management, 29(2), 345-353. https://doi.org/10.1016/j.tourman.2007.03.001

Yi, Y., \& Gong, T. (2013). Customer value co-creation behavior: Scale development and validation. Journal of Business Research, 66(9), 1279-1284. https://doi.org/10.1016/j.jbusres.2012.02.026 
Yi, Y., \& Kim, S. Y. (2017). The role of other customers during self-service technology failure. Service Business, 11(4), 695-715. https://doi.org/10.1007/s11628-016-0325-2

Yim, M. Y.-C., Yoo, S.-C., Sauer, P. L., \& Seo, J. H. (2014). Hedonic shopping motivation and co-shopper influence on utilitarian grocery shopping in superstores. Journal of the Academy of Marketing Science, 42(5), 528-544. https://doi.org/10.1007/s11747-013-0357-2

Yin, R. K. (2013). Case Study Research: Design and Methods (Applied Social Research Methods) (5 ${ }^{\text {th }}$ ed.). Sage Publications.

Yu, E., \& Sangiorgi, D. (2018). Service Design as an Approach to Implement the Value Cocreation Perspective in New Service Development. Journal of Service Research, 21(1), 40-58. https://doi. org/10.1177/1094670517709356

Zhao, X., Lynch, J. G., \& Chen, Q. (2010). Reconsidering Baron and Kenny: Myths and Truths about Mediation Analysis. Journal of Consumer Research, 37(2), 197-206. https://doi. org/10.1086/651257 
